Supporting Information

\title{
A Supramolecular Strategy Towards An Efficient and Selective Capture of Platinum(II) Complexes
}

\author{
Zhen Chen, Alan Kwun-Wa Chan, Victor Chun-Hei Wong, \\ Vivian Wing-Wah Yam* \\ *Corresponding author. E-mail: wwyam@hku.hk (V.W.W.Y.)
}




\section{Table of Contents}

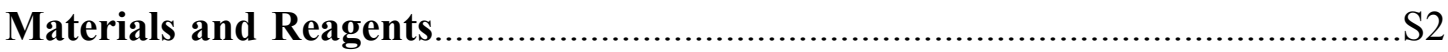

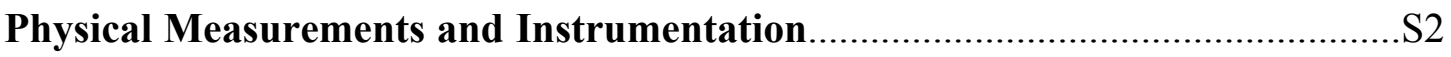

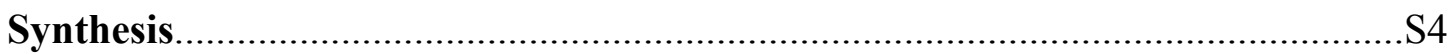

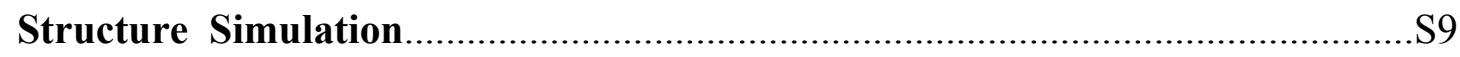

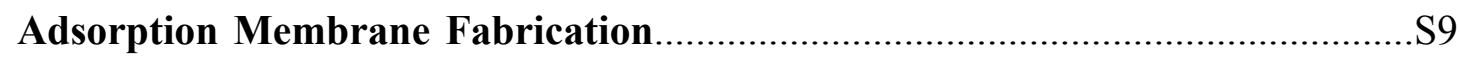

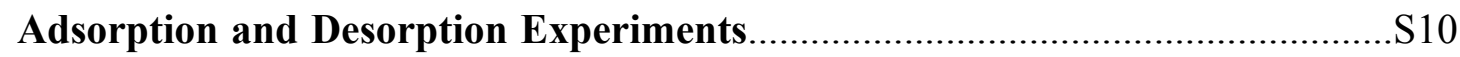

Supporting Notes

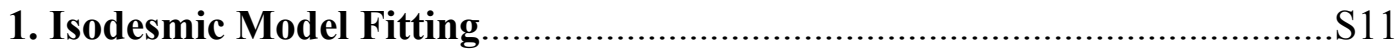

2. Monomer-Dimer Equilibrium............................................................. 12

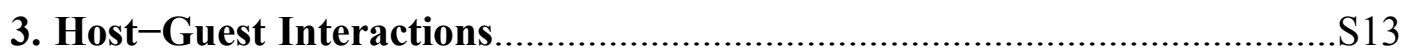

4. Binding Constants of Host-Guest Interactions........................................S14

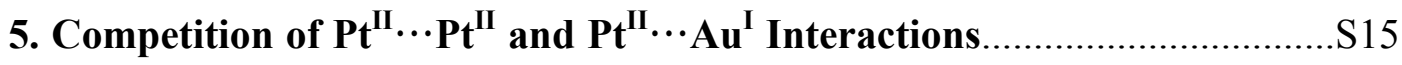

6. Competition of $\mathrm{Pt}^{\mathrm{II}} \ldots \mathrm{Pt}^{\mathrm{II}}$ and $\mathrm{Pt}^{\mathrm{II}} \ldots \mathrm{Pd}^{\mathrm{II}}$ Interactions................................. 16

7. Mechanism of Emission Quenching and Enhancement............................S17

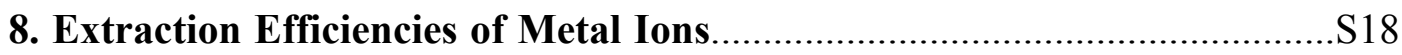

9. Adsorption Efficiencies of Metal Ions........................................................ 19

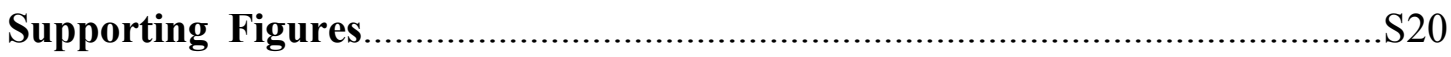

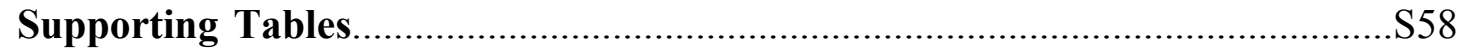

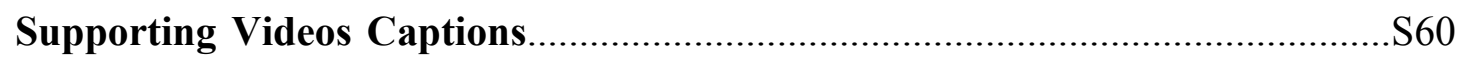

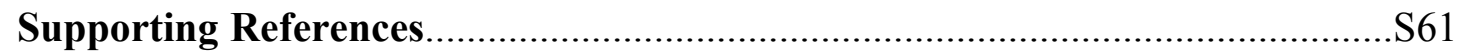




\section{Materials and Reagents}

Unless otherwise noted, reagents were used as received from Alfa Aesar \{1-dodecanol, sodium hydride (NaH, 60 wt.\% dispersion in mineral oil), pyridine, triethylamine $\left(\mathrm{Et}_{3} \mathrm{~N}\right)$, copper(I) iodine $(\mathrm{CuI})$, silver triflate $(\mathrm{AgOTf})$, silver nitrate $\left(\mathrm{AgNO}_{3}\right)$, nickel(II) chloride hexahydrate $\left.\left(\mathrm{NiCl}_{2} \cdot 6 \mathrm{H}_{2} \mathrm{O}\right)\right\}$ and Sigma-Aldrich \{hydrogen bromide solution ( $\mathrm{HBr}, 33 \mathrm{wt} . \%$ in acetic acid), trifluoromethanesulfonic anhydride, tetrakis(triphenylphosphine)palladium(0) $\left[\mathrm{Pd}\left(\mathrm{PPh}_{3}\right)_{4}\right]$, cis-dichlorobis(dimethyl sulfoxide)platinum(II) [Pt(DMSO) $\left.{ }_{2} \mathrm{Cl}_{2}\right]$, phenylacetylene, potassium tetrachloroplatinate(II) $\left(\mathrm{K}_{2}\left[\mathrm{PtCl}_{4}\right]\right)$, potassium tetracyanoplatinate(II) $\left(\mathrm{K}_{2}\left[\mathrm{Pt}(\mathrm{CN})_{4}\right]\right)$, potassium hexachloroplatinate(IV) $\left(\mathrm{K}_{2}\left[\mathrm{PtCl}_{6}\right]\right)$, palladium(II) chloride $\left(\mathrm{PdCl}_{2}\right)$, potassium tetrachloropalladate(II) $\left(\mathrm{K}_{2}\left[\mathrm{PdCl}_{4}\right]\right), \quad$ potassium tetrachloroaurate(III) $\left(\mathrm{K}\left[\mathrm{AuCl}_{4}\right]\right)$, rhodium(III) chloride hydrate $\left(\mathrm{RhCl}_{3} \cdot \mathrm{xH}_{2} \mathrm{O}\right)$, copper(II) perchlorate hexahydrate $\left[\mathrm{Cu}\left(\mathrm{ClO}_{4}\right)_{2} \cdot 6 \mathrm{H}_{2} \mathrm{O}\right]$, potassium hexacyanoferrate(III) $\quad\left(\mathrm{K}_{3}\left[\mathrm{Fe}(\mathrm{CN})_{6}\right]\right), \quad$ di- $\mu$-chloro-tetracarbonyldirhodium(I) $\left(\left[\mathrm{Rh}(\mathrm{CO})_{2} \mathrm{Cl}\right]_{2}\right)$, bis(triphenylphosphine)iminium chloride $(\mathrm{PPNCl}), \quad$ isopore $^{\mathrm{TM}}$ polycarbonate (PC) filter membranes (pore size $0.2 \mu \mathrm{m}$, diam. $25 \mathrm{~mm}$ ) $\}$. Compound 1 and $7,{ }^{1}$ triethynylmesitylene, ${ }^{2}$ compound $\mathbf{6} \cdot 2 \mathrm{~K},{ }^{3}$ anionic $\mathrm{Pt}(\mathrm{II})$ complex guest, ${ }^{3}$ neutral $\mathrm{Pt}(\mathrm{II})$ complex guest, ${ }^{4}$ anionic $\mathrm{Au}(\mathrm{I})$ complex guest, ${ }^{5}$ and potassium tetrachlorocuprate(II) $\left(\mathrm{K}_{2}\left[\mathrm{CuCl}_{4}\right]\right)^{6}$ were prepared according to reported procedures. Potassium cis-dichloro-dicarbonylrhodium(I) $\left(\mathrm{K}\left[\mathrm{RhCl}_{2}(\mathrm{CO})_{2}\right]\right)$ was freshly prepared by mixing equivalent amounts of $\left[\mathrm{Rh}(\mathrm{CO})_{2} \mathrm{Cl}\right]_{2}$ and potassium chloride in the aqueous solution. Dimethyl sulfoxide (DMSO) was dried over $\mathrm{CaH}_{2}$ and stored over $3 \AA$ molecular sieve prior to use. Pyridine was dried over $\mathrm{KOH}$ before use. Other solvents for synthesis were used as received. Deionized water was produced by a Milli-Q apparatus (Millipore).

\section{Physical Measurements and Instrumentation}

${ }^{1} \mathrm{H}$ NMR and ${ }^{13} \mathrm{C}\left\{{ }^{1} \mathrm{H}\right\}$ NMR spectra were recorded on a Bruker DPX-400 Fourier transform NMR spectrometer, operating at 400 and $100 \mathrm{MHz}$, respectively, where chemical shifts (in ppm) were determined with respect to tetramethylsilane as an internal reference. Matrix-assisted laser desorption ionization time-of-flight (MALDI-TOF) mass spectrometry was performed on an Applied Biosystems model MDS SCIEX 4800 Plus MALDI TOF/TOFTM Analyzer using dithranol as a matrix. Positive and negative FAB mass spectra were recorded on a Thermo Scientific DFS High-Resolution Magnetic Sector Mass Spectrometer. IR spectra were obtained as $\mathrm{KBr}$ disks on a Bio-Rad FTS-7 FTIR spectrometer (4000-400 $\mathrm{cm}^{-1}$ ). Elemental analyses of the newly synthesized complexes were performed on a Flash EA 1112 elemental analyzer at the Institute of Chemistry, Chinese Academy of Sciences. Atomic force microscopy (AFM) experiments were performed on an Asylum MFP3D 
AFM with an ARC2 SPM Controller under constant temperature and atmospheric pressure at $298 \mathrm{~K}$ with standard silicon cantilevers (OMCL-AC160TS-R3) in the tapping mode. Transmission electron microscope (TEM) was performed on a Tecnai G2 20 S-TWIN TEM with an accelerating voltage of $200 \mathrm{kV}$. A dilute THF solution of sample was dispersed in water. After sonication, the samples for TEM study were prepared by dropping one drop of the aqueous solution onto a carbon-nickel grid and solvent annealing at $298 \mathrm{~K}$ for 1 hour. High-resolution TEM image was obtained by samples negatively stained with uranyl acetate. Dynamic light scattering (DLS) was performed on a Malvern Zetasizer 3000HSA with an internal HeNe laser $(\lambda=632.8$ $\mathrm{nm}$ ), equipped with the Varian Cary Single-Cell Peltier Thermostat. Wide-angle X-ray diffraction (WAXD) experiments were carried out at beamline 1W2A of the Beijing synchrotron radiation facility (Beijing, China) with an imaging plate area detector. Grazing incidence X-ray diffraction (GI-XRD) experiments were carried out at beamline 1W1A in Beijing synchrotron radiation facility (Beijing, China) with an imaging plate area detector with exposure time of 300 seconds. The grazing incident angle of X-ray to the film surface was $0.2^{\circ}$. The film exfoliated from a composite membrane for GI-XRD measurement was obtained from selectively dissolving the PC support in toluene and carefully transferring it onto the wafer. Scattering vector, $q=$ $4 \pi \sin \theta / \lambda$, and position of incident X-ray on the detector were calibrated using several orders of layer reflections from silver behenate $(d=58.380 \AA)$, where $2 \theta$ and $\lambda$ are scattering angle and wavelength of X-ray $(\lambda=1.5406 \AA)$, respectively. The sample-to-detector distances of WAXD and GI-XRD measurement were 0.25 and 0.4 $\mathrm{m}$, respectively. The scattering/diffraction images recorded were integrated along the Debye-Scherrer ring, affording one-dimensional intensity data using the FIT2D software. ${ }^{7}$ The simulation of powder X-ray diffraction (PXRD) pattern was obtained by using Materials Studio v.6.0 Reflex software. ${ }^{8}$ The UV-vis absorption spectra at various temperatures were recorded by using a Hewlett-Packard 8453 diode array spectrophotometer, installed with the Varian Cary Single-Cell Peltier Thermostat. Steady-state emission spectra at various temperatures were recorded by using a Spex Fluorolog-3 model FL3-211 fluorescence spectrofluorometer equipped with an R2658P PMT detector, installed with the Varian Cary Single-Cell Peltier Thermostat. The excitation wavelength is $430 \mathrm{~nm}$. Cyclic voltammetric measurements were performed by using a $\mathrm{CH}$ Instruments, Inc. model CHI 620A electrochemical analyzer. Electrochemical measurements were performed in dichloromethane $\left(\mathrm{CH}_{2} \mathrm{Cl}_{2}\right)$ solutions with $0.1 \mathrm{M}^{n} \mathrm{Bu}_{4} \mathrm{NPF}_{6}$ used as supporting electrolyte at room temperature. The reference electrode was a $\mathrm{Ag} / \mathrm{AgNO}_{3}(0.1 \mathrm{M}$ in acetonitrile) electrode, and the working electrode was a glassy carbon electrode ( $\mathrm{CH}$ Instruments, Inc.) with a platinum wire as the counter electrode. The ferrocenium/ferrocene couple $\left(\mathrm{Fc}^{+} / \mathrm{Fc}\right)$ was used as the internal reference. All solutions for electrochemical studies were deaerated with prepurified argon gas prior to measurements. Inductively coupled plasma mass spectrometry (ICP-MS) was performed on Agilent's 7700 Series 
ICP-MS under Argon atmosphere at $298 \mathrm{~K}$. The ionic concentration was measured by using scandium as standard. Scanning electron microscopy (SEM) was performed on a Hitachi S4800 Field Emission SEM using electron beam accelerated at $5.0 \mathrm{kV}$. The fabricated membrane on PC filter support was embrittled in liquid nitrogen and cut into pieces for cross-section SEM measurements. Filtration experiments were conducted by using VF8-filtration glass set connected to a vacuum pump with a manometer. X-Ray photoelectron spectroscopy (XPS) was performed on a PHI Model 5802 XPS equipped with an electron energy analyzer using mono-energetic Al Ka X-ray. The film samples for XPS measurements followed a procedure similar to that for GI-XRD measurement. Contact angle measurements were performed on a Theta Optical Tensiometer.

\section{Synthesis}

1. Synthesis of Ligand

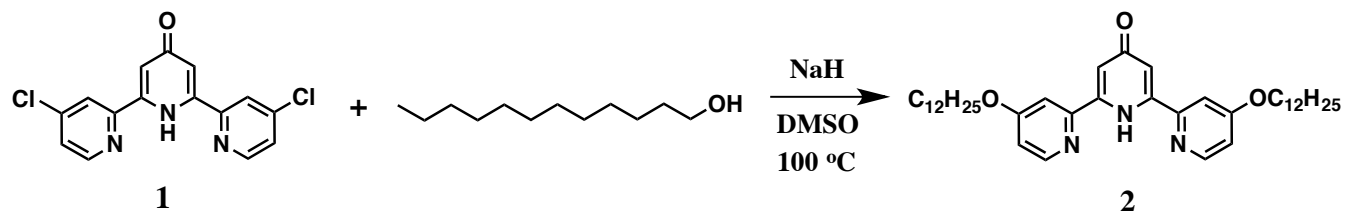

Compound 2. To a dehydrated DMSO solution $(10 \mathrm{~mL})$ of 1-dodecanol (1.00 g, $5.40 \mathrm{mmol})$ was slowly added $\mathrm{NaH}(0.15 \mathrm{~g}, 6.25 \mathrm{mmol})$ over a period of $10 \mathrm{~min}$ and the mixture was stirred for $1 \mathrm{~h}$ at $25^{\circ} \mathrm{C}$ under nitrogen atmosphere. To the resulting solution was added $1(0.50 \mathrm{~g}, 1.60 \mathrm{mmol})$ and the mixture was then stirred for $10 \mathrm{~h}$ at $100{ }^{\circ} \mathrm{C}$ under nitrogen atmosphere. The reaction mixture was poured into brine (200 $\mathrm{mL}$ ), and the white precipitate was collected by filtration. After washing the precipitate with water $(100 \mathrm{~mL})$ for three times and acetone $(100 \mathrm{~mL})$ for 2 times and drying under vacuum, 2 was obtained as a white solid $(0.94 \mathrm{~g}, 1.52 \mathrm{mmol})$ in $95 \%$ yield. ${ }^{1} \mathrm{H}$ NMR $\left(400 \mathrm{MHz}, \mathrm{CDCl}_{3}, 298 \mathrm{~K}\right.$, relative to $\left.\mathrm{Me}_{4} \mathrm{Si}, \delta / \mathrm{ppm}\right): \delta 8.55$ [doublet (d), $J=5.6 \mathrm{~Hz}, 2 \mathrm{H}$, tpy], 7.37 (d, $J=2.2 \mathrm{~Hz}, 2 \mathrm{H}$, tpy), 7.00 [singlet (s), 2H, tpy], 6.90 [doublet of doublets (dd), $J=5.6 \mathrm{~Hz}, 2.2 \mathrm{~Hz}, 2 \mathrm{H}$, tpy], 4.08 [triplet (t), $J=6.5 \mathrm{~Hz}, 4 \mathrm{H}$, tpy- $\mathrm{OCH}_{2}-$ ], 1.84 [multiplet (m), 4H, $-\mathrm{CH}_{2}-$ ], $1.48\left(\mathrm{~m}, 4 \mathrm{H},-\mathrm{CH}_{2}-\right), 1.40-1.27$ (m, $\left.36 \mathrm{H},-\mathrm{CH}_{2}-\right), 0.86\left(\mathrm{~m}, 6 \mathrm{H},-\mathrm{CH}_{3}\right) .{ }^{13} \mathrm{C}\left\{{ }^{1} \mathrm{H}\right\} \mathrm{NMR}\left(100 \mathrm{MHz}, \mathrm{CDCl}_{3}, 298 \mathrm{~K}\right.$, relative to $\left.\mathrm{Me}_{4} \mathrm{Si}, \delta / \mathrm{ppm}\right): \delta 185.72,165.28,159.10,156.64,148.23,117.37,115.89,102.63$, 68.70, 31.95, 29.62, 29.56, 29.30, 28.93, 25.99, 22.71, 14.14. HR-MS (positive EI): calcd. for $\mathrm{C}_{39} \mathrm{H}_{60} \mathrm{~N}_{3} \mathrm{O}_{3}: m / z=618.4563$; found: 618.4584 . 


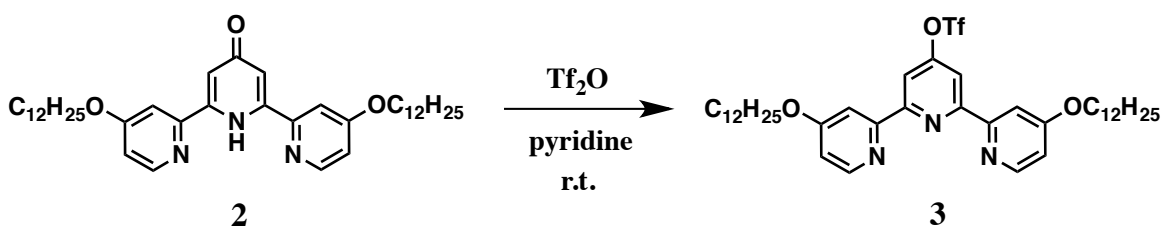

Compound 3. To a dehydrated pyridine solution $(5 \mathrm{~mL})$ of $2(0.90 \mathrm{~g}, 1.46 \mathrm{mmol})$ was slowly added dropwise trifluoromethanesulfonic anhydride $\left(\mathrm{Tf}_{2} \mathrm{O}, 1.00 \mathrm{~g}, 3.0\right.$ mmol) and the resulting solution was stirred for $10 \mathrm{~h}$ at $25^{\circ} \mathrm{C}$. Then, the reaction mixture was poured into ice water $(300 \mathrm{~mL})$, and the white precipitate was collected by filtration. After washing the precipitate with water $(100 \mathrm{~mL})$ for 3 times and methanol $(100 \mathrm{~mL})$ for two times and drying under vacuum, the residue was subjected to column chromatography $\left(\mathrm{SiO}_{2}, \mathrm{CHCl}_{3} / \mathrm{EtOAc}=3 / 1 \mathrm{v} / \mathrm{v}\right)$ to allow isolation of 3 as a white solid (0.87 g, $1.17 \mathrm{mmol})$ in $80 \%$ yield. ${ }^{1} \mathrm{H} \mathrm{NMR}\left(400 \mathrm{MHz}, \mathrm{CDCl}_{3}, 298 \mathrm{~K}\right.$, relative to $\left.\mathrm{Me}_{4} \mathrm{Si}, \delta / \mathrm{ppm}\right): \delta 8.52(\mathrm{~d}, J=5.6 \mathrm{~Hz}, 2 \mathrm{H}, \mathrm{tpy}), 8.39$ (s, 2H, tpy), 8.11 (d, $J$ $=2.3 \mathrm{~Hz}, 2 \mathrm{H}$, tpy), 6.89 (dd, $J=5.6 \mathrm{~Hz}, 2.3 \mathrm{~Hz}, 2 \mathrm{H}, \mathrm{tpy}), 4.15(\mathrm{t}, J=6.5 \mathrm{~Hz}, 4 \mathrm{H}$, tpy- $\left.\mathrm{OCH}_{2}-\right), 1.87\left(\mathrm{~m}, 4 \mathrm{H},-\mathrm{CH}_{2}-\right), 1.51\left(\mathrm{~m}, 4 \mathrm{H},-\mathrm{CH}_{2}-\right), 1.39-1.26(\mathrm{~m}, 36 \mathrm{H}$, $\left.-\mathrm{CH}_{2}-\right), 0.87\left(\mathrm{~m}, 6 \mathrm{H},-\mathrm{CH}_{3}\right) .{ }^{13} \mathrm{C}\left\{{ }^{1} \mathrm{H}\right\} \mathrm{NMR}\left(100 \mathrm{MHz}, \mathrm{CDCl}_{3}, 298 \mathrm{~K}\right.$, relative to $\left.\mathrm{Me}_{4} \mathrm{Si}, \delta / \mathrm{ppm}\right): \delta 166.20,158.66,158.32,155.89,150.70,113.45,110.80,108.25$, 68.23, 50.91, 31.92, 29.65, 29.59, 29.37, 28.95, 25.98, 22.70, 14.13. HR-MS (positive EI): calcd. for $\mathrm{C}_{40} \mathrm{H}_{59} \mathrm{~F}_{3} \mathrm{~N}_{3} \mathrm{O}_{5} \mathrm{~S}: m / z=750.4049$; found: 750.4090 .

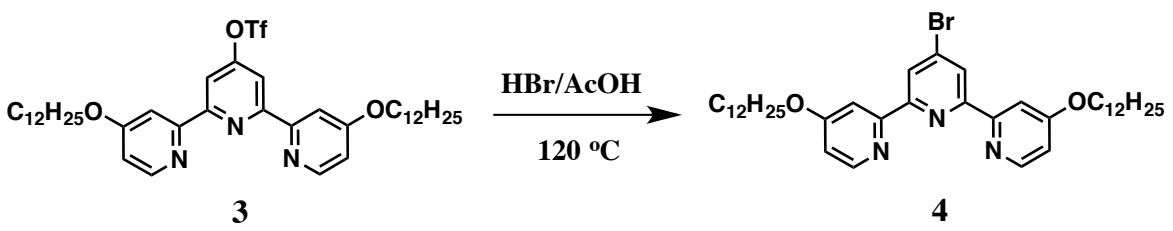

Compound 4. To an acetic acid solution $(5 \mathrm{~mL})$ of $3(0.75 \mathrm{~g}, 1.00 \mathrm{mmol})$ was added dropwise $\mathrm{HBr}$ solution ( $5 \mathrm{~mL}$ ) and the resulting solution was stirred for $10 \mathrm{~h}$ at $120^{\circ} \mathrm{C}$. Then, the reaction mixture was poured into ice water $(300 \mathrm{~mL})$, and the white precipitate was collected by filtration. After washing the precipitate with water (100 $\mathrm{mL})$ for three times and methanol $(100 \mathrm{~mL})$ for 2 times, the residue was subjected to column chromatography $\left(\mathrm{SiO}_{2}, \mathrm{CHCl}_{3} / \mathrm{EtOAc}=3 / 1 \mathrm{v} / \mathrm{v}\right)$ to allow isolation of $\mathbf{4}$ as a white solid (0.65 g, $0.95 \mathrm{mmol})$ in $95 \%$ yield. ${ }^{1} \mathrm{H} \mathrm{NMR}\left(400 \mathrm{MHz}, \mathrm{CDCl}_{3}, 298 \mathrm{~K}\right.$, relative to $\left.\mathrm{Me}_{4} \mathrm{Si}, \delta / \mathrm{ppm}\right): \delta 8.62$ (s, 2H, tpy), 8.51 (d, $J=5.5 \mathrm{~Hz}, 2 \mathrm{H}$, tpy), 8.09 (s, 2H, tpy), 6.87 (d, $J=5.5 \mathrm{~Hz}, 2 \mathrm{H}$, tpy), 4.14 (t, $J=6.5 \mathrm{~Hz}, 4 \mathrm{H}$, tpy- $\mathrm{OCH}_{2}-$ ), 1.86 (m, $\left.4 \mathrm{H},-\mathrm{CH}_{2}-\right), 1.51\left(\mathrm{~m}, 4 \mathrm{H},-\mathrm{CH}_{2}-\right), 1.38-1.26\left(\mathrm{~m}, 36 \mathrm{H},-\mathrm{CH}_{2}-\right), 0.88\left(\mathrm{~m}, 6 \mathrm{H},-\mathrm{CH}_{3}\right)$. ${ }^{13} \mathrm{C}\left\{{ }^{1} \mathrm{H}\right\} \mathrm{NMR}\left(100 \mathrm{MHz}, \mathrm{CDCl}_{3}, 298 \mathrm{~K}\right.$, relative to $\left.\mathrm{Me}_{4} \mathrm{Si}, \delta / \mathrm{ppm}\right): \delta 171.81,148.81$, $148.52,144.24,137.55,128.55,114.16,109.99,72.31,31.91,29.63,29.61,29.53$, 29.36, 28.67, 25.81, 22.68, 14.13. HR-MS (positive EI): calcd. for $\mathrm{C}_{39} \mathrm{H}_{59} \mathrm{BrN}_{3} \mathrm{O}_{2}: \mathrm{m} / z$ 


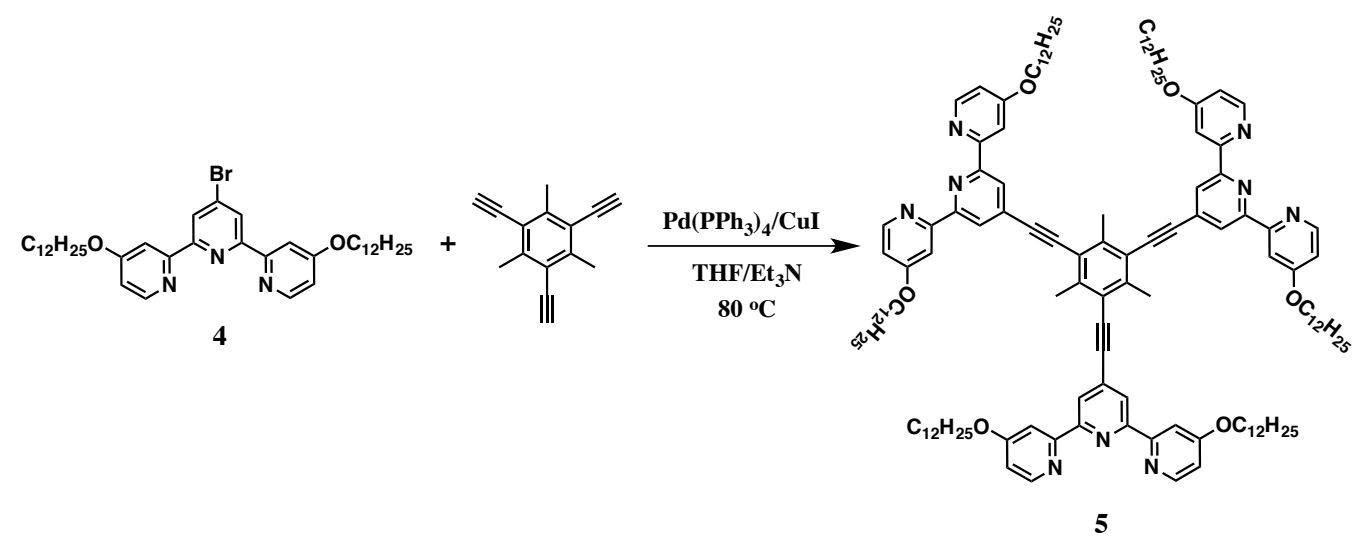

Ligand 5. To a degassed THF and $\mathrm{Et}_{3} \mathrm{~N}$ solution mixture $(10 \mathrm{~mL}, 1 / 1 \mathrm{v} / \mathrm{v})$ of 4 ( $0.60 \mathrm{~g}, 0.88 \mathrm{mmol})$ were added $\mathrm{Pd}\left(\mathrm{PPh}_{3}\right)_{4}(30 \mathrm{mg}, 0.026 \mathrm{mmol})$, $\mathrm{CuI}(2 \mathrm{mg}, 0.011$ $\mathrm{mmol})$ and triethynylmesitylene $(0.04 \mathrm{~g}, 0.208 \mathrm{mmol})$ and the mixture was stirred for $48 \mathrm{~h}$ at $80^{\circ} \mathrm{C}$ under nitrogen atmosphere. After filtration, the filtrate was collected and concentrated to a brown solid. Recrystallization of the crude product from methanol for two times allows isolation of 5 as a white solid $(0.25 \mathrm{~g}, 0.12 \mathrm{mmol})$ in $57 \%$ yield. ${ }^{1} \mathrm{H}$ NMR (400 MHz, $\mathrm{CDCl}_{3}, 298 \mathrm{~K}$, relative to $\left.\mathrm{Me}_{4} \mathrm{Si}, \delta / \mathrm{ppm}\right): \delta 8.58$ (s, 6H, tpy), 8.56 (d, $J=5.6 \mathrm{~Hz}, 6 \mathrm{H}, \mathrm{tpy}), 8.15$ (s, 6H, tpy), 6.88 (d, $J=5.6 \mathrm{~Hz}, 6 \mathrm{H}, \mathrm{tpy}), 4.17$ (t, $J$ $=6.5 \mathrm{~Hz}, 12 \mathrm{H}$, tpy- $\left.\mathrm{OCH}_{2}-\right), 2.86\left(\mathrm{~s}, 9 \mathrm{H}, \mathrm{Ph}-\mathrm{CH}_{3}\right), 1.88\left(\mathrm{~m}, 12 \mathrm{H},-\mathrm{CH}_{2}-\right), 1.51(\mathrm{~m}$, $\left.12 \mathrm{H},-\mathrm{CH}_{2}-\right), 1.39-1.27\left(\mathrm{~m}, 108 \mathrm{H},-\mathrm{CH}_{2}-\right), 0.88\left(\mathrm{~m}, 18 \mathrm{H},-\mathrm{CH}_{3}\right) .{ }^{13} \mathrm{C}\left\{{ }^{1} \mathrm{H}\right\} \mathrm{NMR}$ $\left(100 \mathrm{MHz}, \mathrm{CDCl}_{3}, 298 \mathrm{~K}\right.$, relative to $\left.\mathrm{Me}_{4} \mathrm{Si}, \delta / \mathrm{ppm}\right): \delta 166.12,157.42,155.42$, $150.47,144.13,133.41,122.98,120.89,110.50,107.71,95.70,90.74,68.09,31.94$, 29.71, 29.66, 29.62, 29.42, 29.39, 29.03, 26.02, 22.71, 20.75, 14.15. MALDI-TOF MS: calcd. for $\mathrm{C}_{132} \mathrm{H}_{184} \mathrm{~N}_{9} \mathrm{O}_{6}[\mathrm{M}+\mathrm{H}]^{+}: m / z=1991.973$; found: 1992.348 .

\section{Synthesis of Complex $\mathbf{P t}_{\underline{3}}$}



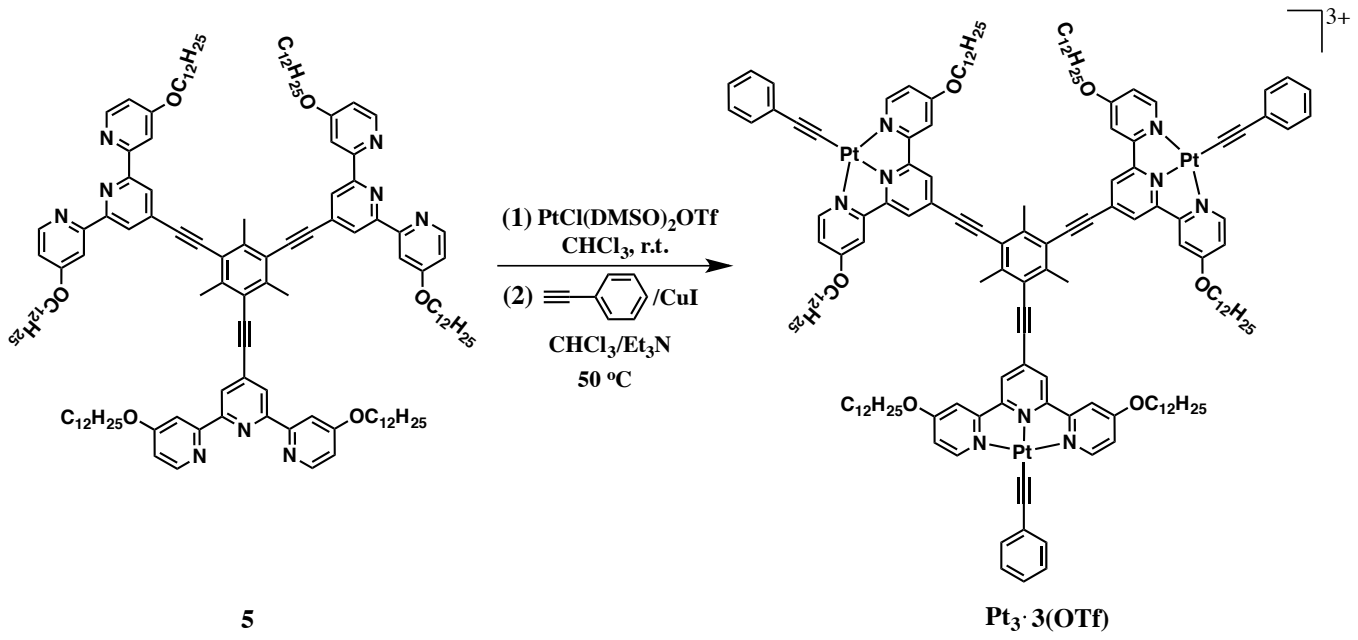

Complex Pt P. $_{3}$ To an acetone solution $(5 \mathrm{~mL})$ of $\left[\mathrm{Pt}(\mathrm{DMSO})_{2} \mathrm{Cl}_{2}\right](0.10 \mathrm{~g}, 0.24$ mmol) was added $\operatorname{AgOTf}(0.061 \mathrm{~g}, 0.24 \mathrm{mmol})$ and the resulting solution was stirred for $1 \mathrm{~h}$ at $25^{\circ} \mathrm{C}$. After filtration, the filtrate was collected and concentrated to $0.1 \mathrm{~mL}$. To a degassed $\mathrm{CHCl}_{3}$ solution $(5 \mathrm{~mL})$ of $5(0.15 \mathrm{~g}, 0.072 \mathrm{mmol})$ was added dropwise the above concentrated acetone solution and the resulting mixture was stirred for $12 \mathrm{~h}$ at $25{ }^{\circ} \mathrm{C}$ until the color of the solution turned to brownish yellow. Then, to the resultant mixture were added $\mathrm{CuI}(2 \mathrm{mg}, 0.011 \mathrm{mmol}), \mathrm{Et}_{3} \mathrm{~N}(2 \mathrm{~mL})$ and phenylacetylene $(0.05 \mathrm{~mL}, 0.49 \mathrm{mmol})$ under nitrogen atmosphere. After stirring for $24 \mathrm{~h}$ at $50^{\circ} \mathrm{C}$, the reaction mixture was concentrated and recrystallized from methanol to give a red solid. The crude product was subjected to column chromatography $\left(\mathrm{Al}_{2} \mathrm{O}_{3}, \mathrm{CHCl}_{3} / \mathrm{MeOH}=3 / 1 \mathrm{v} / \mathrm{v}\right)$ to allow isolation of $\mathbf{P t}_{3} \cdot 3 \mathrm{OTf}$ as a dark red solid $(0.12 \mathrm{~g}, 0.035 \mathrm{mmol})$ in $49 \%$ yield. ${ }^{1} \mathrm{H} \mathrm{NMR}\left(400 \mathrm{MHz}, \mathrm{C}_{2} \mathrm{D}_{4} \mathrm{Cl}_{4}, 363 \mathrm{~K}\right.$, relative to $\left.\mathrm{Me}_{4} \mathrm{Si}, \delta / \mathrm{ppm}\right): \delta 8.96(\mathrm{~m}, 6 \mathrm{H}), 8.84(\mathrm{~m}, 6 \mathrm{H}), 8.35(\mathrm{~m}, 6 \mathrm{H}), 7.44(\mathrm{~m}, 6 \mathrm{H}), 7.23(\mathrm{~m}$, $9 \mathrm{H}), 6.86(\mathrm{~m}, 6 \mathrm{H}), 4.40(\mathrm{~m}, 12 \mathrm{H}), 3.11(\mathrm{~m}, 9 \mathrm{H}), 1.81(\mathrm{~m}, 12 \mathrm{H}), 1.44(\mathrm{~m}, 12 \mathrm{H})$, $1.39-1.20(\mathrm{~m}, 108 \mathrm{H}), 0.79(\mathrm{~m}, 18 \mathrm{H})$. IR $(\mathrm{KBr}): 2115,2215 \mathrm{~cm}^{-1} v(\mathrm{C} \equiv \mathrm{C})$. Elemental analyses calculated for $\mathrm{C}_{59} \mathrm{H}_{198} \mathrm{~F}_{9} \mathrm{~N}_{9} \mathrm{O}_{15} \mathrm{Pt}_{3} \mathrm{~S}_{3}$ found (calculated): $\mathrm{C}, 57.43$ (57.39); $\mathrm{H}$, 6.01 (6.00); N, 3.76 (3.79).

\section{Synthesis of Complexs $\mathbf{G}_{\mathbf{P d}}$ and $\mathbf{G}_{\mathbf{C u}}$.}

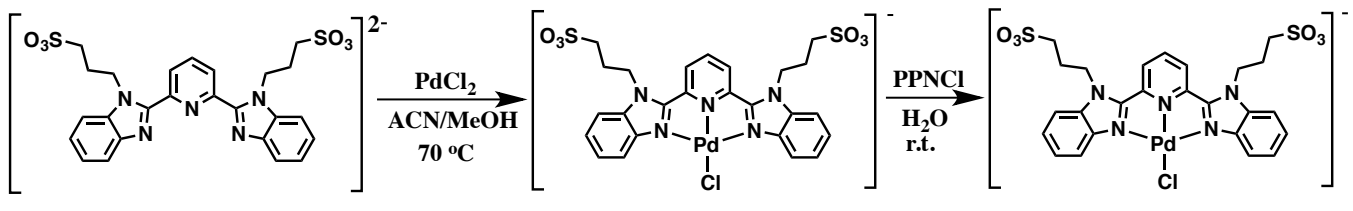

$6 \cdot 2 K^{+}$

$\mathbf{G}_{\mathbf{P d}} \mathbf{P P N}^{+}$

Complex $\mathbf{G}_{\mathbf{P d}}$. To an acetonitrile and methanol solution mixture $(5 \mathrm{~mL}, 1 / 1 \mathrm{v} / \mathrm{v})$ of 
6.2K (0.21 g, $0.33 \mathrm{mmol})$ was added $\mathrm{PdCl}_{2}(0.060 \mathrm{~g}, 0.34 \mathrm{mmol})$ and the resulting solution was stirred for $12 \mathrm{~h}$ at $70{ }^{\circ} \mathrm{C}$. Then, the reaction mixture was concentrated to $0.1 \mathrm{~mL}$ and added into the PPNCl aqueous solution $(0.30 \mathrm{~g}, 0.52 \mathrm{mmol})$. After filtration, the brown precipitate was collected and washed with water $(50 \mathrm{~mL})$ for three times. Dehydration of the precipitate afforded $\mathbf{G}_{\mathbf{P d}} \cdot \mathrm{PPN}$ as a brown solid $(0.25 \mathrm{~g}$, $0.20 \mathrm{mmol})$ in $61 \%$ yield. ${ }^{1} \mathrm{H}$ NMR $\left(400 \mathrm{MHz}, \mathrm{CDCl}_{3}, 298 \mathrm{~K}\right.$, relative to $\mathrm{Me}_{4} \mathrm{Si}$, $\delta / \mathrm{ppm}): \delta 9.13\left(\mathrm{~d}, J=8.2 \mathrm{~Hz}, 2 \mathrm{H}, \mathrm{H}_{\mathrm{A}}\right), 8.60$ (t, $\left.J=8.2 \mathrm{~Hz}, 1 \mathrm{H}, \mathrm{H}_{\mathrm{B}}\right), 8.35$ (d, $J=7.6$ $\left.\mathrm{Hz}, 2 \mathrm{H}, \mathrm{H}_{\mathrm{C}}\right), 7.60\left(\mathrm{t}, J=7.6 \mathrm{~Hz}, 6 \mathrm{H}, \mathrm{H}_{\mathrm{D}}\right), 7.52-7.41(\mathrm{~m}, 30 \mathrm{H}), 4.99(\mathrm{t}, J=5.6 \mathrm{~Hz}$, $4 \mathrm{H}), 3.13(\mathrm{t}, J=5.6 \mathrm{~Hz}, 4 \mathrm{H}), 2.35(\mathrm{t}, J=5.6 \mathrm{~Hz}, 4 \mathrm{H})$. Negative ESI-MS: $m / z=$ $693.983\left[\mathrm{M}^{-}\right]$.

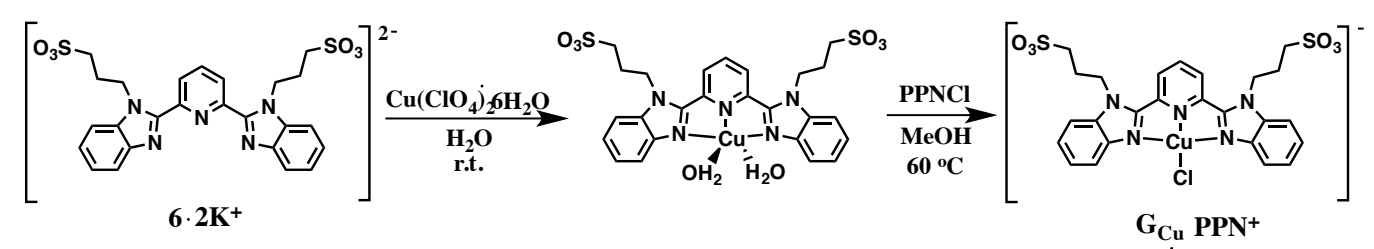

Complex $\mathbf{G}_{\mathbf{C u}}$. To an aqueous solution $(1 \mathrm{~mL})$ of $\mathbf{6} \cdot 2 \mathrm{~K}(0.21 \mathrm{~g}, 0.33 \mathrm{mmol})$ was added $\mathrm{Cu}\left(\mathrm{ClO}_{4}\right)_{2} \cdot 6 \mathrm{H}_{2} \mathrm{O}(0.125 \mathrm{~g}, 0.34 \mathrm{mmol})$ and the resulting solution was stirred for $12 \mathrm{~h}$ at $25^{\circ} \mathrm{C}$. After filtration, the light-green precipitate was collected and washed with water $(50 \mathrm{~mL})$ for 3 times. To a methanol suspension of the above precipitate was added PPNCl $(0.30 \mathrm{~g}, 0.52 \mathrm{mmol})$ and the reaction mixture was stirred for $12 \mathrm{~h}$ at $60{ }^{\circ} \mathrm{C}$ until a clear green solution was formed. Then, the resulting solution was concentrated to give a light-green solid. After washing with water $(50 \mathrm{~mL})$ for three times and drying, $\mathbf{G}_{\mathbf{C u}} \cdot$ PPN was obtained as a light-green solid $(0.22 \mathrm{~g}, 0.22 \mathrm{mmol})$ in $66 \%$ yield. Negative ESI-MS: $m / z=650.982\left[\mathrm{M}^{-}\right]$.

\section{Synthesis of Complex ${ }^{{ }^{\text {core }} \mathbf{P t}_{\underline{3}}}$}

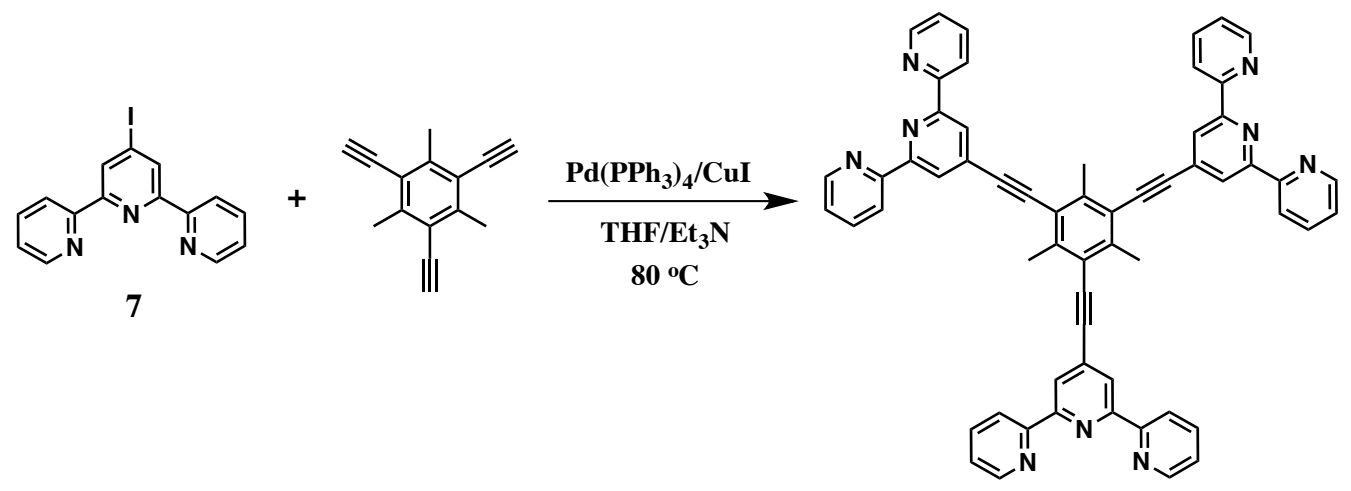

8 
Ligand 8. To a degassed $\mathrm{THF}$ and $\mathrm{Et}_{3} \mathrm{~N}$ solution mixture $(10 \mathrm{~mL}, 1 / 1 \mathrm{v} / \mathrm{v})$ of 7 (0.16 g, $0.42 \mathrm{mmol})$ were added $\mathrm{Pd}\left(\mathrm{PPh}_{3}\right)_{4}(15 \mathrm{mg}, 0.013 \mathrm{mmol}), \mathrm{CuI}(1 \mathrm{mg}, 0.0056$ $\mathrm{mmol})$ and triethynylmesitylene $(20 \mathrm{mg}, 0.10 \mathrm{mmol})$ and the mixture was stirred for $48 \mathrm{~h}$ at $80^{\circ} \mathrm{C}$ under nitrogen atmosphere. After filtration, the filtrate was collected and concentrated to a brown solid. Recrystallization of the crude product from methanol for two times led to the isolation of $\mathbf{8}$ as a white solid (76 mg, $0.086 \mathrm{mmol}$ ) in $86 \%$ yield. ${ }^{1} \mathrm{H}$ NMR $\left(400 \mathrm{MHz}, \mathrm{CDCl}_{3}, 298 \mathrm{~K}\right.$, relative to $\left.\mathrm{Me}_{4} \mathrm{Si}, \delta / \mathrm{ppm}\right): \delta 8.76(\mathrm{~d}, J=$ $5.6 \mathrm{~Hz}, 6 \mathrm{H}$, tpy), 8.62 (d, $J=5.6 \mathrm{~Hz}, 6 \mathrm{H}$, tpy), 8.51 (s, 6H, tpy), 7.89 (t, $J=7.4 \mathrm{~Hz}$, $6 \mathrm{H}$, tpy), 7.36 (t, $J=7.4 \mathrm{~Hz}, 6 \mathrm{H}$, tpy), $2.86\left(\mathrm{~s}, 9 \mathrm{H}, \mathrm{Ph}-\mathrm{CH}_{3}\right) .{ }^{13} \mathrm{C}\left\{{ }^{1} \mathrm{H}\right\}$ NMR (100 $\mathrm{MHz}, \mathrm{CDCl}_{3}, 298 \mathrm{~K}$, relative to $\left.\mathrm{Me}_{4} \mathrm{Si}, \delta / \mathrm{ppm}\right): \delta 155.23,150.27,137.28,131.91$, $123.58,122.87,121.39,110.31,96.90,90.64,20.55$. HR-MS (positive EI): calcd. for $\mathrm{C}_{60} \mathrm{H}_{40} \mathrm{~N}_{9}: m / z=886.3328$; found: 886.3357 .

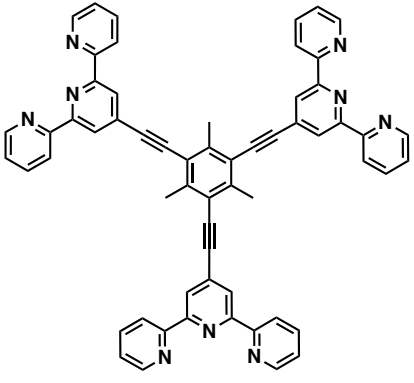

8
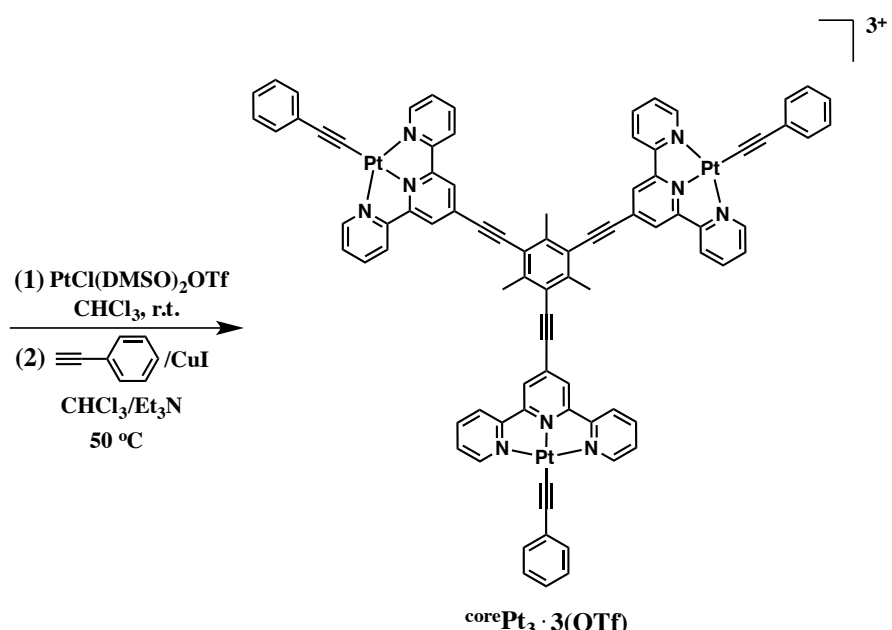

Complex ${ }^{\text {core }} \mathbf{P t}_{3}$. By a procedure similar to that for $\mathbf{P t}_{3} \cdot 3$ OTf, ${ }^{\text {core }} \mathbf{P t}_{3} \cdot 3$ OTf was obtained as a dark red solid in $42 \%$ yield $(47 \mathrm{mg}, 0.021 \mathrm{mmol}$ ) from the reaction of 8 (44 mg, $0.050 \mathrm{mmol})$, [PtCl(DMSO) $2 \mathrm{OTf}](60 \mathrm{mg}, 0.17 \mathrm{mmol})$, phenylacetylene $(0.10 \mathrm{~mL}, 0.98 \mathrm{mmol})$ and $\mathrm{Et}_{3} \mathrm{~N}(2 \mathrm{~mL}) .{ }^{1} \mathrm{H}$ NMR $\left(400 \mathrm{MHz}, d^{6}\right.$-DMSO, $353 \mathrm{~K}$, relative to $\left.\mathrm{Me}_{4} \mathrm{Si}, \delta / \mathrm{ppm}\right): \delta 9.27$ (m, $6 \mathrm{H}$, tpy), 8.84 (m, 6H, tpy), 8.76 (s, 6H, tpy), 8.54 (m, 6H, tpy), 7.95 (m, 6H, tpy), 7.53 (m, 6H, Ph), 7.34 (m, 6H, Ph), 7.28 (m, 3H, $\mathrm{Ph}), 3.00\left(\mathrm{~s}, 9 \mathrm{H}, \mathrm{Ph}-\mathrm{CH}_{3}\right)$. Positive ESI-MS: $m / z=925.647[\mathrm{M}+\mathrm{OTf}]^{2+}$.

\section{Structure Simulation}

The simulated structure was determined using the Material Studio Visualizer. In order to optimize the simulation, a simplified complex bearing six methoxy groups was modeled with 2D P6mm lattice conceived from the Pt $\cdots$ Pt connectivity and geometry of the building blocks. The bulk structure was geometrically optimized using the MS Forcite molecular dynamics module and simulated PXRD pattern was obtained. The lattice parameters of $a=b=36.3 \AA$ and $\gamma=120^{\circ}$ calculated from experimental PXRD 
profile is well matched with the simulated ones of $a=b=35.8 \AA$ and $\gamma=120^{\circ}$ (Table S1).

\section{Adsorption Membrane Fabrication}

Adsorption membranes were prepared by drop-casting certain volumes of $\mathrm{CHCl}_{3}$ /isopropanol (= 5/95 v/v) solution of $\mathbf{P t}_{\mathbf{3}}\left(1.5 \mathrm{mg} \mathrm{mL}^{-1}\right)$ on a supporting filter isopore ${ }^{\mathrm{TM}} \mathrm{PC}$ membrane (diameter: $2.5 \mathrm{~cm}$; pore size: $0.2 \mu \mathrm{m}$ ) followed by air-drying, and then complete drying under vacuum at room temperature for 12 hours. The membrane thickness was tunable by adding various volumes of solution, for example, $12.5 \mu \mathrm{L}$ for $0.11-\mu \mathrm{m}, 25 \mu \mathrm{L}$ for $0.19-\mu \mathrm{m}, 50 \mu \mathrm{L}$ for $0.41-\mu \mathrm{m}, 75 \mu \mathrm{L}$ for $0.58-\mu \mathrm{m}$, and $100 \mu \mathrm{L}$ for $0.89-\mu \mathrm{m}$, respectively. Taking the effective filtration area $\left(3.14 \mathrm{~cm}^{2}\right)$ into account, the effective amounts of $\mathbf{P t}_{\mathbf{3}}$ adsorbent in the resulting membranes were 12, $24,48,72$, and $96 \mu \mathrm{g}$, respectively. By a similar procedure, control membranes were also obtained by drop-casting certain volumes of corresponding solution of the reference ${ }^{\text {core }} \mathbf{P t}_{\mathbf{3}}$ compound without the dodecyl chains.

\section{Adsorption and Desorption Experiments}

In order to evaluate the permeation of water, one membrane was placed in a filtration device connected to a vacuum pump with reduced pressure of about -0.07 bar. When the water steadily permeated, the flowing volume and time were recorded. In one batch of the uptake experiments of metal ions in water, $1 \mathrm{~mL}$ of the corresponding salts in aqueous solution (1-2 $\mu \mathrm{g} \mathrm{mL}^{-1}$ ) was used as feed for filtration. Then, the concentration of metal ions in the filtrate was determined by ICP-MS. As for the desorption experiments of metal ions enriched in membranes, $1 \mathrm{~mL}$ of $\mathrm{NH}_{4} \mathrm{Cl}_{(\mathrm{aq})}$ solution ( $\sim 10 \mathrm{wt} . \%)$ was used in one batch for rinsing by filtration. The concentration of metal ions in the filtrate was determined by ICP-MS. For the regeneration experiments, the adsorption/desorption cycle was repeated for four times. To rule out the leaching possibility of $\mathbf{P t}_{3}$ in the membranes, $1 \mathrm{~mL}$ of $\mathrm{NH}_{4} \mathrm{Cl}_{(\mathrm{aq})}$ solution was used for rinsing the blank membrane by filtration for four times. The concentration of $\mathrm{Pt}$ in the filtrate was almost identical to the corresponding feed as determined by ICP-MS. 


\section{Supporting Note 1. Isodesmic Model Fitting}

The self-assembled mechanism of $\mathbf{P t}_{\mathbf{3}}$ in solution was investigated by analyzing the temperature-dependent UV-vis absorption spectral traces (Figure S6a). The degree of aggregation $(\alpha)$ was calculated according to the following Equation (S1):

$$
\alpha=\frac{A_{\mathrm{T}}-A_{363}}{A_{293}-A_{363}}
$$

where $A_{363}, A_{\mathrm{T}}$, and $A_{293}$ represent the absorbance at $525 \mathrm{~nm}$ recorded at $363 \mathrm{~K}, T \mathrm{~K}$, and $293 \mathrm{~K}$ respectively. By fitting the plot of $\alpha$ as a function of temperature $(T)$ (Figure S9a) according the following Equation (S2), the self-assembly process of $\mathbf{P t}_{\mathbf{3}}$ in solution was found to follow an isodesmic equilibrium (Figure S9c), in which the aggregation of monomers was governed by a single equilibrium constant $\left(K_{\mathrm{e}}\right)$ (Figure S9b).

$$
\alpha=1 /\left\{1+\operatorname{Exp}\left[-0.908 \Delta H \frac{T-T_{\mathrm{m}}}{R T_{\mathrm{m}}^{2}}\right]\right\}
$$

where $T_{\mathrm{m}}$ is the melting temperature defined as the temperature for which $\alpha$ is 0.5 ; $\triangle H$ is the molar enthalpy release related to the formation of noncovalent intermolecular interactions and $R$ is the gas constant. Inserting $\alpha$ into the following Equation (S3) yielded the equilibrium constant $\left(K_{\mathrm{e}} / \mathrm{M}^{-1}\right)$, from which the changes in entropy $(\triangle S)$ as well as Gibbs free energy $(\triangle G)$ were calculated by the Van't Hoff equation (inset in Figure S9b). The thermodynamic parameters are given in Table S2.

$$
K_{\mathrm{e}}=\left[\left(2 / \sqrt{1-\alpha_{\mathrm{T}}}-1\right)^{2}-1\right] / 4 C
$$




\section{Supporting Note 2. Monomer-Dimer Equilibrium}

The equilibrium constants of dimerization resulting from metal $\cdots$ metal interactions $\left(K_{\mathrm{MM}} / \mathrm{M}^{-1}\right)$ and $\pi-\pi$ interactions $\left(K_{\pi \pi} / \mathrm{M}^{-1}\right)$ of $\mathbf{P t}_{3}$ at $298 \mathrm{~K}$ were determined at different concentrations $(2.24-225 \mu \mathrm{M}$, Figure S10) by the following Equation (S4), ${ }^{10}$

$$
\frac{[\mathrm{Pt}]}{\sqrt{A}}=\frac{1}{\sqrt{\varepsilon_{\mathrm{MM}} K_{\mathrm{MM}}}}+\left(\frac{2}{\varepsilon_{\mathrm{MM}}}+\frac{2 K_{\pi \pi}}{\varepsilon_{\mathrm{MM}} K_{\mathrm{MM}}}\right) \sqrt{A}
$$

where $[\mathrm{Pt}]$ is the concentration of the platinum complex, which was in principle three times the concentration of $\mathbf{P t}_{3} ; A$ is the absorbance at $525 \mathrm{~nm} ; \varepsilon_{\mathrm{MM}}$ is defined as the extinction coefficient of the MMLCT band $(525 \mathrm{~nm})$ due to the aggregation via $\mathrm{Pt}^{\mathrm{II}} \cdots \mathrm{Pt}^{\mathrm{II}}$ interactions and was taken to be $3060 \mathrm{M}^{-1} \mathrm{~cm}^{-1}$ as determined from the UV-vis absorption spectra (inset in Figure S10a). The two processes of dimerization are shown below:

$$
\begin{aligned}
& 2 \mathrm{Pt} \stackrel{K_{\mathrm{MM}}}{\rightleftharpoons}(\mathrm{Pt} . . \mathrm{Pt})_{\mathrm{MM}} \\
& 2 \mathrm{Pt} \stackrel{K_{\mathrm{mm}}}{\rightleftharpoons}(\mathrm{Pt} . . \mathrm{Pt})_{\mathrm{mm}}
\end{aligned}
$$




\section{Supporting Note 3. Host-Guest Interactions}

Upon the addition of $\mathbf{P t}_{\mathbf{3}}$ to $\mathbf{G}_{\mathbf{P t}}$ in $\mathrm{CDCl}_{3}$, the intensity of peaks assigned to the protons of $\mathbf{G}_{\mathbf{P t}}$ continuously decreased until disappearing completely (Figure S12). Considering the host-guest interactions between $\mathbf{S P}_{\mathbf{P t 3}}$ and $\mathbf{G}_{\mathbf{P t}}$, it was possible that $\mathbf{G}_{\mathbf{P t}}$ was captured by $\mathbf{S P}_{\mathbf{P t 3}}$ and readily bound to the $\mathrm{Pt}^{\mathrm{II}}$ (tpy) building bocks of $\mathbf{S P}_{\mathbf{P t 3}}$ via $\mathrm{Pt}^{\mathrm{II}} \cdots \mathrm{Pt}^{\mathrm{II}}$ interactions. Due to the aggregated structure of $\mathbf{S P}_{\mathbf{P t 3}}$ and $\mathbf{G}_{\mathbf{P t}} \subset \mathbf{S P} \mathbf{P}_{\mathbf{P t} 3}$ association, no peaks assigned to the protons of their aromatic rings were observed (Figures S2a and S12). As a result, the concentration of free $\mathbf{G}_{\mathbf{P t}},\left[\mathbf{G}_{\mathbf{P t}}\right]_{\text {free}}$, whose protons can be detected from the NMR spectra, were gradually decreased to zero when $\mathbf{P t}_{\mathbf{3}}$ was added.

Given the concentration of the counter-ion $\mathrm{PPN}^{+}$was constant, the mole ratio of the free to total guest, $\left[\mathbf{G}_{\mathbf{P t}}\right]_{\text {free }} /\left[\mathbf{G}_{\mathbf{P t}}\right]_{\text {total }}$, was calculated by the following Equation (S5) after the normalization of the peaks corresponding to the protons of $\mathrm{PPN}^{+}$(marked as * and \#, Figure S12),

$$
\frac{\left[\mathbf{G}_{\mathbf{P t}}\right]_{\text {Free }}}{\left[\mathbf{G}_{\mathbf{P t}}\right]_{\text {Total }}}=\frac{I_{\mathrm{a}}^{\prime}+I_{\mathrm{b}}^{\prime}+I_{\mathrm{C}}^{\prime}}{I_{\mathrm{a}}+I_{\mathrm{b}}+I_{\mathrm{c}}}
$$

where $\left(I_{\mathrm{a}}+I_{\mathrm{b}}+I_{\mathrm{c}}\right)$ and $\left(I_{\mathrm{a}}{ }^{\prime}+I_{\mathrm{b}}{ }^{\prime}+I_{\mathrm{c}}{ }^{\prime}\right)$ represents the total integration of the peaks assigned to the protons of $\mathbf{G}_{\mathbf{P t}}$ in Figure $\mathrm{S} 12$ before and after the addition of $\mathbf{P t}_{\mathbf{3}}$, respectively. 


\section{Supporting Note 4. Binding Constants of Host-Guest Interactions}

As shown in Table $\mathrm{S} 3$, the binding constants $\left(K_{\mathrm{a}} / \mathrm{M}^{-3}\right)$ and Hill coefficient $(n)$ for the host-guest systems were evaluated by the Hill plots (Figure S17), ${ }^{11}$ according to the following Equation (S6),

$$
\log \left(\frac{\theta}{1-\theta}\right)=n \cdot \log \left[\mathbf{G}_{\mathbf{M}}\right]+\log K_{\mathrm{a}}
$$

where $\theta$ is defined as the fraction of the guest $\left(\mathbf{G}_{\mathbf{M}}, \mathbf{M}=\mathrm{Pt}, \mathrm{Au}\right.$, and $\left.\mathrm{Pd}\right)$ that was bound with $\mathbf{S P}_{\mathbf{P t} 3}$ and $\left[\mathbf{G}_{\mathbf{M}}\right]$ is the concentration of guest added. The UV-vis absorption (Figures S11a, S13a and S14a) and emission (Figures S11b, S13b and $\mathrm{S} 14 \mathrm{~b})$ spectral titration experiments were performed in $\mathrm{CHCl}_{3}$ solution at $298 \mathrm{~K}$, affording the corresponding $K_{\mathrm{a}}$ and $n$ obtained by the fitting of Hill plots. The $\theta$ value measured by UV-vis absorption and emission spectral titration were calculated by the following Equations (S7) and (S8), respectively,

$$
\begin{aligned}
& \theta=\frac{A-A_{0}}{A_{\max }-A_{0}} \\
& \theta=\frac{I-I_{0}}{I_{\max }-I_{0}}
\end{aligned}
$$

where $A_{0}$ and $I_{0}$ represent the absorbance at $525 \mathrm{~nm}\left(\mathbf{G}_{\mathbf{P t}}\right), 435 \mathrm{~nm}\left(\mathbf{G}_{\mathbf{A u}}\right)$, or $520 \mathrm{~nm}$ $\left(\mathbf{G}_{\mathbf{P d}}\right)$ and emission intensity at $700 \mathrm{~nm}$ of $\mathbf{S P}_{\mathbf{P t 3}}$ without addition of $\mathbf{G}_{\mathbf{M}}$ respectively; $A$ and $I$ represent the absorbance at $525 \mathrm{~nm}\left(\mathbf{G}_{\mathbf{P t}}\right), 435 \mathrm{~nm}\left(\mathbf{G}_{\mathbf{A u}}\right)$, or $520 \mathrm{~nm}\left(\mathbf{G}_{\mathbf{P d}}\right)$ and emission intensity at $700 \mathrm{~nm}$ of $\mathbf{S P}_{\mathbf{P t 3}}$ after addition of certain amount of $\mathbf{G}_{\mathbf{M}}$ respectively; $A_{\max }$ and $I_{\max }$ represent the absorbance at $525 \mathrm{~nm}\left(\mathbf{G}_{\mathbf{P t}}\right), 435 \mathrm{~nm}\left(\mathbf{G}_{\mathbf{A u}}\right)$, or $520 \mathrm{~nm}\left(\mathbf{G}_{\mathbf{P d}}\right)$ and emission intensity at $700 \mathrm{~nm}$ of $\mathbf{S P}_{\mathbf{P t 3}}$ after addition of a saturated concentration of $\mathbf{G}_{\mathbf{M}}$ respectively. 


\section{Supporting Note 5. Competition of $\mathrm{Pt}^{\mathrm{II}} \cdot \mathrm{Pt}^{\mathrm{II}}$ and $\mathrm{Pt}^{\mathrm{II}} \cdots \mathrm{Au}^{\mathrm{I}}$ Interactions}

Upon the addition of $\mathbf{P t}_{\mathbf{3}}$ to an admixture of $\mathbf{G}_{\mathbf{P t}}$ and $\mathbf{G}_{\mathbf{A u}}$ in $\mathrm{CDCl}_{3}$, the intensity of peaks assignable to the protons of $\mathbf{G}_{\mathbf{P t}}$ rapidly decreased while the intensity of peaks assignable to the protons of $\mathbf{G}_{\mathbf{A u}}$ were constant (Figure S18). Once the peaks of $\mathbf{G}_{\mathbf{P t}}$ mostly disappeared, the peaks assigned to $\mathbf{G}_{\mathbf{A u}}$ began to stepwisely decrease (Figure S18). Considering the stronger host-guest interaction of $\mathbf{G}_{\mathbf{P t}} \subset \mathbf{S P} \mathbf{P}_{\mathbf{P t 3}}\left(\log K_{\mathrm{Pt}} \approx\right.$ $14)$ than that of $\mathbf{G}_{\mathbf{A u}} \subset \mathbf{S} \mathbf{P}_{\mathbf{P t 3}}\left(\log K_{\mathrm{Au}} \approx 7\right)$ (Table S3), it was possible that $\mathbf{G}_{\mathbf{P t}}(\sim 100 \%)$ was absolutely captured by $\mathbf{S P}_{\mathbf{P t 3}}$ and bound to the $\mathrm{Pt}^{\mathrm{II}}$ (tpy) building blocks of $\mathbf{S P}_{\mathbf{P t 3}}$ via strong $\mathrm{Pt}^{\mathrm{II}} \cdots \mathrm{Pt}^{\mathrm{II}}$ interactions. Then, $\mathbf{G}_{\mathbf{A u}}$ was gradually captured by $\mathbf{S P}_{\mathbf{P t 3}}$ and bound to the $\mathrm{Pt}^{\mathrm{II}}$ (tpy) building blocks of $\mathbf{S P}_{\mathbf{P t 3}}$ via relatively weak $\mathrm{Pt}^{\mathrm{II}} \cdots \mathrm{Au}^{\mathrm{I}}$ interactions (Figure 3f,h).

Given the concentration of counter-ion $\mathrm{PPN}^{+}$was constant, the mole ratio of the free to total guest, $\left[\mathbf{G}_{\mathbf{P t}}\right]_{\text {free }} /\left[\mathbf{G}_{\mathbf{P t}}\right]_{\text {total }}$ and $\left[\mathbf{G}_{\mathbf{A u}}\right]_{\text {free }} /\left[\mathbf{G}_{\mathbf{A u}}\right]_{\text {total }}$, were calculated by the following Equations (S9) and (S10) after the normalization of the peaks corresponding to the protons of $\mathrm{PPN}^{+}$(marked as * and \#, Figure S18), respectively,

$$
\begin{aligned}
& \frac{\left[\mathbf{G}_{\mathrm{Pt}}\right]_{\text {Free }}}{\left[\mathbf{G}_{\mathrm{Pt}}\right]_{\text {Total }}}=\frac{I_{\mathrm{a}}^{\prime}+I_{\mathrm{b}}^{\prime}+I_{\mathrm{C}}^{\prime}}{I_{\mathrm{a}}+I_{\mathrm{b}}+I_{\mathrm{c}}} \\
& \frac{\left[\mathbf{G}_{\mathrm{Au}}\right]_{\text {Free }}}{\left[\mathbf{G}_{\text {Au }}\right]_{\text {Total }}}=\frac{I_{\mathrm{A}}^{\prime}+I_{\mathrm{B}}^{\prime}}{I_{\mathrm{A}}+I_{\mathrm{B}}}
\end{aligned}
$$

where $\left(I_{\mathrm{a}}+I_{\mathrm{b}}+I_{\mathrm{c}}\right)$ and $\left(I_{\mathrm{a}}{ }^{\prime}+I_{\mathrm{b}}{ }^{\prime}+I_{\mathrm{c}}{ }^{\prime}\right)$ represent the total integration of the peaks assigned to the protons of $\mathbf{G}_{\mathbf{P t}}$ in Figure S18 before and after the addition of $\mathbf{P t}_{\mathbf{3}}$, respectively; and $\left(I_{\mathrm{A}}+I_{\mathrm{B}}\right)$ and $\left(I_{\mathrm{A}}{ }^{\prime}+I_{\mathrm{B}}{ }^{\prime}\right)$ represent the total integration of the peaks assigned to the protons of $\mathbf{G}_{\mathbf{A u}}$ in Figure S18 before and after the addition of $\mathbf{P t}_{\mathbf{3}}$, respectively. 


\section{Supporting Note 6. Competition of $\mathrm{Pt}^{\mathrm{II}} \cdot{ } \mathrm{Pt}^{\mathrm{II}}$ and $\mathrm{Pt}^{\mathrm{II}} \cdot \mathrm{Pd}^{\mathrm{II}}$ Interactions}

Upon the addition of $\mathbf{P t}_{\mathbf{3}}$ to an admixture of $\mathbf{G}_{\mathbf{P t}}$ and $\mathbf{G}_{\mathbf{P d}}$ in $\mathrm{CDCl}_{3}$, the intensity of peaks assignable to the protons of $\mathbf{G}_{\mathbf{P t}}$ rapidly decreased while the intensity of peaks assignable to the protons of $\mathbf{G}_{\mathbf{P d}}$ slowly decreased (Figure S19). However, when the peaks of $\mathbf{G}_{\mathbf{P t}}$ have almost disappeared, the peaks assigned to $\mathbf{G}_{\mathbf{P d}}$ began to rapidly decrease until almost gone (Figure S19). Considering the competitive host-guest interactions of $\mathbf{G}_{\mathbf{P t}} \subset \mathbf{S} \mathbf{P}_{\mathbf{P t 3}}\left(\log K_{\mathrm{Pt}} \approx 14\right)$ and $\mathbf{G}_{\mathbf{P d}} \subset \mathbf{S} \mathbf{P}_{\mathbf{P t 3}}\left(\log K_{\mathbf{P d}} \approx 10\right)$ (Table S3), it was possible that $\mathbf{G}_{\mathbf{P t}}(\sim 78 \%)$ was preferentially captured by $\mathbf{S P}_{\mathbf{P t 3}}$ and bound to the $\mathrm{Pt}^{\mathrm{II}}$ (tpy) building blocks of $\mathbf{S P}_{\mathbf{P t 3}}$ via stronger $\mathrm{Pt}^{\mathrm{II}} \cdots \mathrm{Pt}^{\mathrm{II}}$ interactions, whereas $\mathbf{G}_{\mathbf{P d}}$ $(\sim 22 \%)$ was bound to the $\mathrm{Pt}^{\mathrm{II}}$ (tpy) building blocks of $\mathbf{S P}_{\mathbf{P t 3}}$ via relatively weak $\mathrm{Pt}^{\mathrm{II}} \cdots \mathrm{Pd}^{\mathrm{II}}$ interactions at the middle point of $\left[\mathbf{P t}_{\mathbf{3}}\right] /\left[\mathbf{G}_{\mathbf{P t}}+\mathbf{G}_{\mathbf{P d}}\right]_{\text {total }}(0.16$, Figure $3 \mathrm{~g})$

Given the concentration of counter-ion $\mathrm{PPN}^{+}$was constant, the mole ratio of the free to total guest, $\left[\mathbf{G}_{\mathbf{P t}}\right]_{\text {free }} /\left[\mathbf{G}_{\mathbf{P t}}\right]_{\text {total }}$ and $\left[\mathbf{G}_{\mathbf{P d}}\right]_{\text {free }} /\left[\mathbf{G}_{\mathbf{P d}}\right]_{\text {total }}$, were calculated by the following Equations (S11) and (S12) after the normalization of the peaks corresponding to the protons of $\mathrm{PPN}^{+}$(marked as * and \#, Figure S19), respectively,

$$
\begin{aligned}
& \frac{\left[\mathbf{G}_{\mathbf{P t}}\right]_{\text {Free }}}{\left[\mathbf{G}_{\mathbf{P t}}\right]_{\text {Total }}}=\frac{I_{\mathrm{a}}^{\prime}+I_{\mathrm{b}}^{\prime}}{I_{\mathrm{a}}+I_{\mathrm{b}}} \\
& \frac{\left[\mathbf{G}_{\mathbf{P d}}\right]_{\text {Free }}}{\left[\mathbf{G}_{\mathbf{P d}}\right]_{\text {Total }}}=\frac{I_{\mathrm{A}}^{\prime}+I_{\mathrm{B}}^{\prime}}{I_{\mathrm{A}}+I_{\mathrm{B}}}
\end{aligned}
$$

where $\left(I_{\mathrm{a}}+I_{\mathrm{b}}\right)$ and $\left(I_{\mathrm{a}}{ }^{\prime}+I_{\mathrm{b}}{ }^{\prime}\right)$ represent the total integration of the peaks assigned to the protons of $\mathbf{G}_{\mathbf{P t}}$ in Figure S19 before and after the addition of $\mathbf{P t}_{\mathbf{3}}$, respectively; and $\left(I_{\mathrm{A}}\right.$ $\left.+I_{\mathrm{B}}\right)$ and $\left(I_{\mathrm{A}}{ }^{\prime}+I_{\mathrm{B}}{ }^{\prime}\right)$ represent the total integration of the peaks assigned to the protons of $\mathbf{G}_{\mathbf{P d}}$ in Figure S19 before and after the addition of $\mathbf{P t}_{\mathbf{3}}$, respectively. 


\section{Supporting Note 7. Mechanism of Emission Quenching and Enhancement}

In general, the emission quenching and enhancement of host-guest associations could occur through electron-transfer and energy-transfer pathways or both. ${ }^{12}$ To reveal the underlying mechanism, the electrochemical and photophysical properties of $\mathbf{P t}_{3},\left[\mathrm{PtCl}_{4}\right]^{2-}$ and $\left[\mathrm{Pt}(\mathrm{CN})_{4}\right]^{2-}$ were investigated. The triplet state energy of $\mathbf{P t}_{\mathbf{3}}$ was determined to be $2.32 \mathrm{eV}$ from the $0-0$ transition of the ${ }^{3}$ MMLCT state and the data for the emissive $\left[\mathrm{Pt}(\mathrm{CN})_{4}\right]^{2-}$ were obtained from the literature. ${ }^{13}$ As shown in Table $\mathrm{S} 4$, the electrochemical data of $\mathbf{P t}_{\mathbf{3}}$ showed the reversible reduction couples at -0.90 $\mathrm{V}$ and $-1.50 \mathrm{~V}$ and irreversible oxidative wave at $+1.34 \mathrm{~V}$ (vs. SCE), respectively. Therefore, the excited state reduction potentials of $\mathbf{P t}_{3}, E\left(\mathrm{Pt}^{3+/ 2+*}\right)$ and $E\left(\mathrm{Pt}^{2+* /+}\right)$, were determined to be $-0.98 \mathrm{~V}$ and $+1.42 \mathrm{~V}$, respectively. Together taking the electrochemical data of $\mathrm{Pt}^{\mathrm{II}}$-containing anions into account, $\left[\mathrm{PtCl}_{4}\right]^{2-}$ could serve as electron donors, because its $\Delta G$ value of the reductive electron-transfer quenching was more negative than that of the oxidative electron-transfer quenching. As a result, the following electron-transfer process to induce the ${ }^{3} \mathrm{MMLCT}$ emission quenching of $\mathbf{S P}_{\mathbf{P t 3}}$ is thermodynamically favorable.

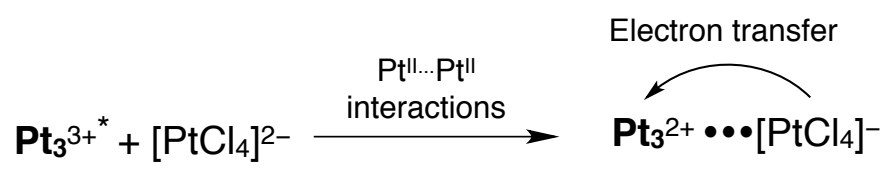

(Reductive quenching)

On the contrary, although both $\Delta G$ values of the oxidative and reductive electron-transfer quenching were also negative for $\left[\mathrm{Pt}(\mathrm{CN})_{4}\right]^{2-}$, the triplet state energy of $\left[\operatorname{Pt}(\mathrm{CN})_{4}\right]^{2-}$ showed a much higher value $(3.37 \mathrm{eV})$ than that of $\mathbf{P t}_{\mathbf{3}}(2.32 \mathrm{eV})$, indicating a possible energy-transfer process to cause the enhancement of the ${ }^{3}$ MMLCT emission of $\mathbf{S P}_{\mathbf{P t 3}}$ as followed.

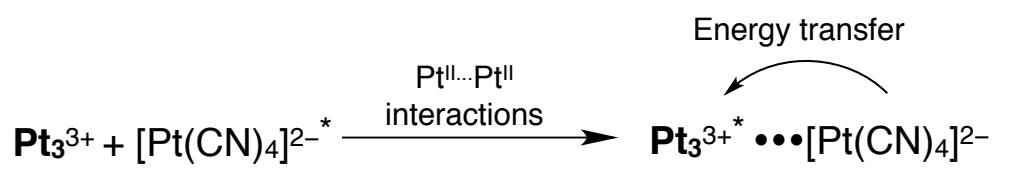

(Emission enhancement)

Apart from the electron/energy-transfer above discussed, there may be another possible mechanism for the ${ }^{3}$ MMLCT emission quenching of $\mathbf{S P}_{\mathbf{P t 3}}$ resulting from the low-lying ligand-field (LF) excited state of $\left[\mathrm{PtCl}_{4}\right]^{2-}$ due to its weak-field $\mathrm{Cl}^{-}$ligands. On the other hand, the emission enhancement may result from the lack of low-lying LF excited state in $\left[\mathrm{Pt}(\mathrm{CN})_{4}\right]^{2-}$ with strong-field $\mathrm{CN}^{-}$ligands. 


\section{Supporting Note 8. Extraction Efficiencies of Metal Ions}

In the cases of extraction experiments, the extraction efficiencies of metal (M) ions from water were evaluated by the following Equation (S13),

$$
\text { Extraction Efficiency }=\left(1-\frac{[\mathrm{M}]_{\mathrm{AE}}}{[\mathrm{M}]_{\mathrm{BE}}}\right) \times 100 \%
$$

where $[\mathbf{M}]_{\mathrm{BE}}$ and $[\mathbf{M}]_{\mathrm{AE}}$ represent the concentrations $\left(\mu \mathrm{g} \mathrm{mL} \mathrm{m}^{-1}\right)$ of $\mathbf{M}$ salts in aqueous phase before and after extractions, respectively, which were determined by ICP-MS according to the following Equation (S14),

$$
[\mathbf{M}]=\frac{I_{\mathrm{R}}}{\varepsilon_{\mathrm{M}}}
$$

where $I_{\mathrm{R}}$ represents the relative signal intensity of $\mathbf{M}$ to the standard scandium (Sc) whose concentration was constant $(10 \mathrm{ppb}) ; \varepsilon_{\mathrm{M}}$ represents a relevant factor, which was obtained by the slope of calibration curve shown in Figure S24. Of a particular note, the concentration of aqueous solution tested by ICP-MS must be diluted initially to $\mathrm{ppb}\left(\mathrm{ng} \mathrm{\textrm {mL } ^ { - 1 } )}\right.$ level in order to obtain reliable data. 


\section{Supporting Note 9. Adsorption Efficiencies of Metal Ions}

In the cases of adsorption experiments, the adsorption efficiencies and capacities $\left(\mathrm{mg} \mathrm{g}^{-1}\right)$ of metal (M, net weight) ions in water were evaluated by the following Equations (S15) and (S16), respectively, ${ }^{14}$

$$
\begin{aligned}
& \text { Adsorption Efficiency }=\left(1-\frac{V_{\mathrm{AF}}[\mathbf{M}]_{\mathrm{AF}}}{V_{\mathrm{BF}}[\mathbf{M}]_{\mathrm{BF}}}\right) \times 100 \% \\
& \text { Adsorption Capacity }=\frac{V_{\mathrm{BF}}[\mathbf{M}]_{\mathrm{BF}}-V_{\mathrm{AF}}[\mathbf{M}]_{\mathrm{AF}}}{m}
\end{aligned}
$$

where $V_{\mathrm{BF}}$ and $[\mathbf{M}]_{\mathrm{BF}}$ represent the volume $(\mathrm{mL})$ of feed and concentrations $\left(\mu \mathrm{g} \mathrm{mL}^{-1}\right)$ of $\mathbf{M}$ salts in it before filtration, respectively; and $\mathrm{V}_{\mathrm{AF}}$ and $[\mathbf{M}]_{\mathrm{AF}}$ represent the volume $(\mathrm{mL})$ of filtrate and concentrations $\left(\mu \mathrm{g} \mathrm{mL}^{-1}\right)$ of $\mathbf{M}$ salts in it after filtration, respectively. $M$ is the mass $(\mathrm{g})$ of $\mathbf{P t}_{\mathbf{3}}$.

In addition, the water permeate flux $\left(J / \mathrm{m}^{3} \mathrm{~m}^{-2} \mathrm{~h}^{-1} \mathrm{bar}^{-1}\right)$ of filtration was calculated according to the following Equation (S17).

$$
J=\frac{V}{P \cdot A \cdot t}
$$

where $V$ is flowing volume; $A$ is effective filtering area $\left(3.14 \mathrm{~cm}^{2}\right) ; t$ is flowing time; and $P$ is reduced pressure value. 
a

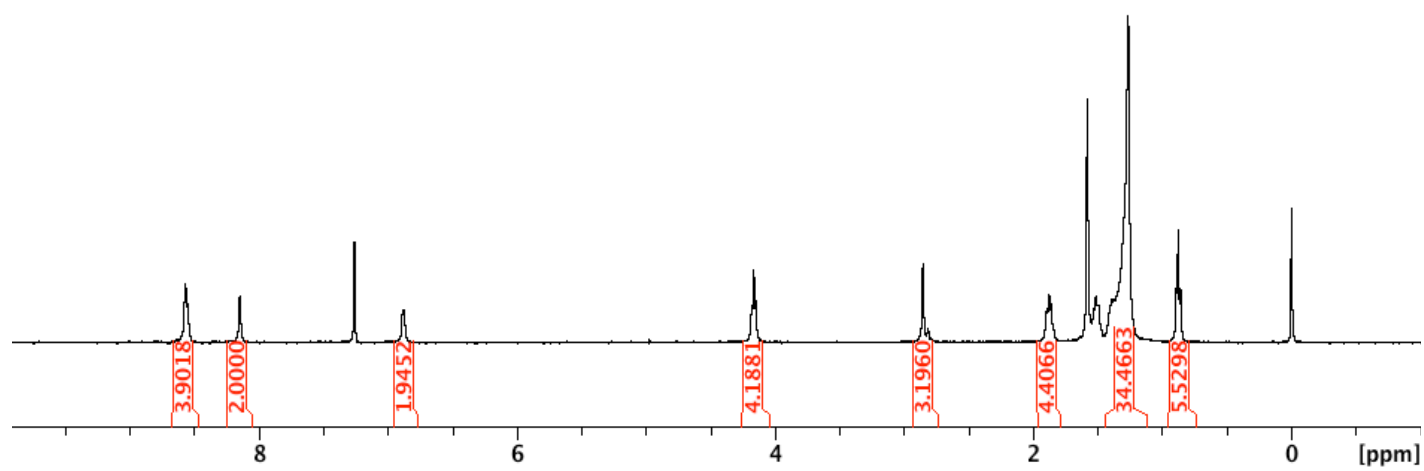

b

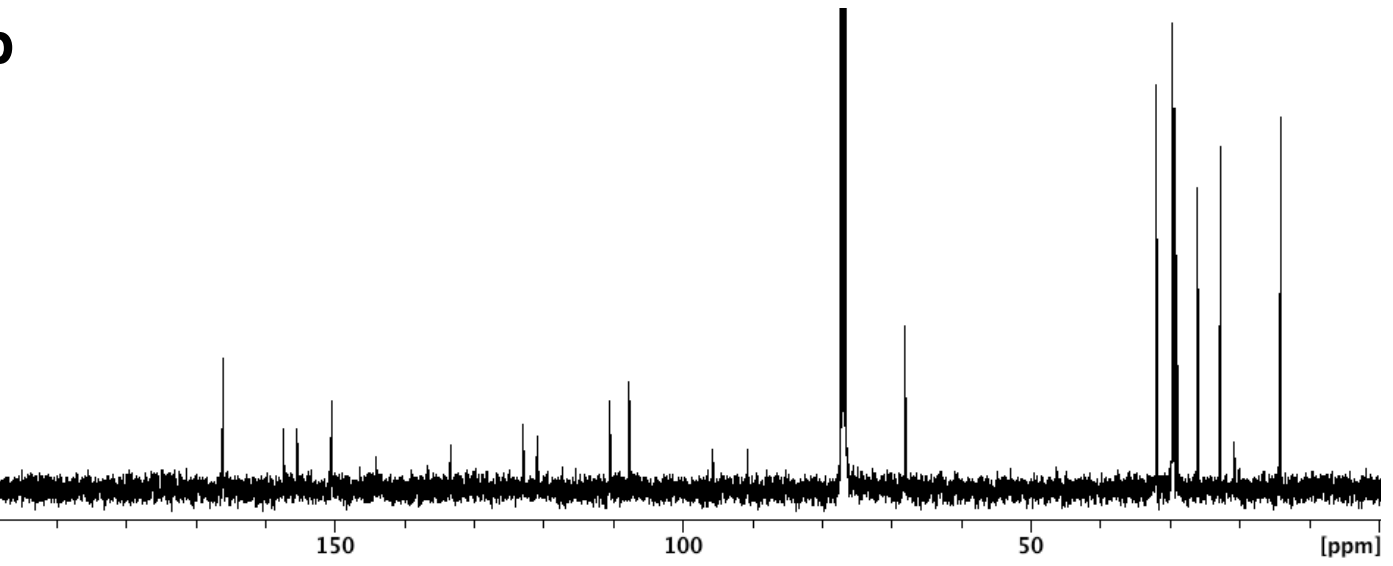

C

1992.348

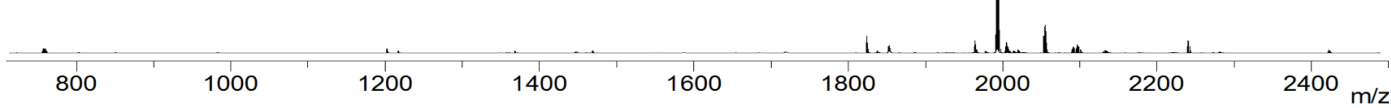

Figure S1. Characterization of ligand 5. (a, b) ${ }^{1} \mathrm{H}$ NMR (a) and ${ }^{13} \mathrm{C}$ NMR (b) spectra of ligand 5 in $\mathrm{CDCl}_{3}$ at $298 \mathrm{~K}$. (c) MALDI-TOF mass spectrum of ligand $\mathbf{5}$ using dithranol as a matrix. 


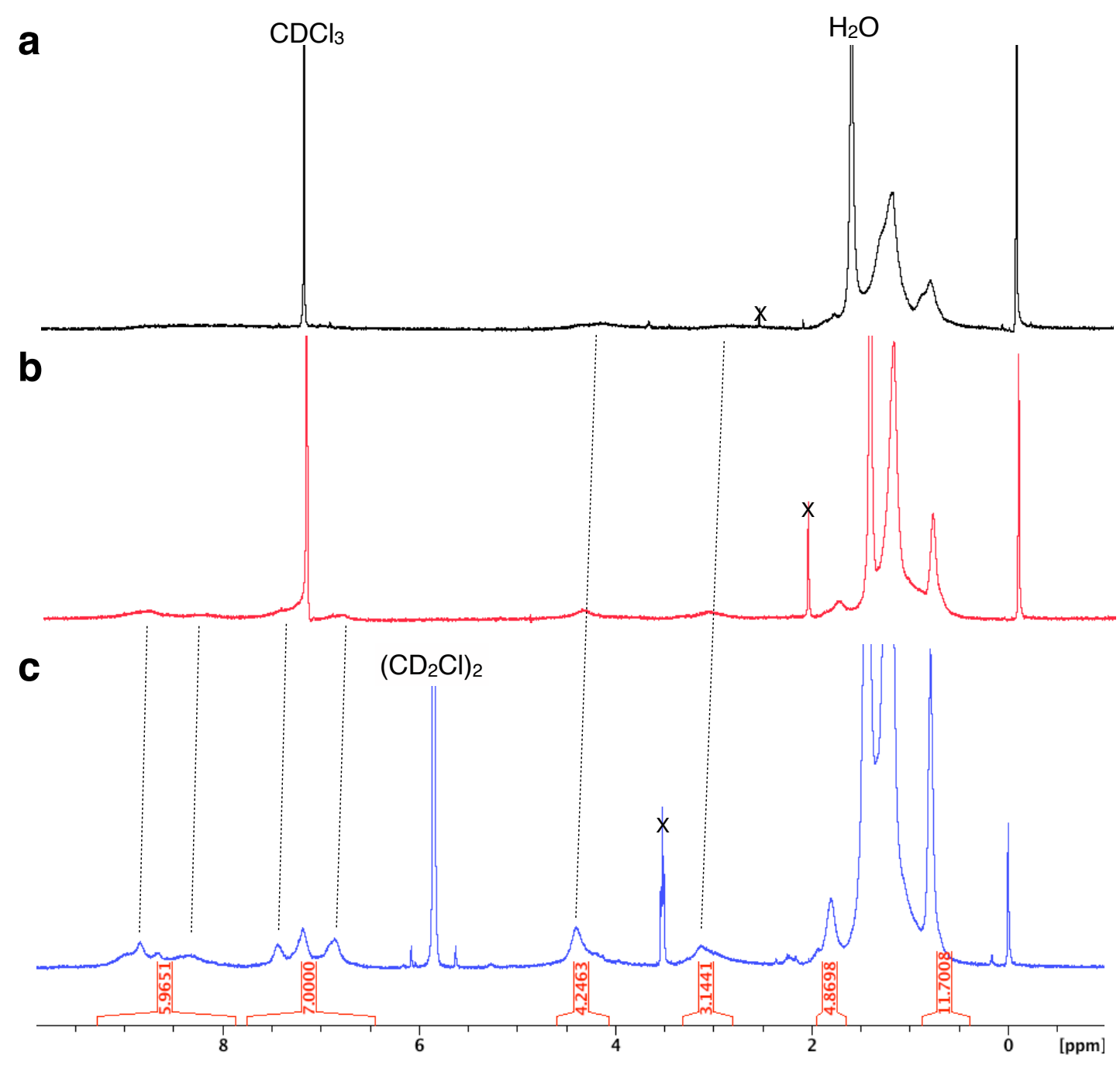

Figure S2. Characterization of complex $\mathbf{P t}_{3}$. $(\mathrm{a}-\mathrm{c}){ }^{1} \mathrm{H}$ NMR spectra of $\mathbf{P t}_{3}$ in $\mathrm{CDCl}_{3}$ at $298 \mathrm{~K}(\mathrm{a})$, in $\mathrm{CDCl}_{3}$ at $323 \mathrm{~K}(\mathrm{~b})$, and in $\left(\mathrm{CD}_{2} \mathrm{Cl}\right)_{2}$ at $353 \mathrm{~K}$ (c). 

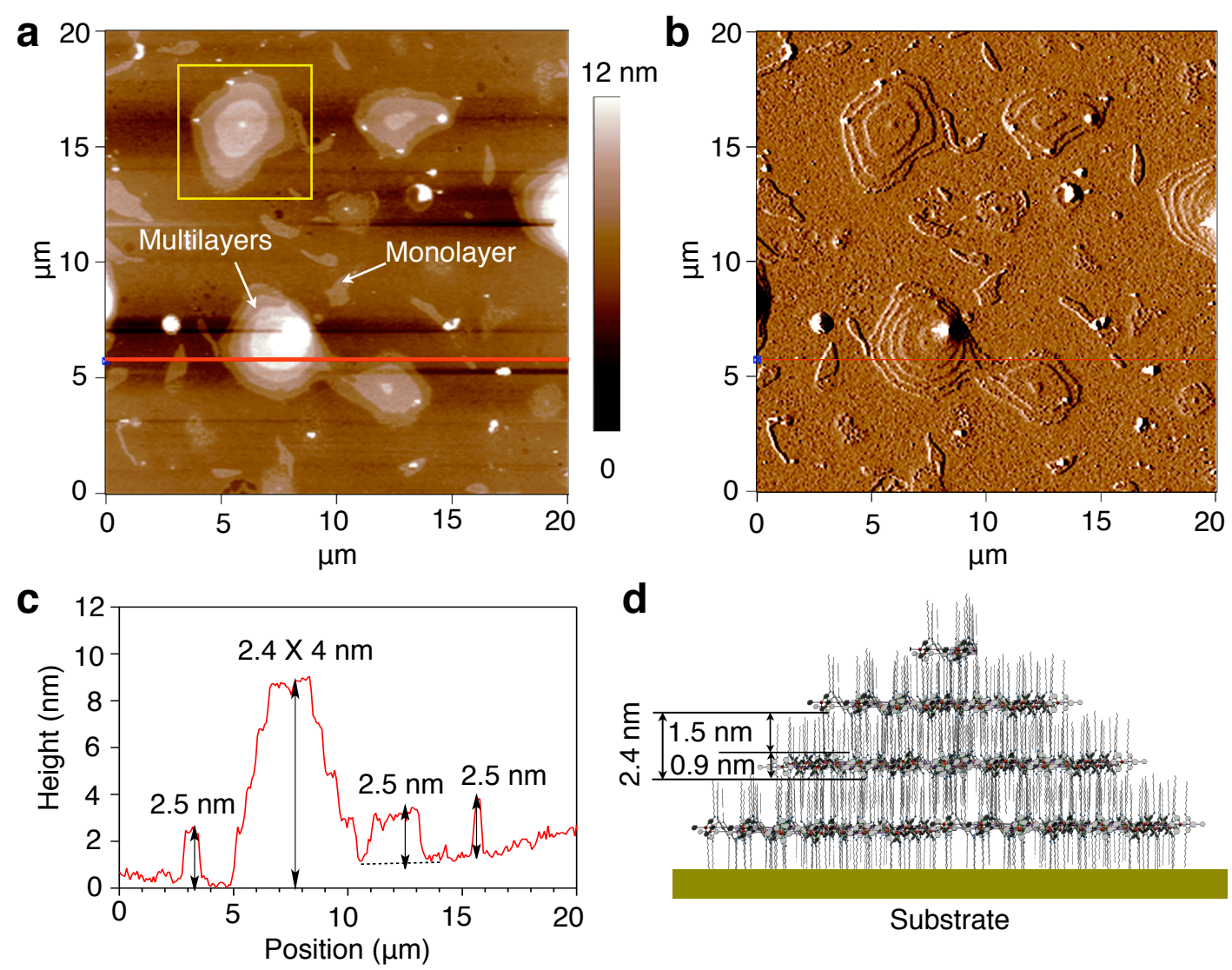

Figure S3. Morphological characterization of the self-assembled structure formed by $\mathbf{P t}_{3}$. (a-d) AFM height image (a), amplitude image (b), height profile (c) and schematic representation (d) of the mono/multi-layered nanosheets formed by $\mathbf{P t}_{\mathbf{3}}$ on a silicon wafer. The height profile (c) was measured along the red line in (a). The schematic representation (d) illustrates the region of yellow box in (a). The sample was fabricated by spin-coating a dilute $\mathrm{CHCl}_{3}$ solution of $\mathbf{P t}_{\mathbf{3}}(0.1 \mathrm{mM})$ on a silicon wafer after annealing in $\mathrm{CHCl}_{3}$ vapor for 1 hour. The average height of each layer was around $2.4 \mathrm{~nm}(\mathrm{c})$, well agreed with the total length of the single perpendicularly aligned dodecyl side chains $(1.5 \mathrm{~nm}, \mathrm{~d})$ as well as the layer consisting of the vertically oriented $\mathrm{Pt}^{\mathrm{II}}$ (tpy) building blocks $(0.9 \mathrm{~nm}, \mathrm{~d})$. 


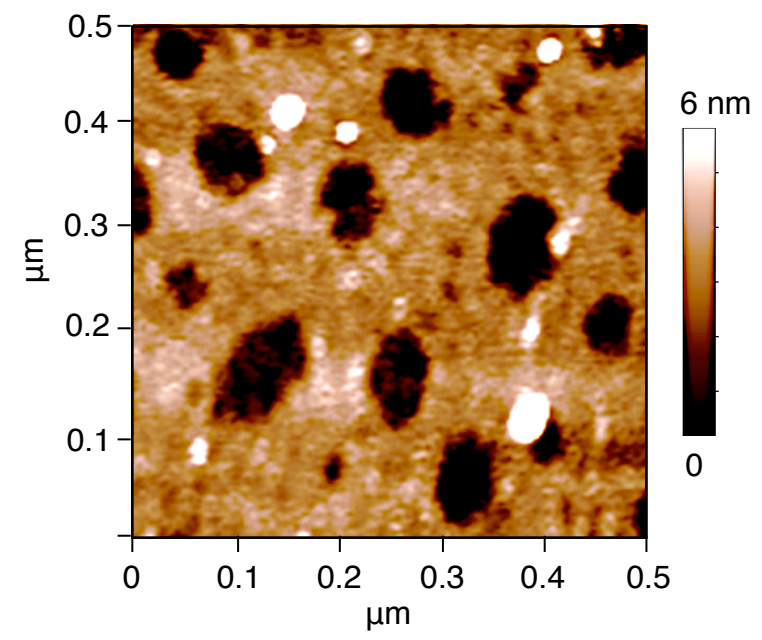

Figure S4. A high-resolution AFM image of nanosheets. The sample for AFM was fabricated by drop-casting a dilute $\mathrm{CHCl}_{3}$ solution of $\mathbf{P t}_{\mathbf{3}}(0.01 \mathrm{mM})$ on a silicon wafer by $\mathrm{CHCl}_{3}$ annealing for 1 hour, respectively. 

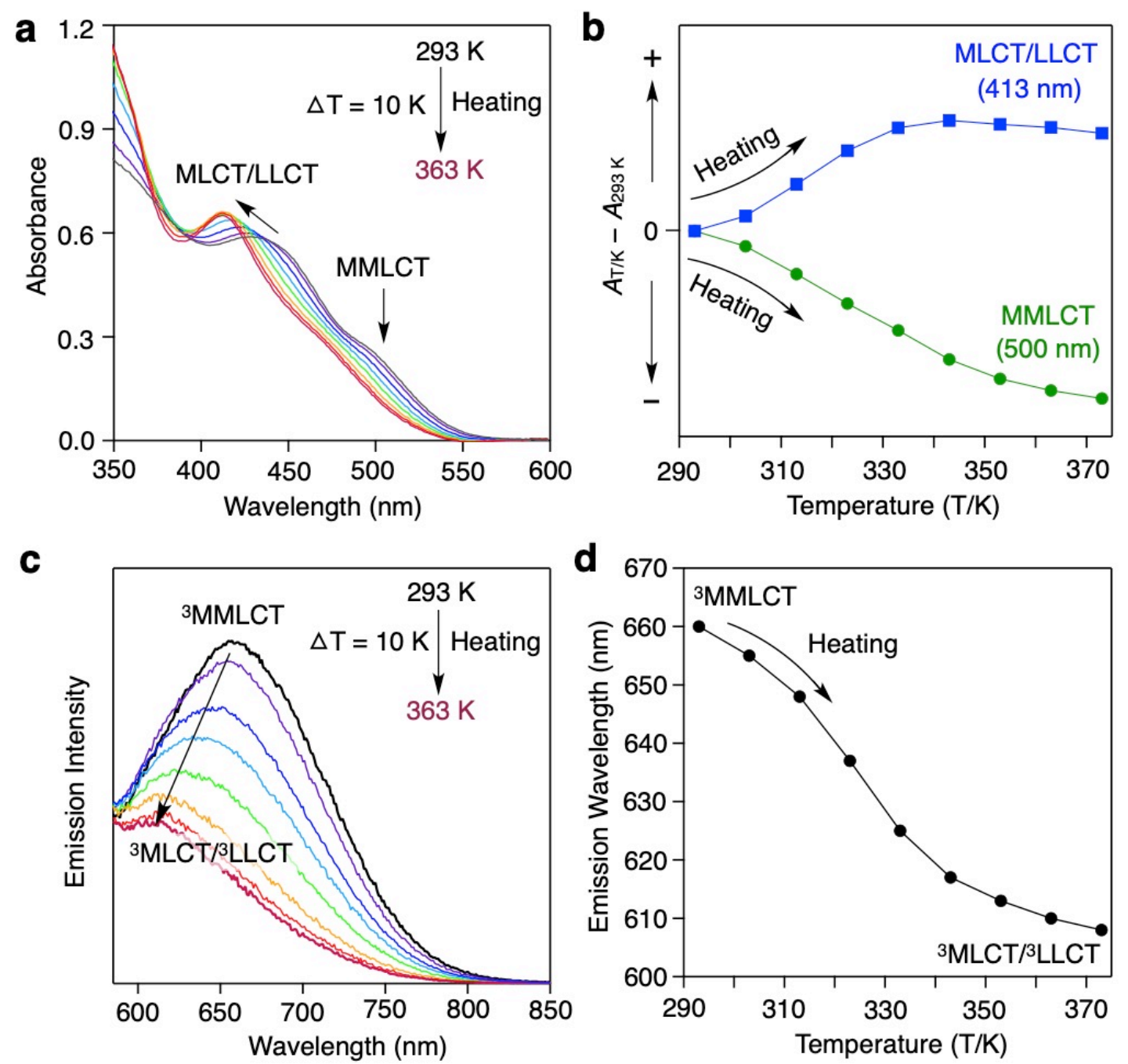

Figure S5. Depolymerization of $\mathbf{S P}_{\mathbf{P t 3}}$ in solution upon heating. (a, c) UV-vis absorption (a) and emission (c) spectral changes of $\mathbf{P t}_{\mathbf{3}}$ in 1,2-dichloroethane (DCE)/DMSO upon heating from $293 \mathrm{~K}$ to $363 \mathrm{~K}$ at $10 \mathrm{~K}$ intervals. The concentration of $\mathbf{P t}_{3}$ is $3.0 \mu \mathrm{M}$. (b) Plot of the absorbance difference at $413 \mathrm{~nm}$ (blue line) and 500 $\mathrm{nm}$ (green line) relative to $293 \mathrm{~K}$ upon heating. (d) Plot of the emission wavelength maxima upon heating. 

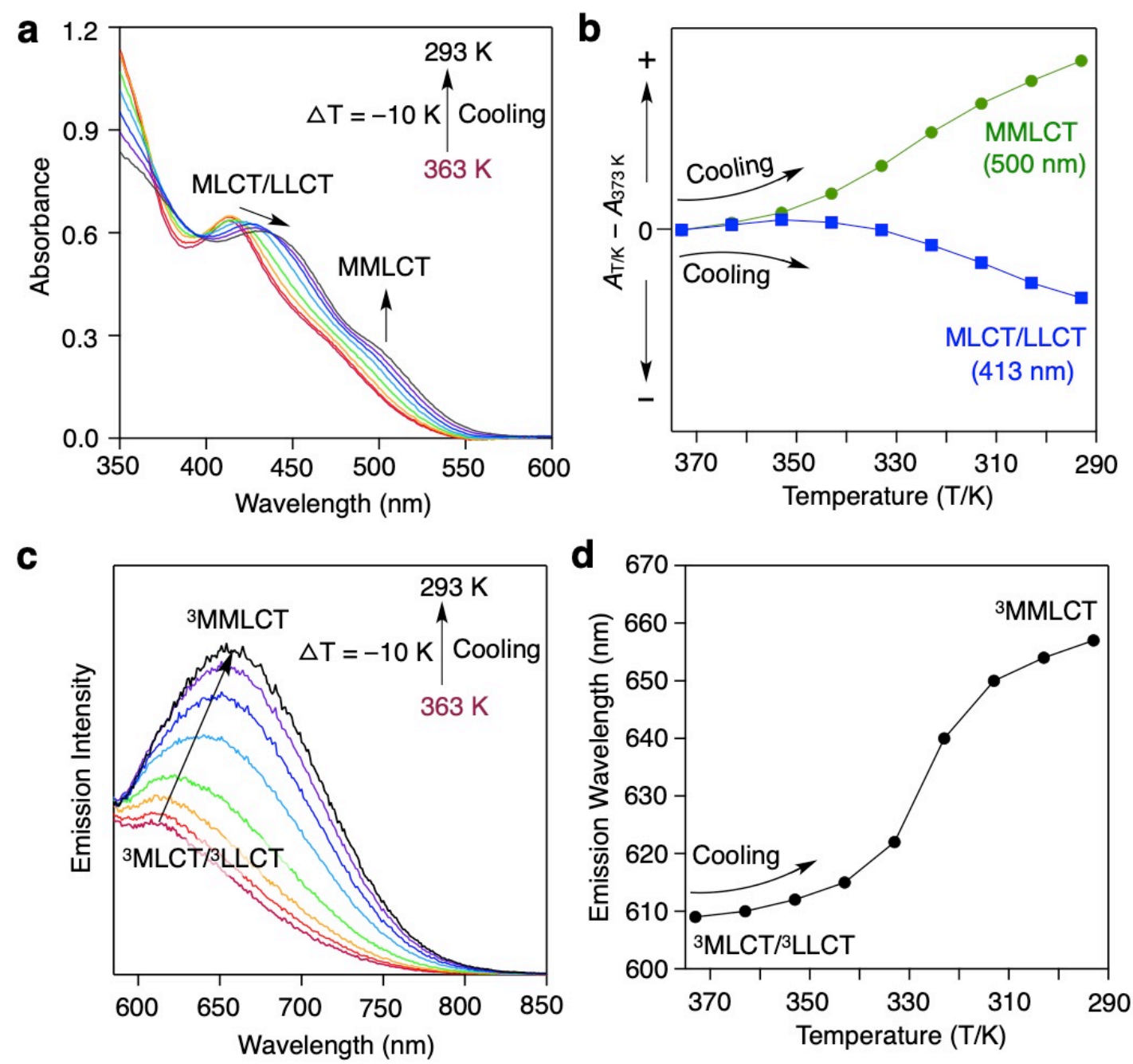

Figure S6. Repolymerization of $\mathrm{SP}_{\mathrm{Pt3}}$ in solution upon cooling. (a, c) UV-vis absorption (a) and emission (c) spectral changes of $\mathbf{P t}_{\mathbf{3}}$ in DCE/DMSO upon cooling from $363 \mathrm{~K}$ to $293 \mathrm{~K}$ at $10 \mathrm{~K}$ intervals. The concentration of $\mathbf{P t}_{\mathbf{3}}$ is $3.0 \mu \mathrm{M}$. (b) Plot of the absorbance difference at $413 \mathrm{~nm}$ (blue line) and $500 \mathrm{~nm}$ (green line) relative to $363 \mathrm{~K}$ upon cooling. (d) Plot of the emission wavelength maxima upon cooling. 


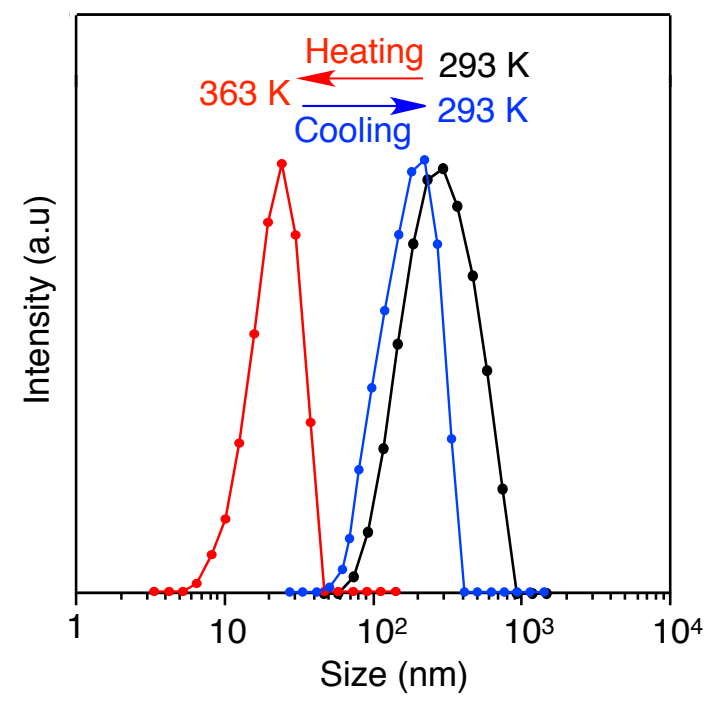

Figure S7. Temperature-dependent DLS traces of $\mathbf{S P}_{\mathrm{Pt3}_{3}}$ in solution. A dilute DCE/DMSO $(=1 / 1 \mathrm{v} / \mathrm{v})$ mixed solution of $\mathbf{P t}_{\mathbf{3}}$ was determined at $293 \mathrm{~K}$ (black line), $363 \mathrm{~K}$ (heating, red line) and $293 \mathrm{~K}$ (cooling back, blue line) respectively. The concentration of $\mathbf{P t}_{\mathbf{3}}$ is $0.1 \mathrm{mM}$. 


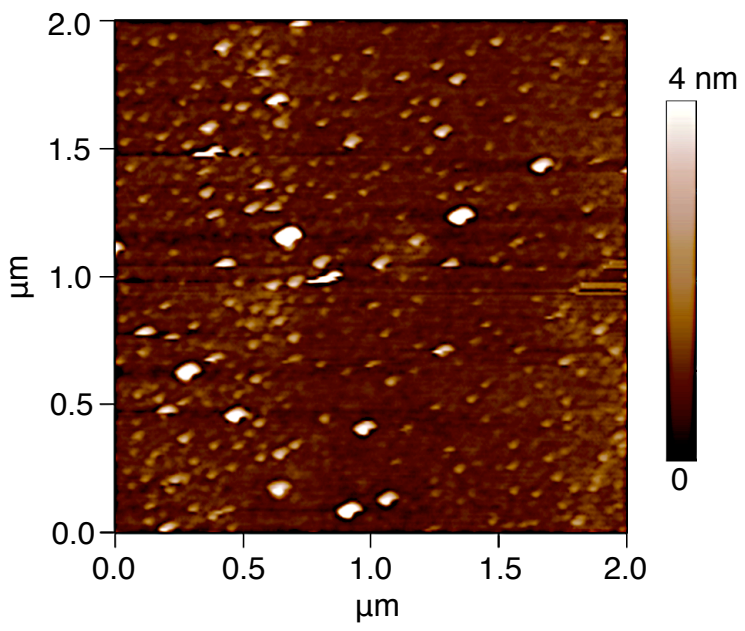

Figure S8. AFM image of $\mathrm{Pt}_{3}$ at $363 \mathrm{~K}$ on a silicon wafer. The sample was fabricated by drop-casting a dilute DCE/DMSO solution of $\mathbf{P t}_{\mathbf{3}}$ on a silicon wafer after air-drying at $363 \mathrm{~K}$. 


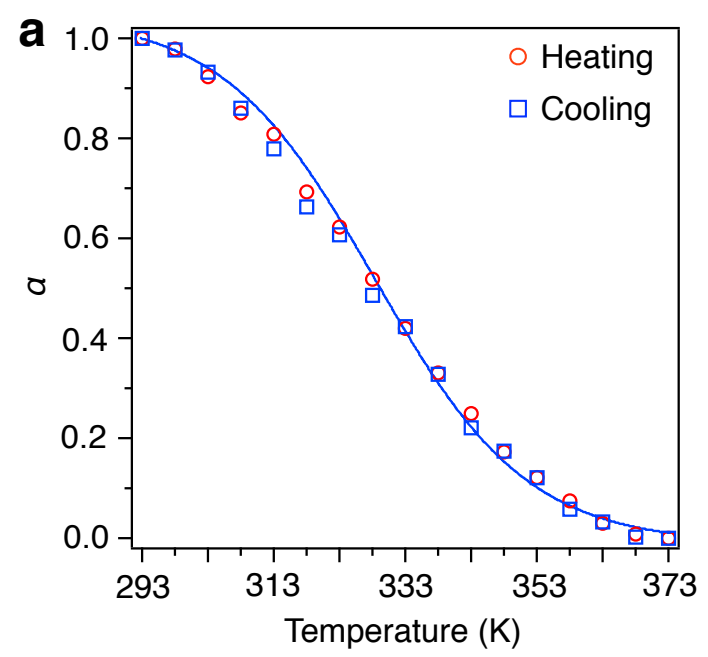

C Isodesmic Model

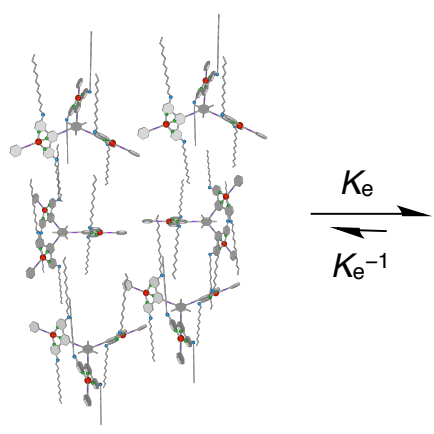

Monomers $\left(\mathrm{Pt}_{3}\right)$

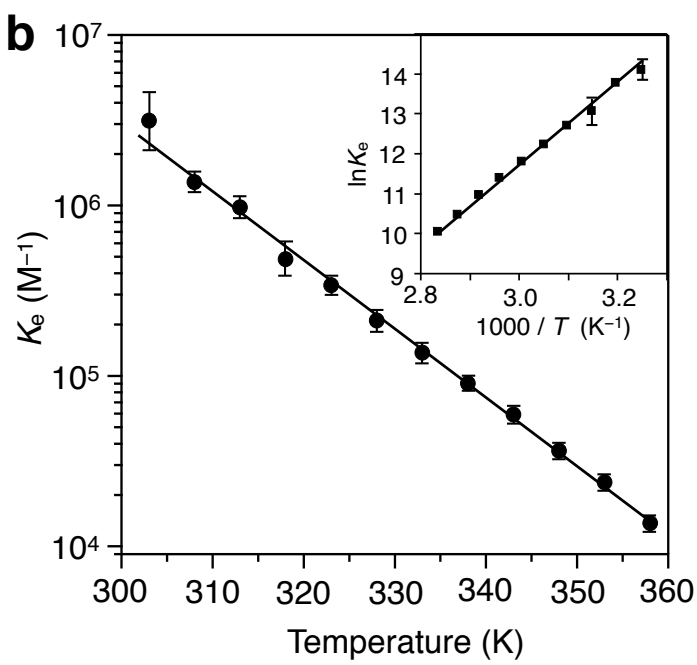

PtIl...PtII Dimers

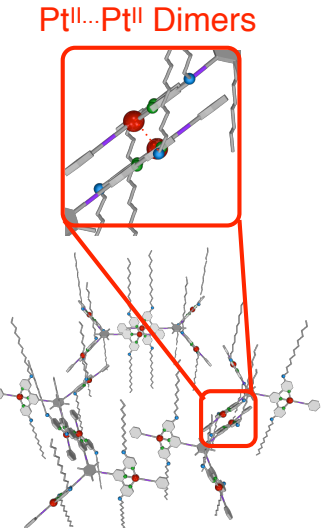

Dimeric links

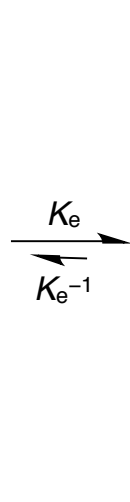

2D Supramolecular Polymer (SPPt3)

Figure S9. Invistigation on self-assembly mechanism of $\mathbf{S P}_{\mathbf{P t 3}}$. (a) Plot of temperature-dependent degree of aggregation $(\alpha)$ and the corresponding isodesmic fit of cooling process (blue, $\left.R^{2}=0.98\right)$. (b) Plot of elongation equilibrium constant $\left(K_{\mathrm{e}}\right)$ versus the temperature and Van't Hoff plot of $\mathbf{P t}_{\mathbf{3}}$ in solution (inset). (c) Schematic representation of the isodesmic model describing the self-assembly process of $2 \mathrm{D}$ SPPt3. 

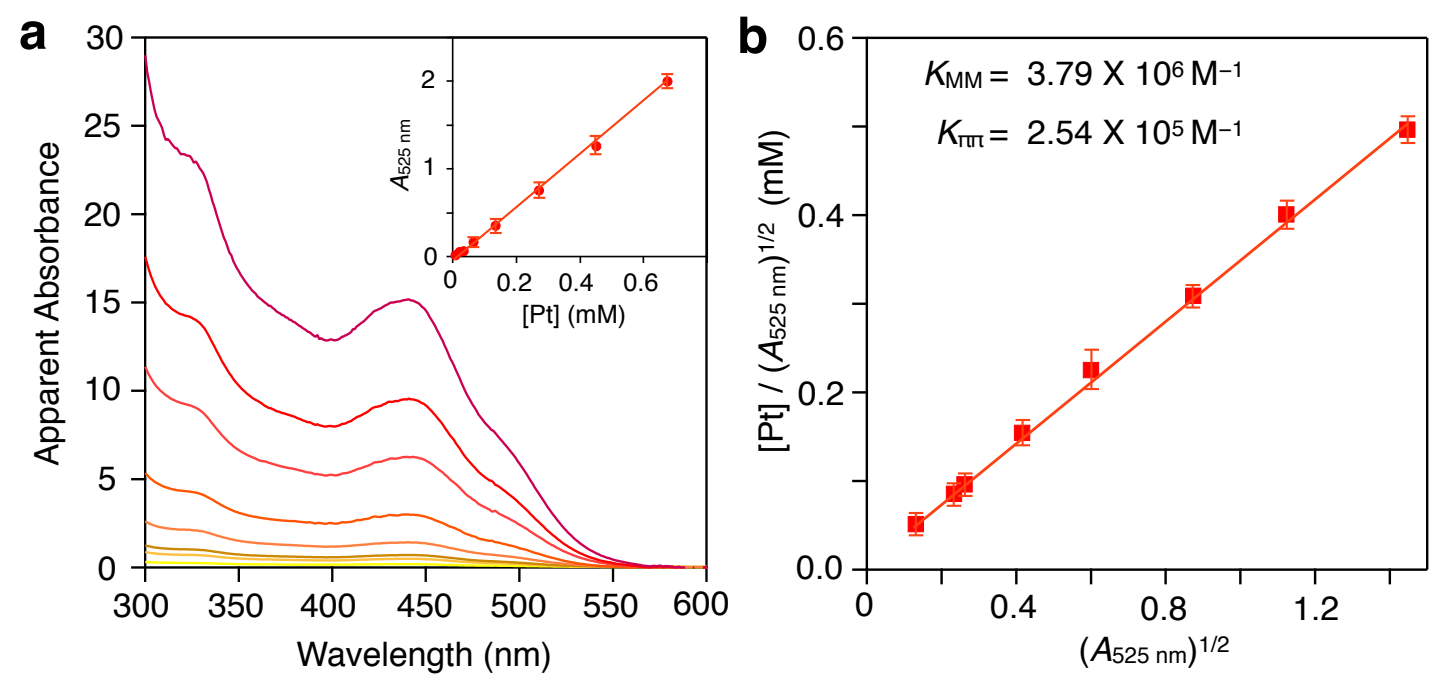

Figure S10. Evaluation on monomer-dimer equilibrium of $\mathbf{P t}_{3}$ in solution. (a) Concentration-dependent UV-vis absorption spectra of $\mathbf{P t}_{3}$ in $\mathrm{CHCl}_{3}$ with the concentration range of $2.24 \mu \mathrm{M}$ to $225 \mu \mathrm{M}$. The apparent absorbance values have been obtained by correcting to $1-\mathrm{cm}$ path length equivalence. Beer-Lambert plot (Inset) of absorbance monitored at $525 \mathrm{~nm}$ against concentration. (b) Dimerization plot $\left(R^{2}=0.99\right)$ of the monomer-dimer equilibrium for $\mathbf{P t}_{\mathbf{3}}$ in $\mathrm{CHCl}_{3}$ monitored at 525 nm. 

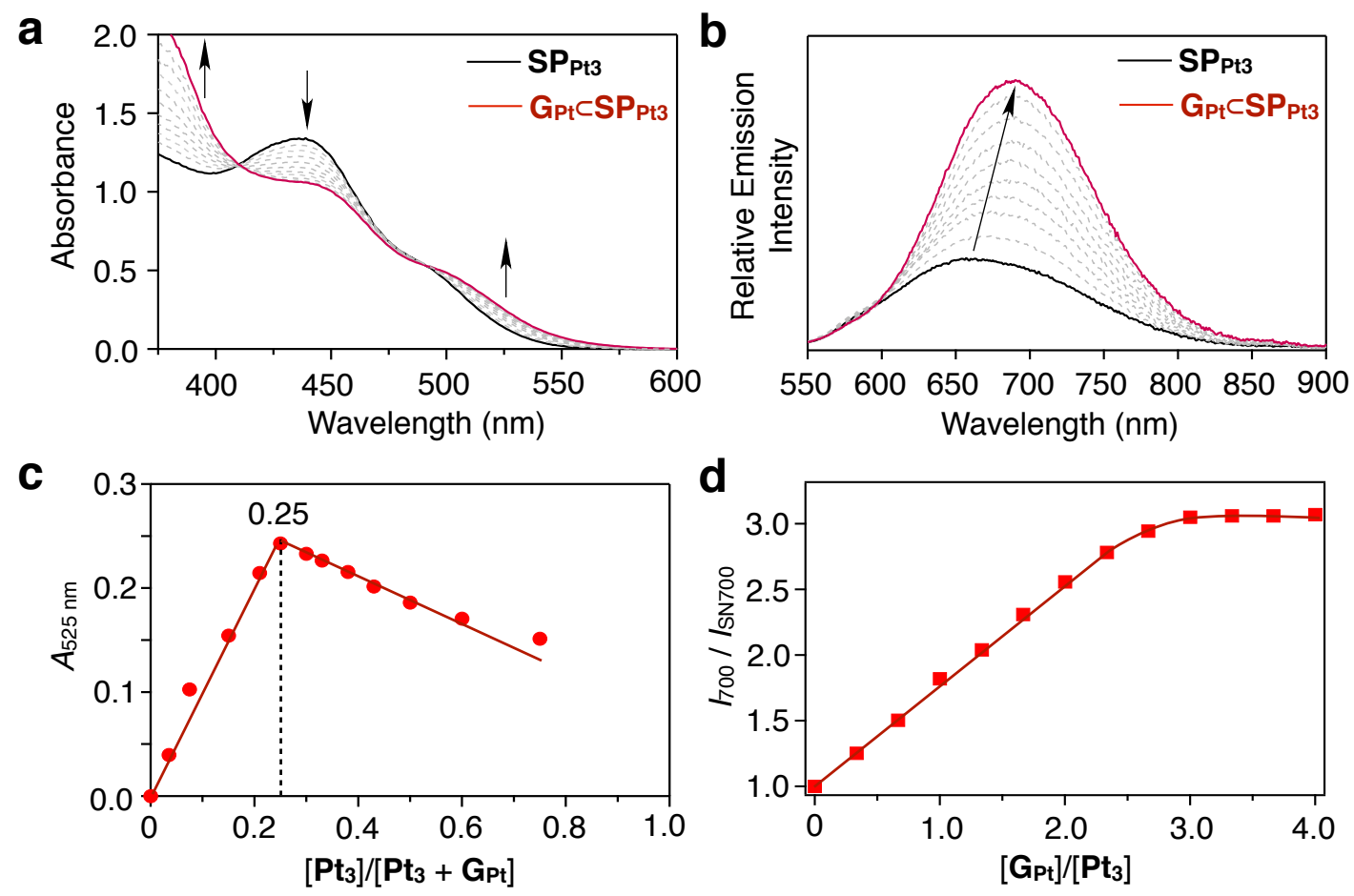

Figure S11. Evaluation on host-guest interactions of $\mathrm{SP}_{\mathrm{Pt} 3}$ and $\mathrm{G}_{\mathrm{Pt}}$ by spectroscopy. (a, b) UV-vis absorption (a) and emission (b) spectra of $\mathbf{S P}_{\mathbf{P t 3}}$ (black line) upon addition of $\mathbf{G}_{\mathbf{P t}}$ in $\mathrm{CHCl}_{3}$ until saturation (red line). The initial concentration of $\mathbf{P t}_{\mathbf{3}}$ is $11.0 \mu \mathrm{M}$. (c) Job's absorbance plot of the host-guest recorded at $525 \mathrm{~nm}$ and its theoretical fit (red line). (d) Plot of the relative emission intensity at $700 \mathrm{~nm}$ of $\mathbf{S P}_{\mathbf{P t} 3}$ upon addition of $\mathbf{G}_{\mathbf{P t}}$ against the mole ratio $\left[\mathbf{G}_{\mathbf{P t}}\right] /\left[\mathbf{P t}_{\mathbf{3}}\right]$. 

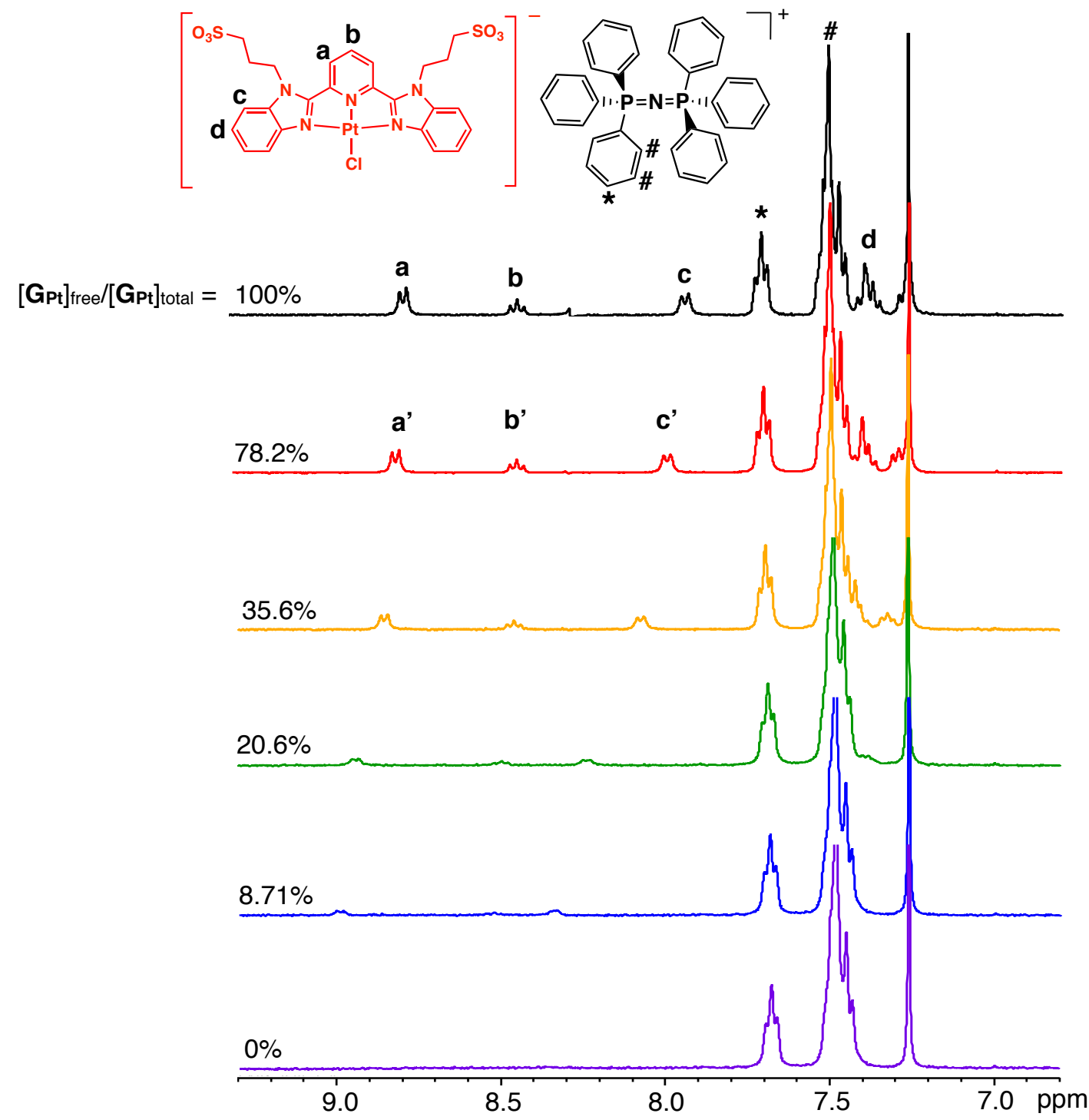

Figure S12. Evaluation on host-guest interactions of $S_{P} P_{P 33}$ and $G_{P t}$ by ${ }^{1} H$ NMR spectroscopy. Partial ${ }^{1} \mathrm{H}$ NMR spectra (9.3-6.8 ppm) upon addition of $\mathbf{P t}_{3}$ to $\mathbf{G}_{\mathbf{P t}}$ in $\mathrm{CDCl}_{3}$ at $298 \mathrm{~K}$ and the assignments of $\mathbf{G}_{\mathbf{P t}}$. To a $\mathrm{CDCl}_{3}$ solution of $\mathbf{G}_{\mathbf{P t}}(0.76 \mu \mathrm{mol})$ was gradually added $\mathbf{P t}_{3}$ of $0 \mu \mathrm{mol}$ (black line), $0.057 \mu \mathrm{mol}$ (red line), $0.15 \mu \mathrm{mol}$ (orange line), $0.19 \mu \mathrm{mol}$ (green line), $0.23 \mu \mathrm{mol}$ (blue line) and $0.26 \mu \mathrm{mol}$ (purple line). 

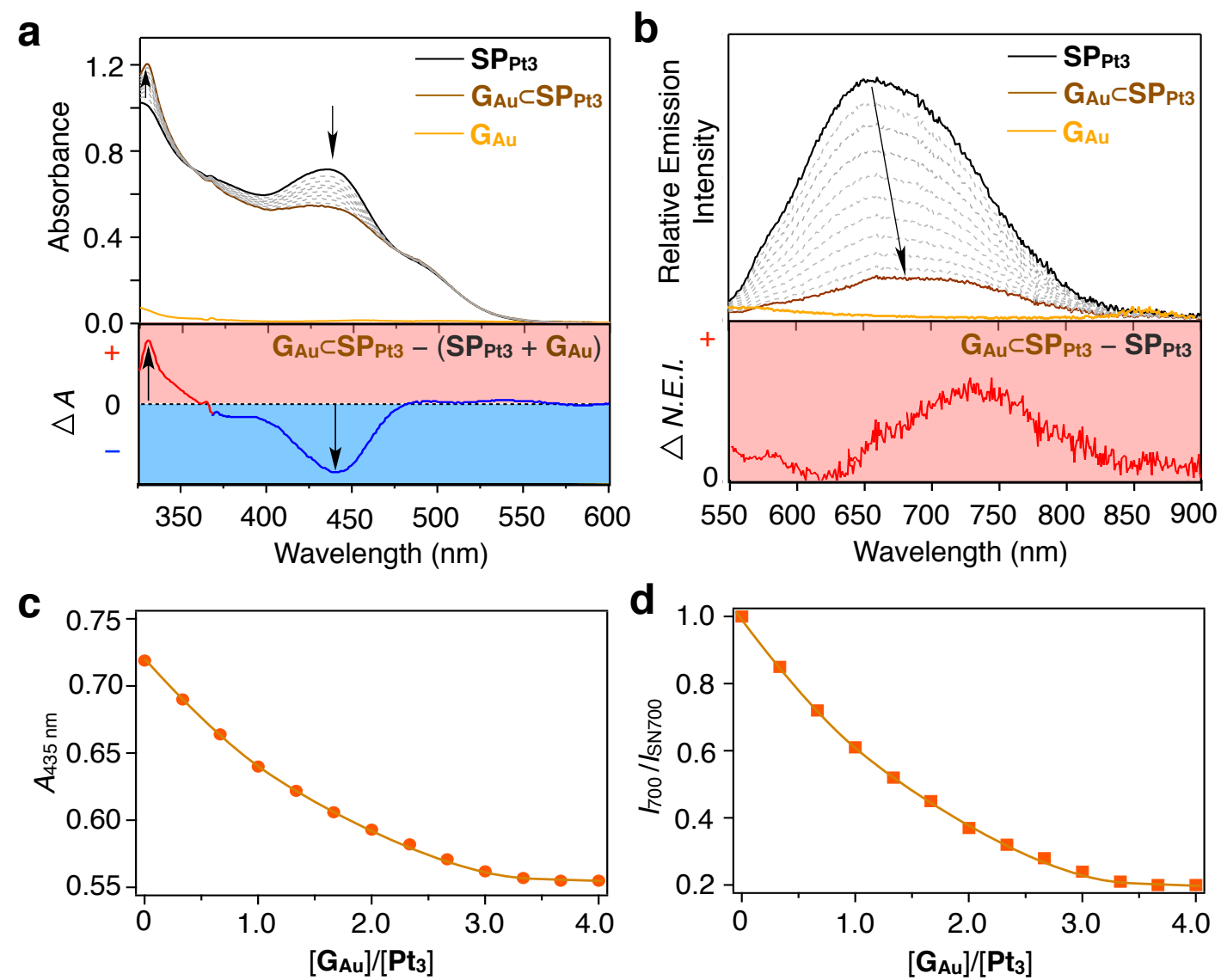

Figure S13. Evaluation on host-guest interactions of $\mathrm{SP}_{\mathrm{Pt3}}$ and $\mathbf{G}_{\mathrm{Au}}$ by spectroscopy. (a) UV-vis absorption with the absorbance difference $(\triangle A)$ spectra of $\mathbf{S P}_{\mathbf{P t 3}}$ (black line) upon addition of $\mathbf{G}_{\mathbf{A u}}$ (orange line) in $\mathrm{CHCl}_{3}$ until saturation (brown line). (b) Relative emission with the normalized emission intensity difference ( $\triangle$ N.E.I.) spectra of $\mathbf{S P}_{\mathbf{P t 3}}$ (black line) upon addition of $\mathbf{G}_{\mathbf{A u}}$ (orange line) in $\mathrm{CHCl}_{3}$ until saturation (brown line). The initial concentration of $\mathbf{P t}_{\mathbf{3}}$ is $5.0 \mu \mathrm{M}$. (c, d) Plot of the absorbance at $435 \mathrm{~nm}$ (c) and relative emission intensity at $700 \mathrm{~nm}$ (d) of $\mathbf{S P}_{\mathbf{P t 3}}$ upon addition of $\mathbf{G}_{\mathbf{A u}}$ against the mole ratio $\left[\mathbf{G}_{\mathbf{A u}}\right] /\left[\mathbf{P t}_{\mathbf{3}}\right]$. 

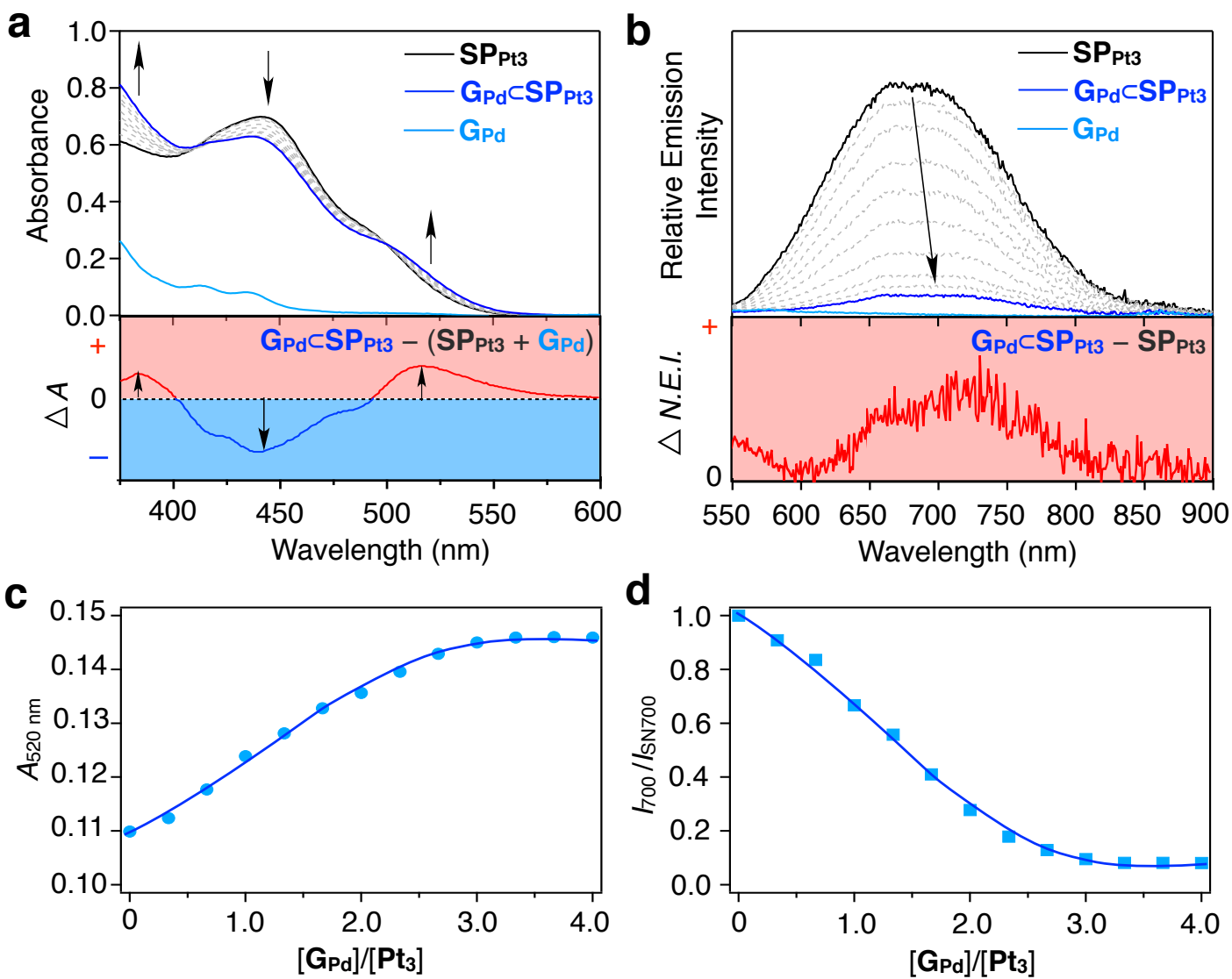

Figure S14. Evaluation on host-guest interactions of $\mathrm{SP}_{\mathrm{Pt3}}$ and $\mathbf{G}_{\mathrm{Pd}}$ by spectroscopy. (a) UV-vis absorption with the absorbance difference $(\triangle A)$ spectra of $\mathbf{S P}_{\mathbf{P t} 3}$ (black line) upon addition of $\mathbf{G}_{\mathbf{P d}}$ (sky blue line) in $\mathrm{CHCl}_{3}$ until saturation (dark blue line). (b) Relative emission with the normalized emission intensity difference ( $\triangle$ N.E.I.) spectra of $\mathbf{S} \mathbf{P}_{\mathbf{P t 3}}$ (black line) upon addition of $\mathbf{G}_{\mathbf{P d}}$ (sky blue line) in $\mathrm{CHCl}_{3}$ until saturation (dark blue line). The initial concentration of $\mathbf{P t}_{3}$ is $5.0 \mu \mathrm{M}$. (c, d) Plot of the absorbance at $520 \mathrm{~nm}$ (c) and relative emission intensity at $700 \mathrm{~nm}$ (d) of $\mathbf{S P}_{\mathbf{P t} 3}$ upon addition of $\mathbf{G}_{\mathbf{P d}}$ against the mole ratio $\left[\mathbf{G}_{\mathbf{P d}}\right] /\left[\mathbf{P} \mathbf{t}_{\mathbf{3}}\right]$. 

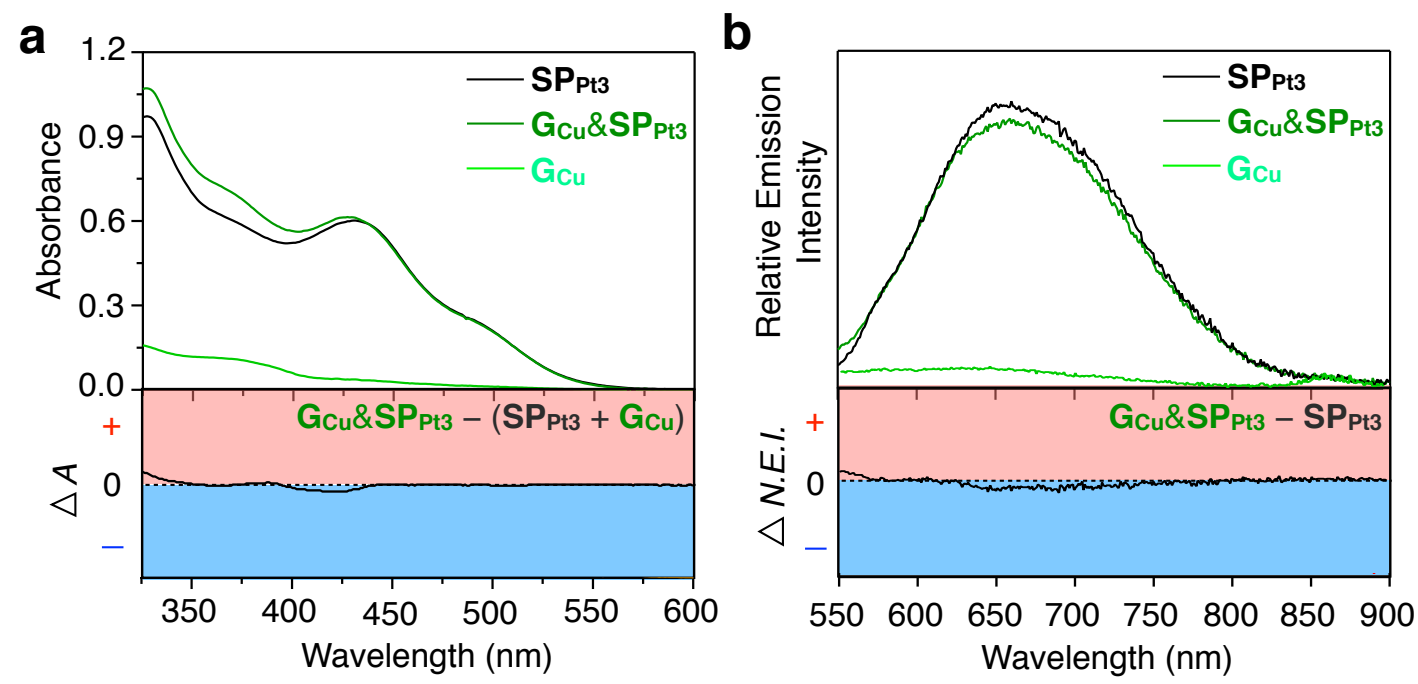

Figure S15. Evaluation on host-guest interactions of $\mathrm{SP}_{\mathrm{Pt3}}$ and $\mathbf{G}_{\mathrm{Cu}}$ by spectroscopy. (a) UV-vis absorption with the absorbance difference ( $\triangle A$ ) spectra of $\mathbf{S} \mathbf{P}_{\mathbf{P t 3}}$ (black line) upon addition of $\mathbf{G}_{\mathbf{C u}}$ (light green line) in $\mathrm{CHCl}_{3}$ until saturation (green line). (b) Relative emission with the normalized emission intensity difference ( $\triangle$ N.E.I.) spectra of $\mathbf{S P}_{\mathbf{P t 3}}$ (black line) upon addition of $\mathbf{G}_{\mathbf{C u}}$ (light green line) in $\mathrm{CHCl}_{3}$ until saturation (green line). The initial concentration of $\mathbf{P t}_{3}$ is $3.0 \mu \mathrm{M}$. 
a
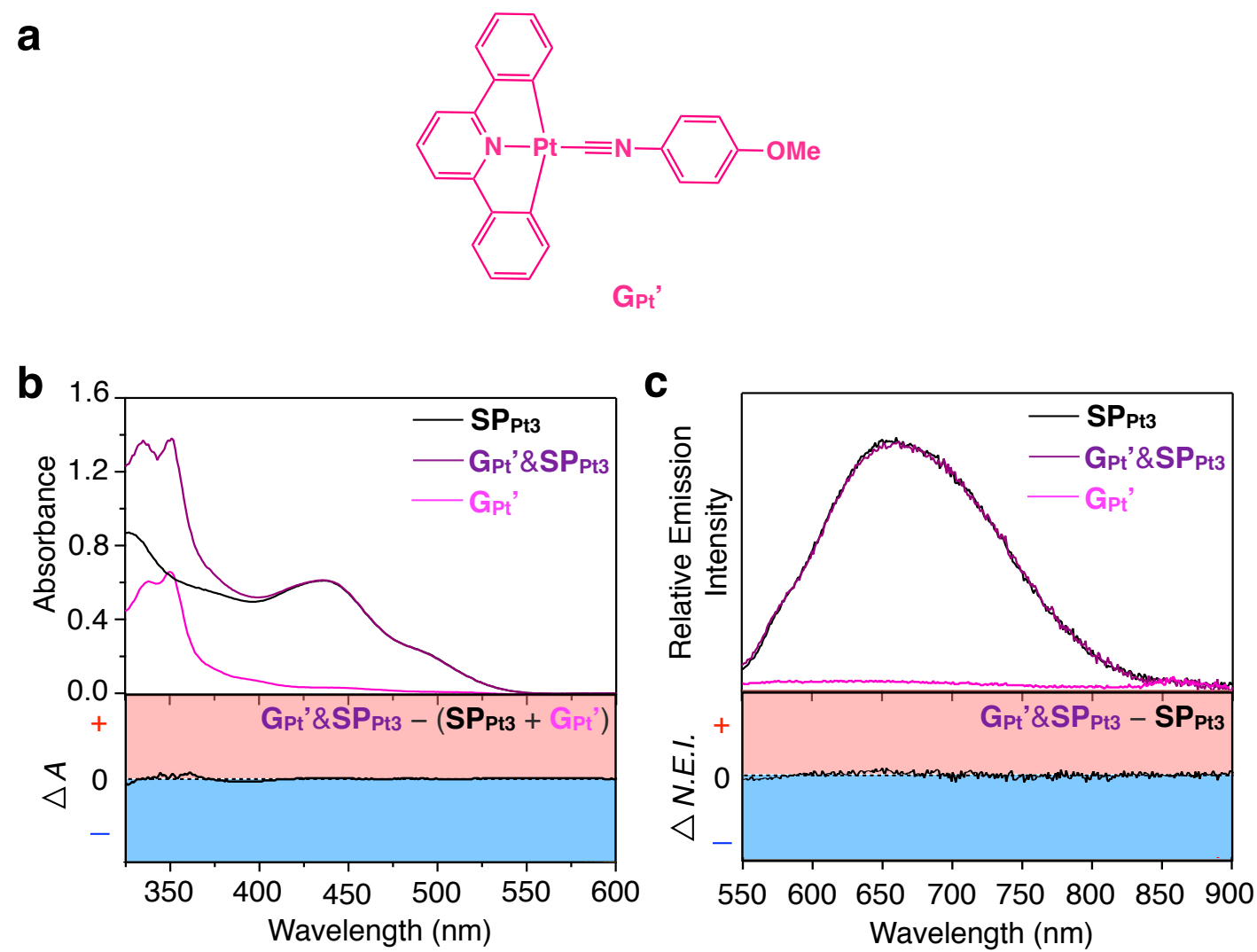

Figure S16. Evaluation on host-guest interactions of $\mathrm{SP}_{\mathrm{Pt3}}$ and $\mathrm{G}_{\mathrm{Pt}}$ 'by spectroscopy. (a) Molecular structure of neural $\mathrm{Pt}^{\mathrm{II}}$ complex $\mathbf{G P t}_{\mathbf{P t}}$. (b) UV-vis absorption with the absorbance difference $(\triangle A)$ spectra of $\mathbf{S P}_{\mathbf{P t 3}}$ (black line) upon addition of $\mathbf{G}_{\mathbf{P t}}$ ' (light purple line) in $\mathrm{CHCl}_{3}$ until saturation (purple line). (c) Relative emission with the normalized emission intensity difference $\left(\triangle N\right.$.E.I.) spectra of $\mathbf{S P}_{\mathbf{P t 3}}$ (black line) upon addition of $\mathbf{G}_{\mathbf{P t}}$ ' (light purple line) in $\mathrm{CHCl}_{3}$ until saturation (purple line). The initial concentration of $\mathbf{P t}_{\mathbf{3}}$ is $5.0 \mu \mathrm{M}$. 

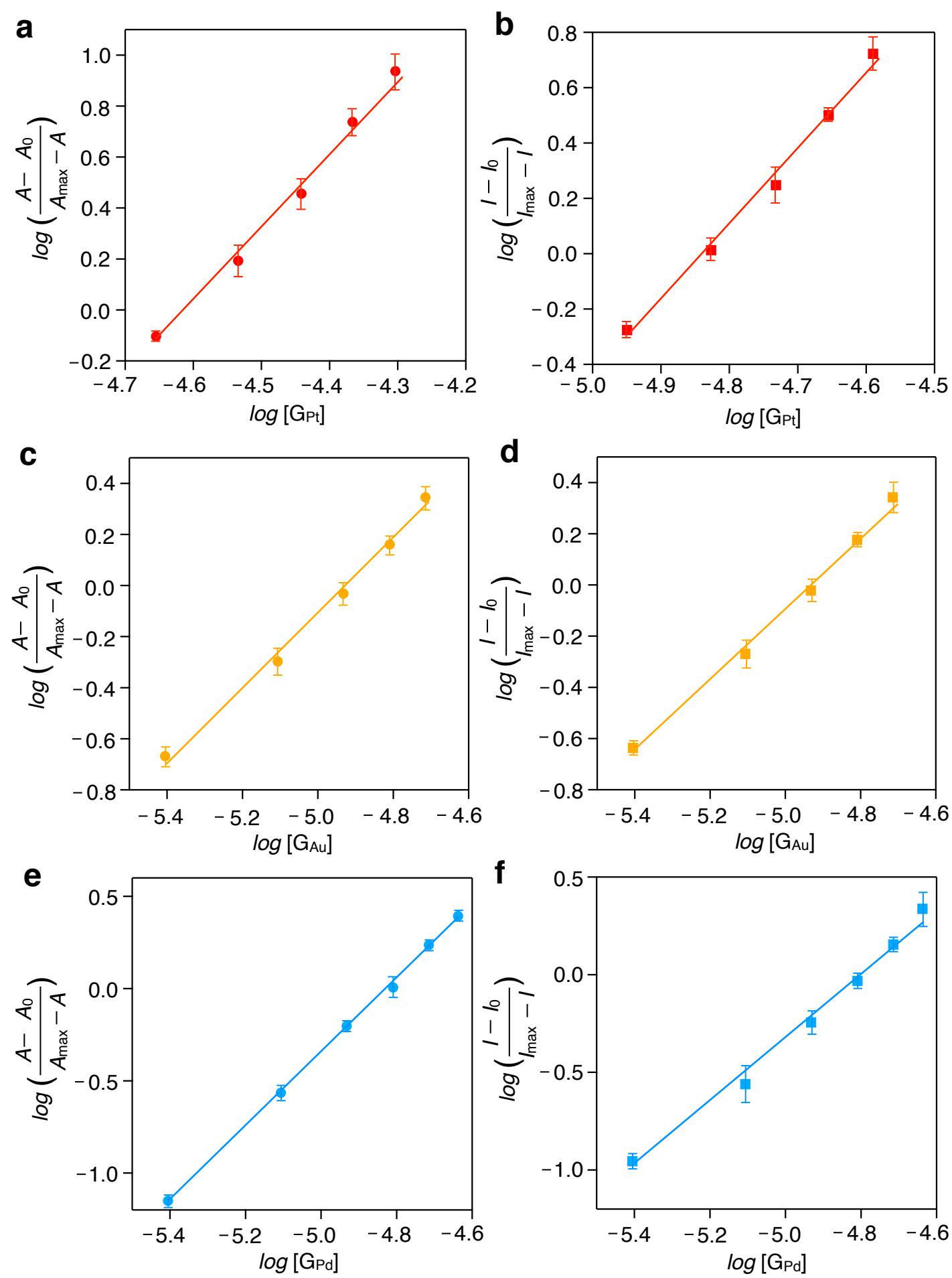

Figure S17. Hill plots $\left(R^{2}>0.98\right)$ of $\operatorname{SP}_{P t 3}$ binding with $G_{P t}(a, b), G_{A u}(c, d)$, and $G_{P d}(e, f)$ obtained by the analysis of $U V$-vis $(a, c, e)$ and emission $(b, d, f)$ spectroscopy. 


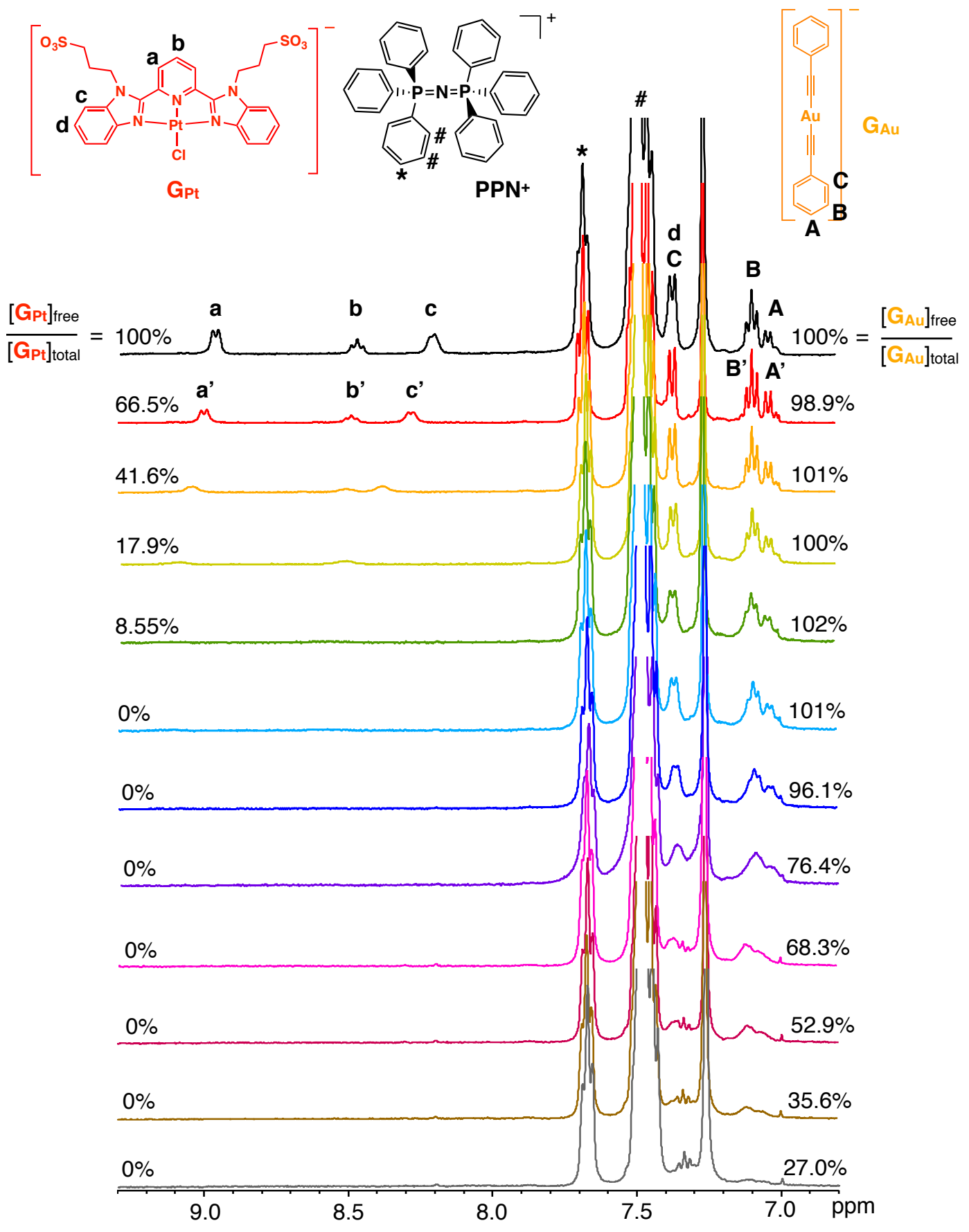

Figure S18. Evaluation on competition of $\mathrm{Pt}^{\mathrm{II}} \cdot \mathrm{Pt}^{\mathrm{II}}$ and $\mathrm{Pt}^{\mathrm{II}} \cdot \cdots \mathrm{Au}^{\mathrm{I}}$ interactions by ${ }^{\mathbf{1}} \mathbf{H}$ NMR spectroscopy. Partial ${ }^{1} \mathrm{H}$ NMR spectra (9.3-6.8 ppm) upon addition of $\mathbf{P t}_{\mathbf{3}}$ to an admixture of $\mathbf{G}_{\mathbf{P t}}$ and $\mathbf{G}_{\mathbf{A u}}$ in $\mathrm{CDCl}_{3}$ at $298 \mathrm{~K}$ and the assignments of $\mathbf{G}_{\mathbf{P t}}$ and $\mathbf{G}_{\mathbf{A u}}$. To a $\mathrm{CDCl}_{3}$ solution of $\mathbf{G}_{\mathbf{P t}}(0.76 \mu \mathrm{mol})$ and $\mathbf{G}_{\mathbf{P t}}(1.00 \mu \mathrm{mol})$ was gradually added $\mathbf{P t}_{\mathbf{3}}$ with an equivalent amount of $0.05 \mu \mathrm{mol}$. 


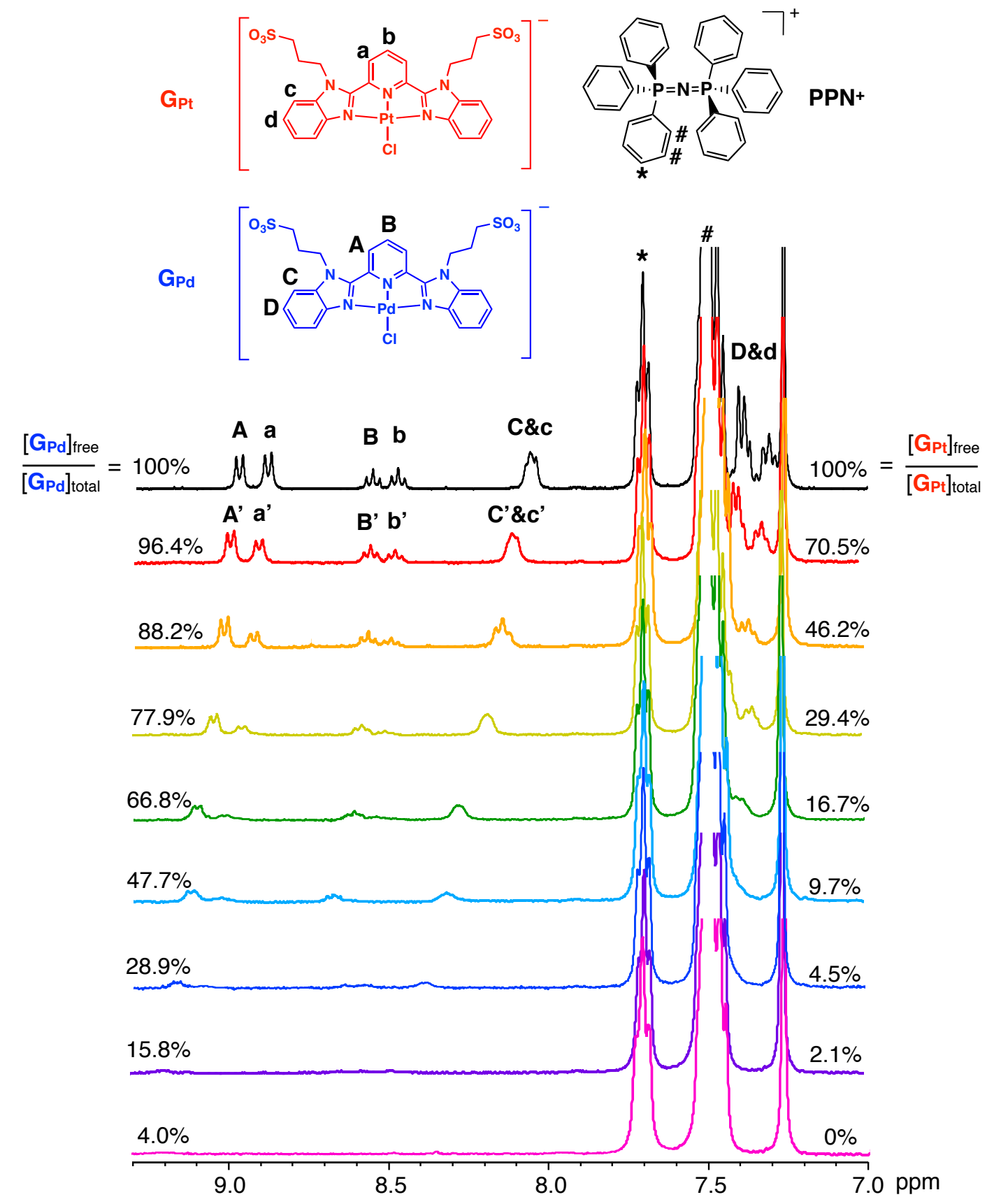

Figure S19. Evaluation on competition of $\mathrm{Pt}^{\mathrm{II}} \cdots \mathrm{Pt}^{\mathrm{II}}$ and $\mathrm{Pt}^{\mathrm{II}} \cdots \mathrm{Pd}^{\mathrm{II}}$ interactions by ${ }^{1} \mathbf{H}$ NMR spectroscopy. Partial ${ }^{1} \mathrm{H}$ NMR spectra (9.3-7.0 ppm) upon addition of $\mathbf{P t}_{\mathbf{3}}$ to an admixture of $\mathbf{G}_{\mathbf{P t}}$ and $\mathbf{G}_{\mathbf{P d}}$ in $\mathrm{CDCl}_{3}$ at $298 \mathrm{~K}$ and the assignments of $\mathbf{G}_{\mathbf{P t}}$ and $\mathbf{G}_{\mathbf{P d}}$. To a $\mathrm{CDCl}_{3}$ solution of $\mathbf{G}_{\mathbf{P t}}(0.76 \mu \mathrm{mol})$ and $\mathbf{G}_{\mathbf{P d}}(0.70 \mu \mathrm{mol})$ was gradually added $\mathbf{P t}_{3}$ with an equivalent amount of $0.05 \mu \mathrm{mol}$. 

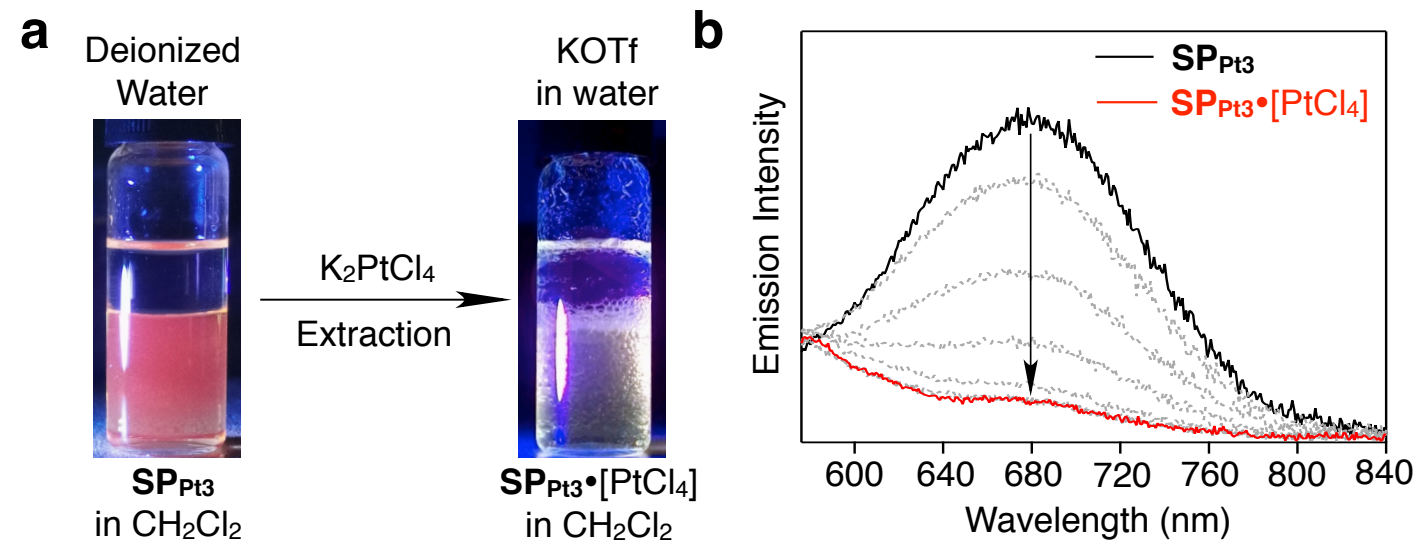

Figure S20. Evaluation on extraction of $\mathbf{K}_{2}\left[\mathbf{P t C l}_{4}\right]$ using $\mathbf{S P} \mathbf{P t 3}$. (a) To a $\mathrm{CH}_{2} \mathrm{Cl}_{2}$ solution of $\mathbf{P t}_{\mathbf{3}}$ (30 nmol) were added dropwise deionized water $(1 \mathrm{~mL})$, and a certain amount $(60 \mathrm{nmol})$ of $\mathrm{K}_{2}\left[\mathrm{PtCl}_{4}\right]$. After vigorous shaking (see Video S1), the photos were taken under the irradiation of blue light with $400 \mathrm{~nm}$. (b) Emission spectra of $\mathbf{S} \mathbf{P}_{\mathbf{P t 3}}$ in $\mathrm{CH}_{2} \mathrm{Cl}_{2}$ before (black line) and after ion exchange with $\mathrm{K}_{2}\left[\mathrm{PtCl}_{4}\right]$ by extraction with various amounts (dash lines) until saturation (red line). 

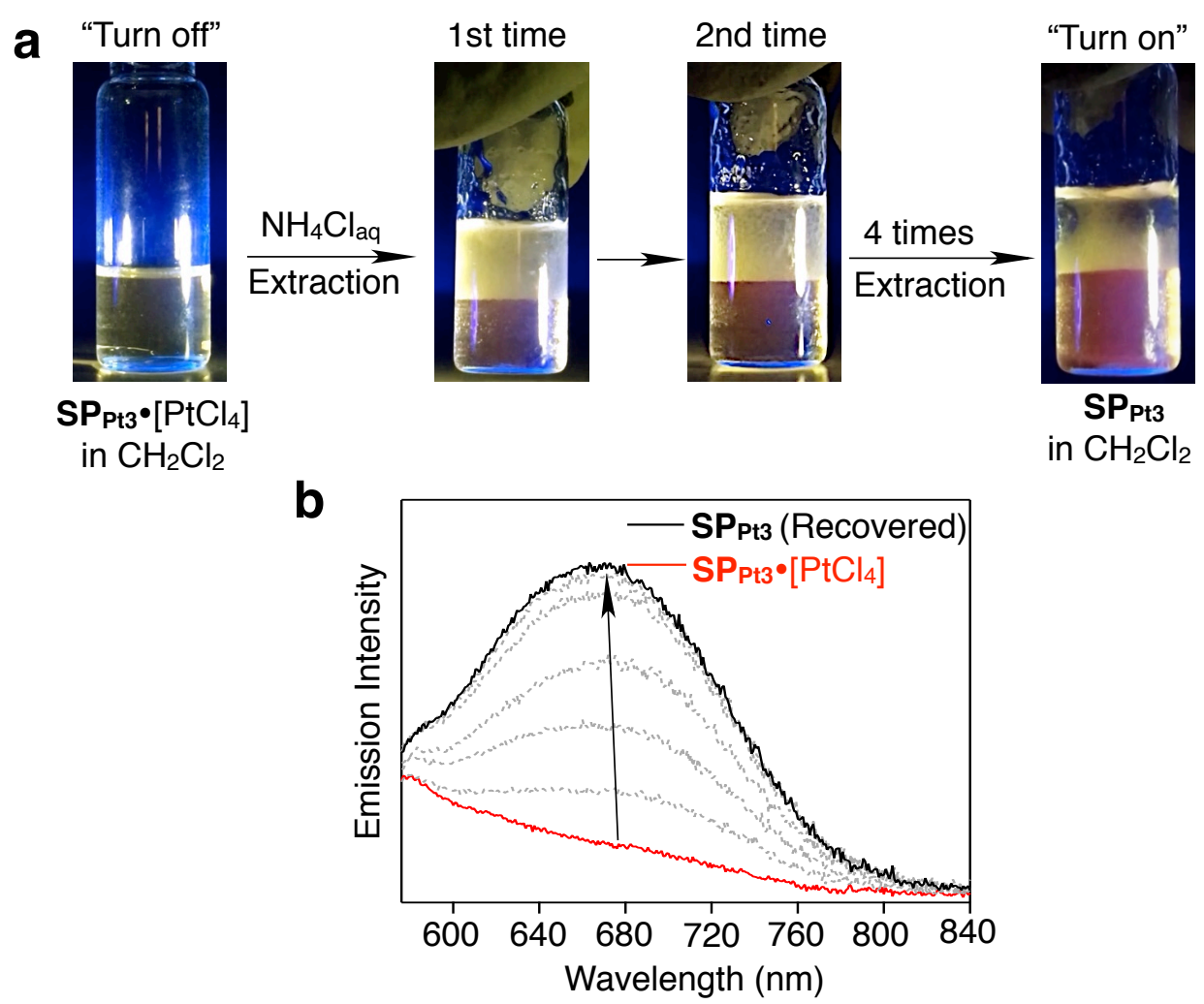

Figure S21. Evaluation on emission recovery of organic phase by inverted extractions with aqueous $\mathbf{N H}_{4} \mathbf{C l}$ solution. (a) $\mathrm{To} \mathrm{a} \mathrm{CH}_{2} \mathrm{Cl}_{2}$ solution of $\mathbf{S P}_{\mathrm{Pt3}_{3}} \cdot\left[\mathrm{PtCl}_{4}\right]$ was added dropwise saturated aqueous $\mathrm{NH}_{4} \mathrm{Cl}$ solution $(1 \mathrm{~mL})$. After vigorous shaking, the photos were taken under the irradiation of UV light with $365 \mathrm{~nm}$ after extracting for several times. (b) Emission spectra of organic phase before (red line) and after extraction by saturated aqueous $\mathrm{NH}_{4} \mathrm{Cl}$ solution $(1 \mathrm{~mL}$, dash lines) for several times until saturation (black line). 
a

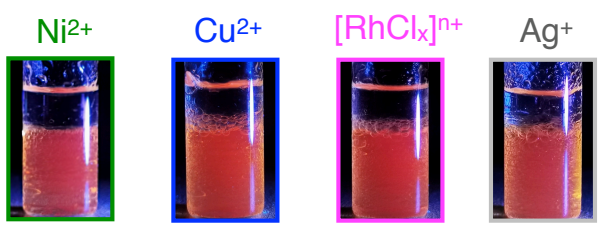

(Cations)

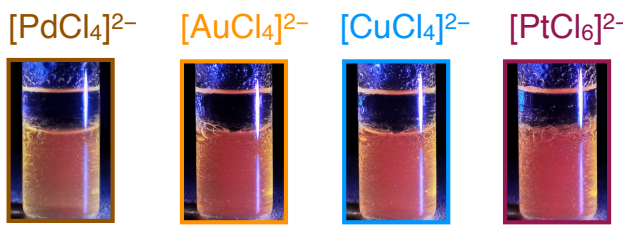

(Anions)

C

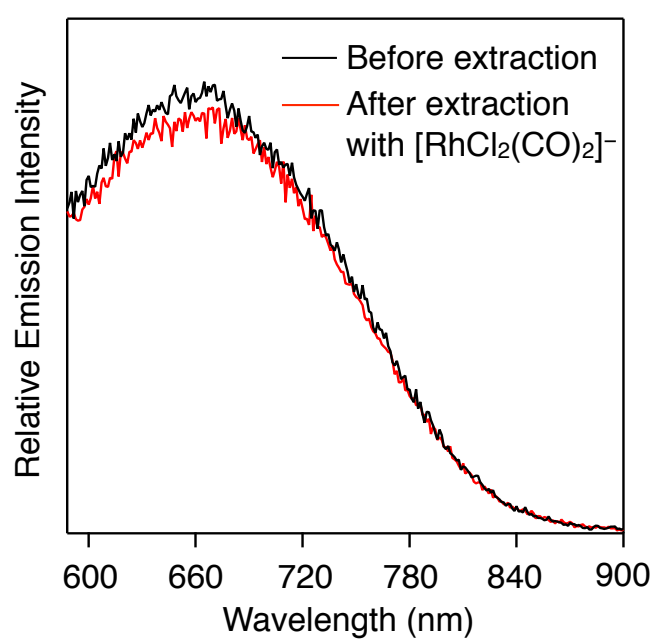

b

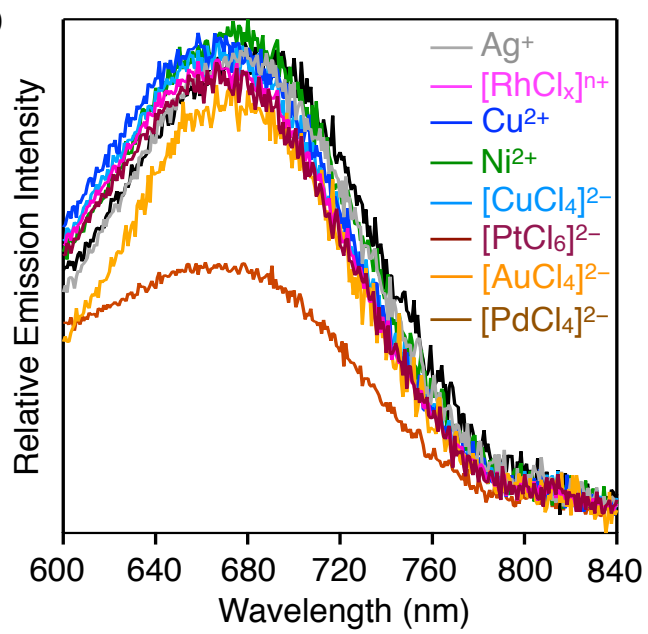

d

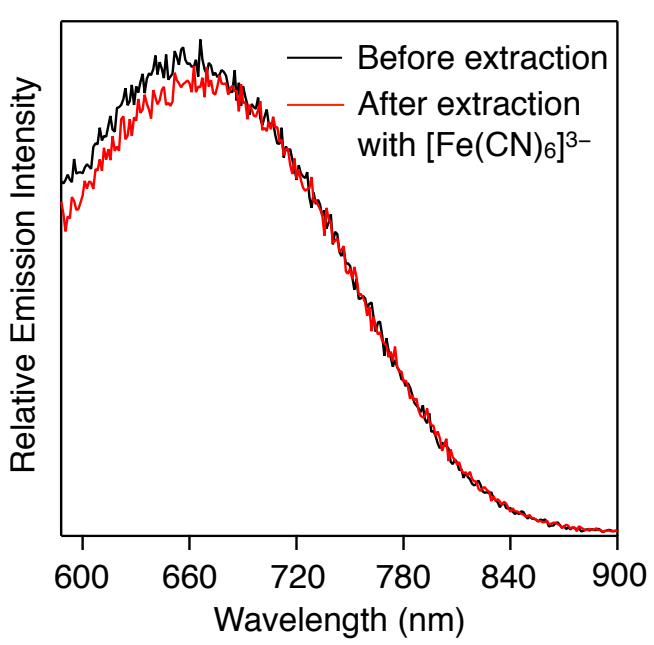

Figure S22. Comparison on extraction of various metal ions using $\mathbf{S P}_{\mathbf{P t 3}}$. (a) To a $\mathrm{CH}_{2} \mathrm{Cl}_{2}$ solution of $\mathbf{P t}_{3}(30 \mathrm{nmol})$ were added dropwise deionized water $(1 \mathrm{~mL})$, and a certain amount $(60 \mathrm{nmol})$ of metal ions, including $\mathrm{Ni}^{2+}, \mathrm{Cu}^{2+},\left[\mathrm{RhCl}_{\mathrm{x}}\right]^{\mathrm{n}+}, \mathrm{Ag}^{+}$, $\left[\mathrm{PdCl}_{4}\right]^{2-},\left[\mathrm{AuCl}_{4}\right]^{-},\left[\mathrm{CuCl}_{4}\right]^{2-}$, and $\left[\mathrm{PtCl}_{6}\right]^{2-}$, respectively. After vigorous shaking, the photos were taken under the irradiation of UV light with $365 \mathrm{~nm}$. (b) Emission spectra of $\mathbf{S P}_{\mathbf{P t 3}}$ before (black line) and after extraction with an aqueous solution of $\mathrm{Ni}^{2+}$ (green line), $\mathrm{Cu}^{2+}$ (blue line), $\left[\mathrm{RhCl}_{\mathrm{x}}\right]^{\mathrm{n}+}$ (purple line), $\mathrm{Ag}^{+}$(gray line), $\left[\mathrm{CuCl}_{4}\right]^{2-}$ (sky-blue line), $\left[\mathrm{PtCl}_{6}\right]^{2-}$ (dark-red line), $\left[\mathrm{AuCl}_{4}\right]^{-}$(gold-color line) and $\left[\mathrm{PdCl}_{4}\right]^{2-}$ (brown line). (c, d) Emission spectra of $\mathbf{S P}_{\mathbf{P t 3}}(30 \mathrm{nmol})$ before (black lines) and after (red lines) extraction with a stoichiometric equivalent of $\left[\mathrm{RhCl}_{2}(\mathrm{CO})_{2}\right]^{-}(\mathrm{c}, 60 \mathrm{nmol})$ and $\left[\mathrm{Fe}(\mathrm{CN})_{6}\right]^{3-}(\mathrm{d}, 60 \mathrm{nmol})$ in their aqueous solutions, respectively. 
a

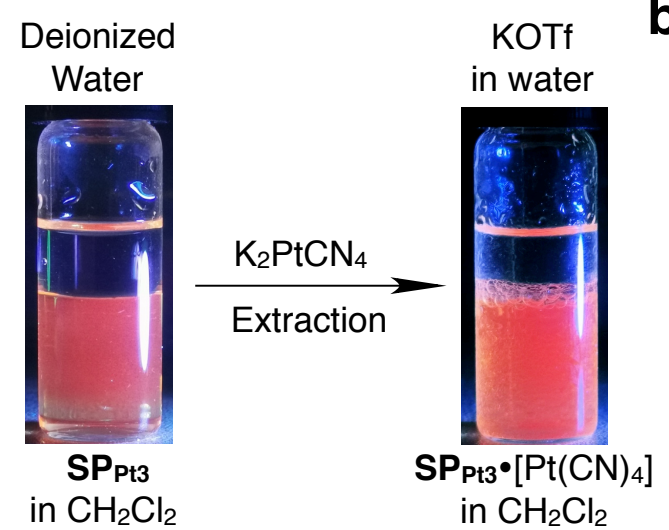

b

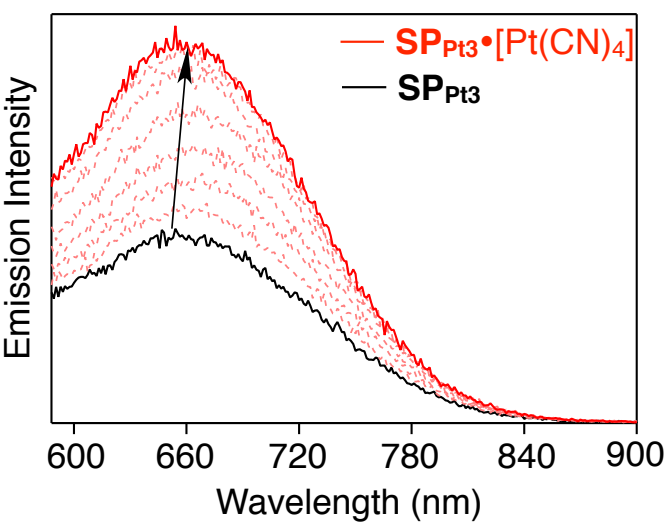

Figure S23. Evaluation on extraction of $\mathbf{K}_{2}\left[\mathbf{P t}(\mathbf{C N})_{4}\right]$ using $\mathbf{S P}_{\mathbf{P t 3}}$. (a) To a $\mathrm{CH}_{2} \mathrm{Cl}_{2}$ solution of $\mathbf{P t}_{\mathbf{3}}$ (30 $\left.\mathrm{nmol}\right)$ was added dropwise deionized water $(1 \mathrm{~mL})$, and a certain amount (60 nmol) of $\mathrm{K}_{2}\left[\mathrm{Pt}(\mathrm{CN})_{4}\right]$. After vigorous shaking (see Video S2), the photos were taken under the irradiation of UV light with $365 \mathrm{~nm}$. (b) Emission spectra of $\mathbf{S P} \mathbf{P}_{\mathbf{P t 3}}$ in $\mathrm{CH}_{2} \mathrm{Cl}_{2}$ before (black line) and after ion exchange with $\mathrm{K}_{2}\left[\mathrm{Pt}(\mathrm{CN})_{4}\right]$ by extraction with various amounts (dash lines) until saturation (red line). 

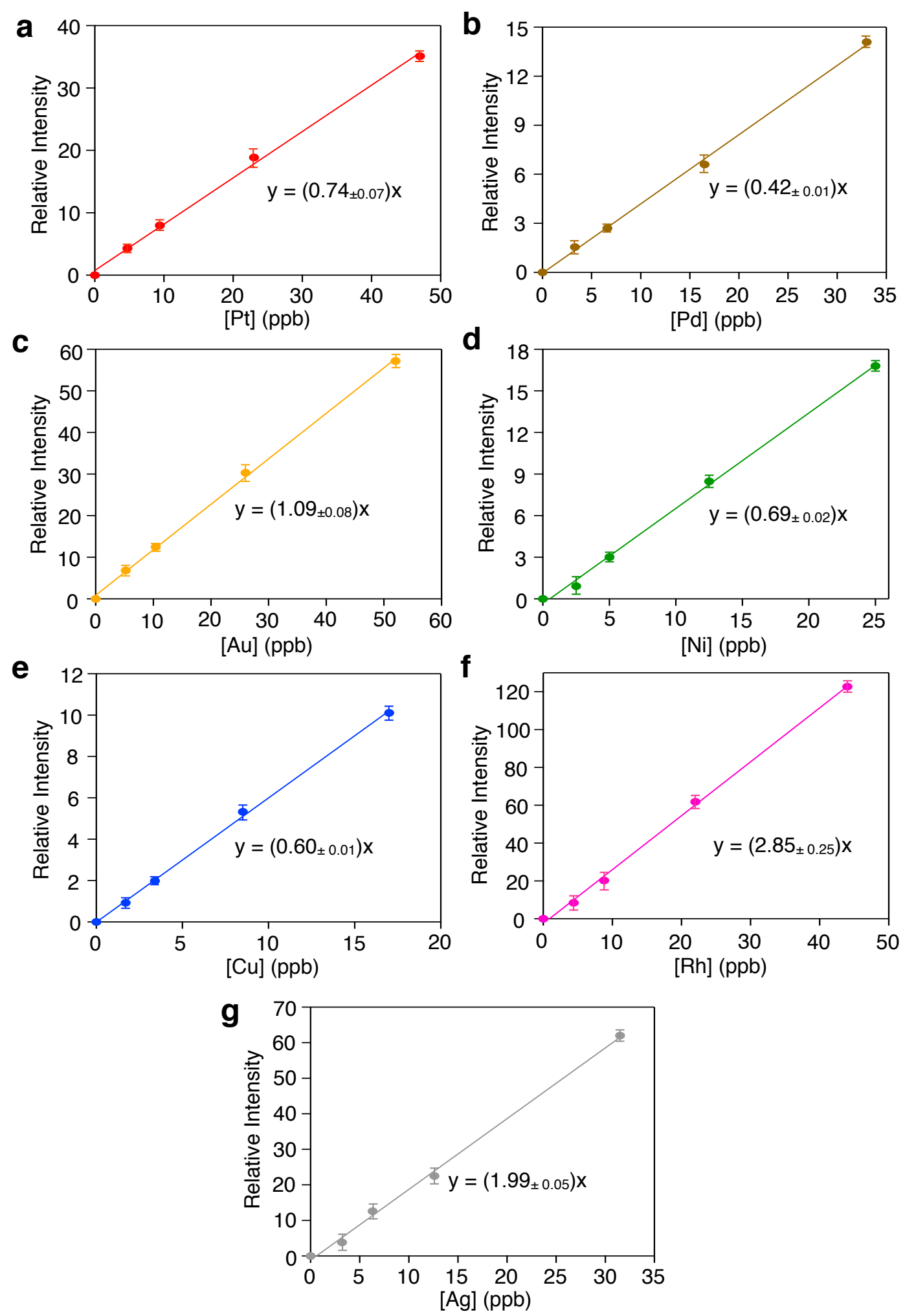

Figure S24. Calibration curves $\left(R^{2}>0.99\right)$ of Pt (a), Pd (b), Au (c), Ni (d), Cu (e), $\mathrm{Rh}(\mathrm{f})$, and $\mathrm{Ag}$ (g) elements in ppb-concentration aqueous solution obtained by ICP-MS. 


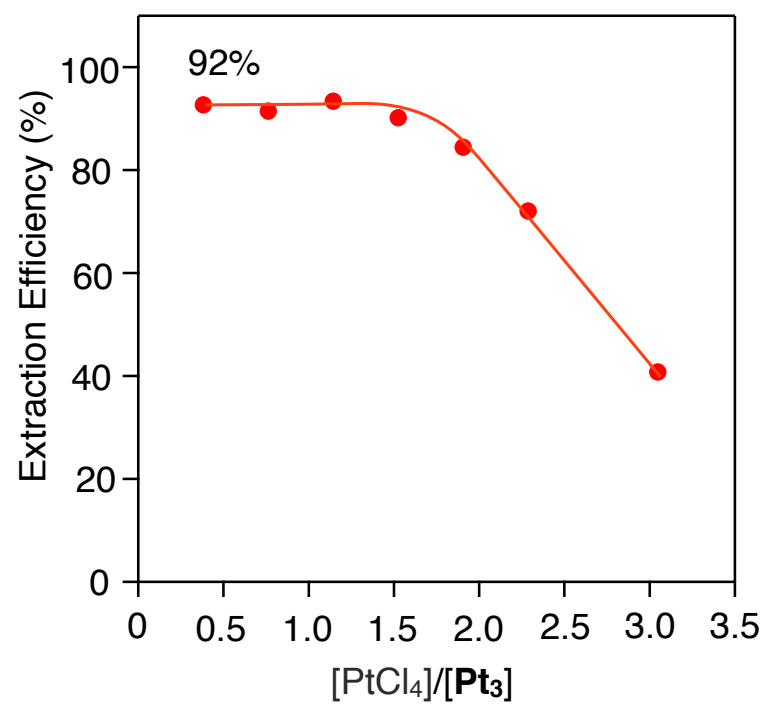

Figure S25. Evaluation on extraction efficiency of $\left[\mathrm{PtCl}_{4}\right]^{2-}$ using $\mathrm{SP}_{\mathrm{Pt3}}$. Plot of the extraction efficiency of $\left[\mathrm{PtCl}_{4}\right]^{2-}$ from its aqueous solution by $\mathbf{S P}_{\mathbf{P t 3}}$ against the mole ratio $\left[\mathrm{PtCl}_{4}\right] /\left[\mathrm{Pt}_{3}\right]$. 

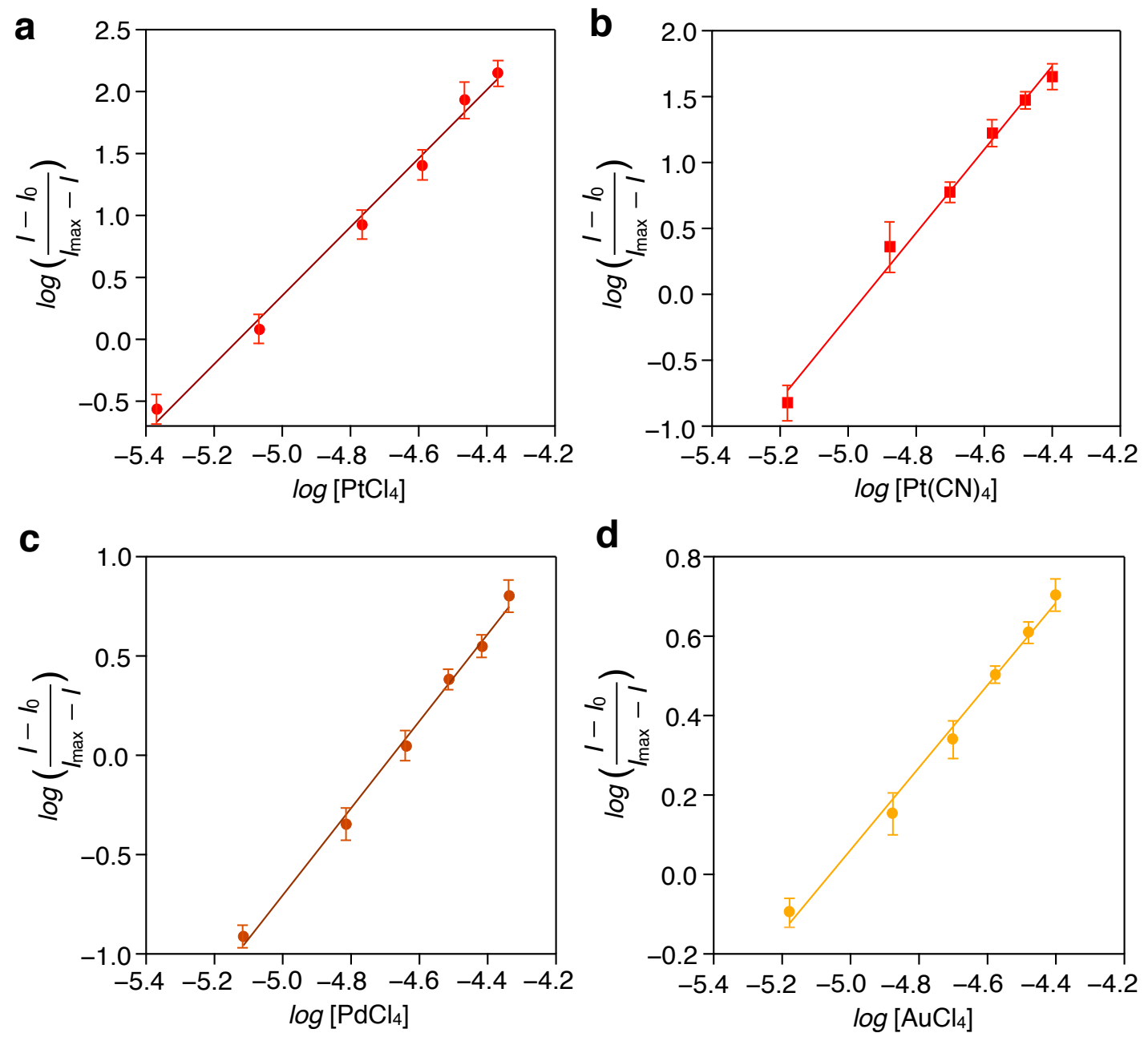

Figure S26. Hill plots of $\mathrm{SP}_{\mathrm{Pt3}}$ binding with $\left[\mathrm{PtCl}_{4}\right]^{2-}(\mathrm{a}),\left[\operatorname{Pt}(\mathrm{CN})_{4}\right]^{2-}(\mathrm{b})$, $\left[\mathrm{PdCl}_{4}\right]^{2-}$ (c) and $\left[\mathrm{AuCl}_{4}\right]^{2-}$ (d) obtained by the analysis of emission spectroscopy. 


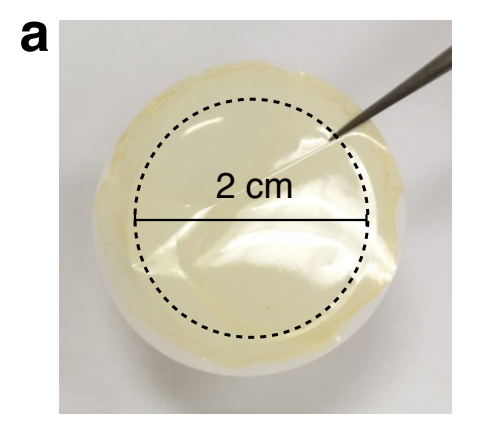

b

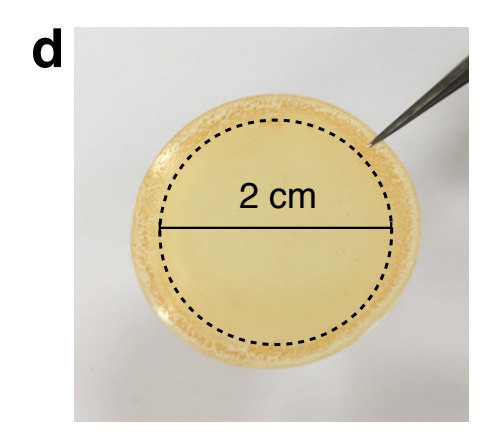

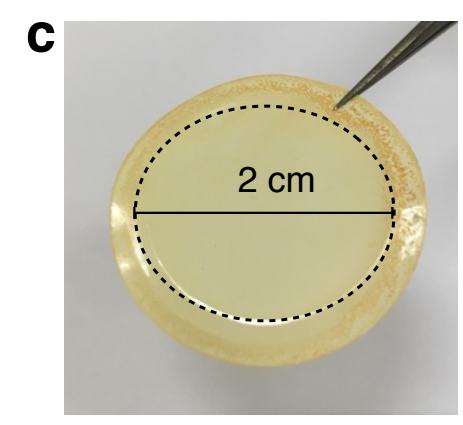

e

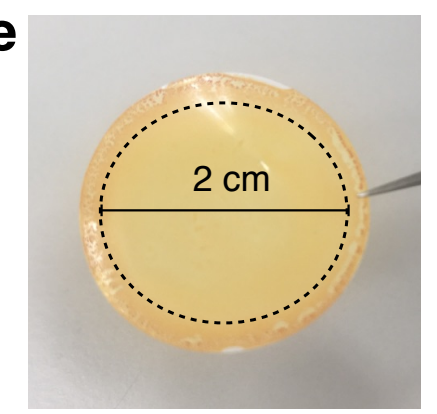

Figure S27. Photographs of composite $\mathrm{SP}_{\mathrm{Pt3}}$-based membranes on PC filter supports. The membranes were prepared by drop-casting the solution of $\mathbf{P t}_{\mathbf{3}}(1.5 \mathrm{mg}$ $\mathrm{mL}^{-1}$ ) with various volumes, for example, 12.5 (a), 25 (b), 50 (c), 75 (d), and 100 (e) $\mu \mathrm{L}$, respectively. The dashed circles in photographs represent the effective filtering areas $\left(3.14 \mathrm{~cm}^{2}\right)$. 

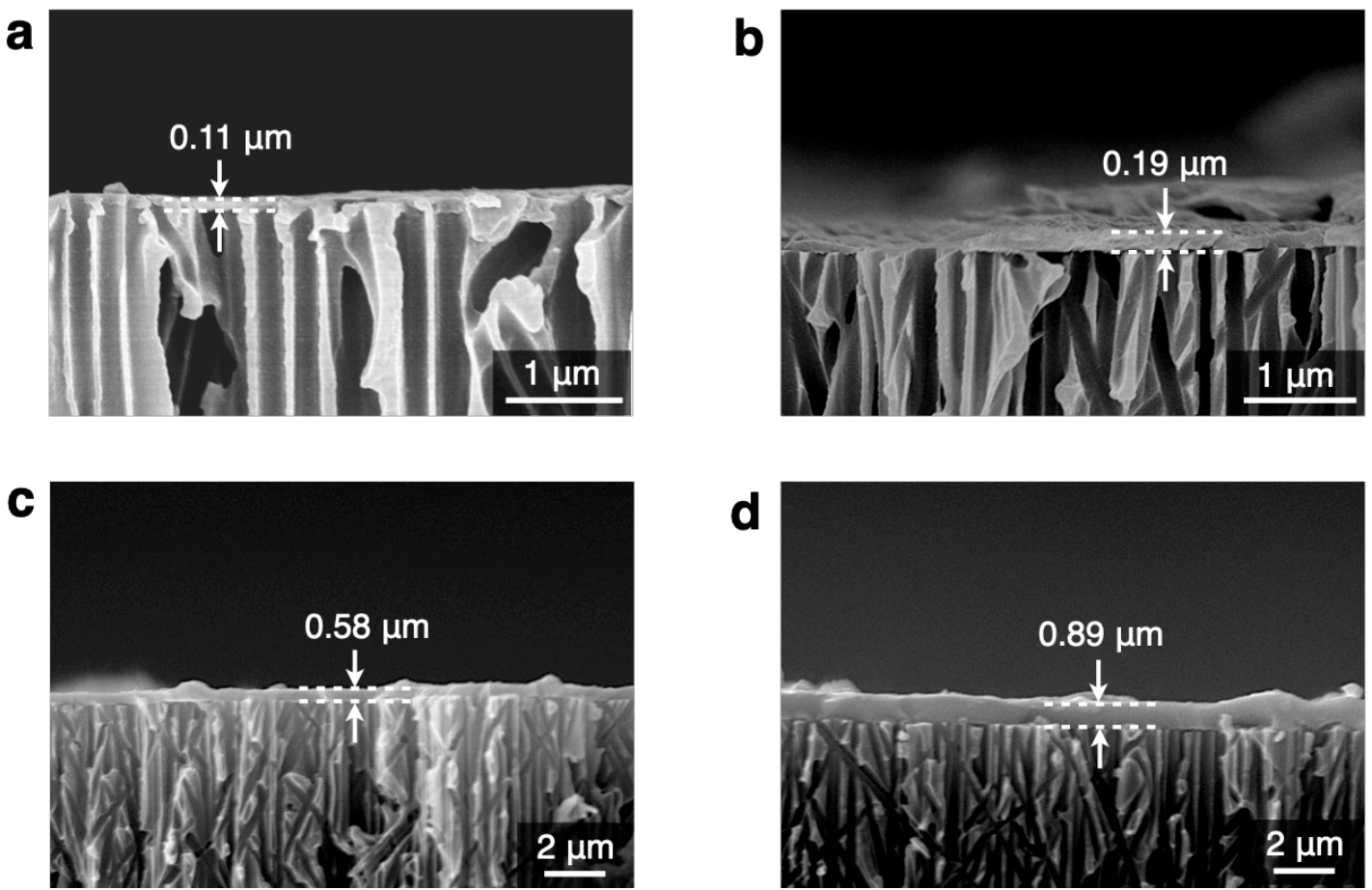

Figure S28. Cross-sectional SEM images of composite membranes comprising $\mathbf{S P}_{\mathrm{Pt3}}$ films deposited on PC membrane supports. The thickness of the membrane was tunable by adding various volumes of solution of $\mathbf{P t}_{\mathbf{3}}$, for example, $12.5 \mu \mathrm{L}$ for $0.11-\mu \mathrm{m}$ (a), $25 \mu \mathrm{L}$ for $0.19-\mu \mathrm{m}$ (b), $75 \mu \mathrm{L}$ for $0.58-\mu \mathrm{m}$ (c), and $100 \mu \mathrm{L}$ for $0.89-\mu \mathrm{m}$ (d), respectively. 

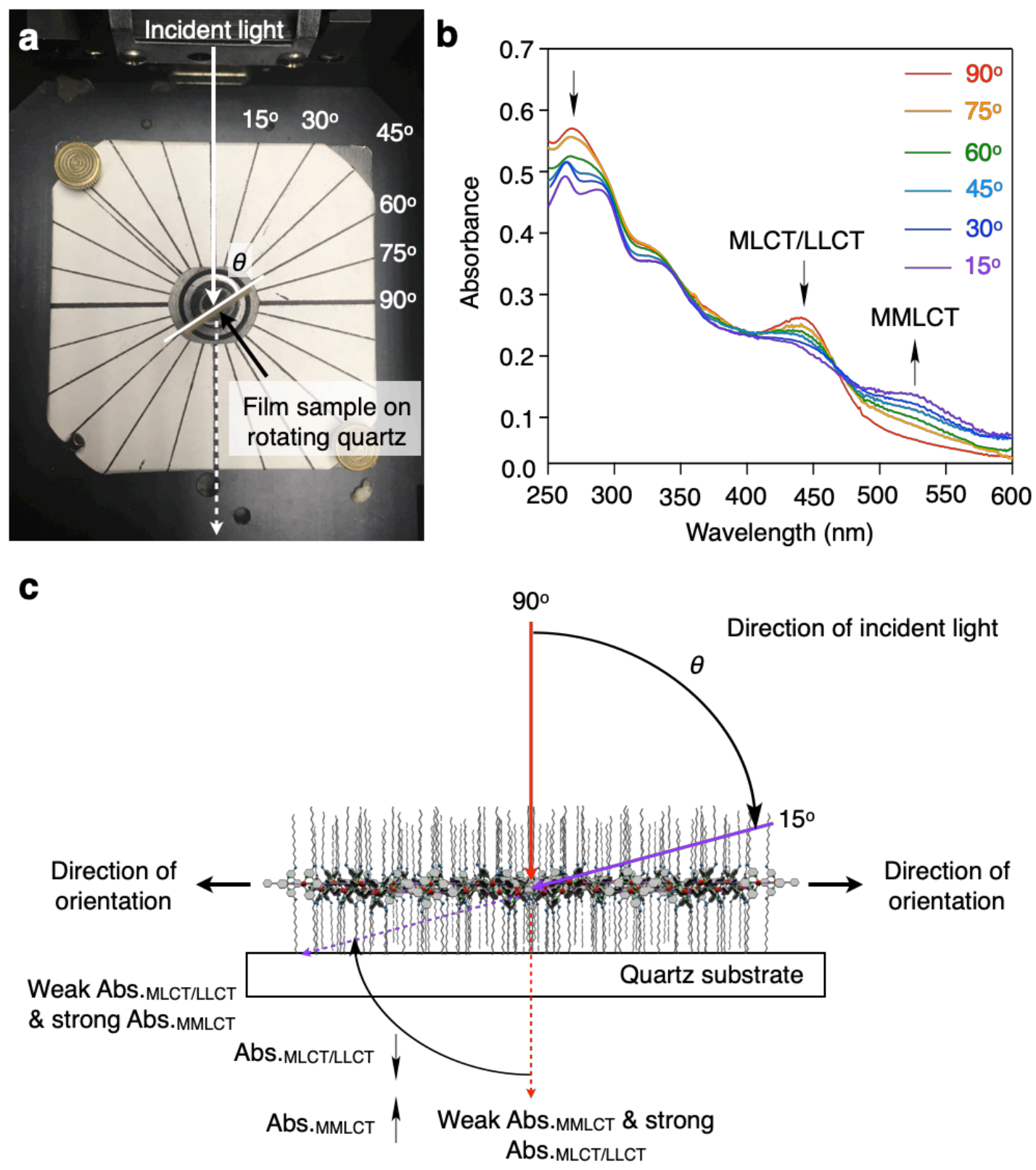

Figure S29. Evaluation on anisotropic orientation of $\mathbf{P t}_{\mathbf{3}}$ in a highly oriented film.

(a) A photograph of incident-angle-dependent electronic absorption setup for the oriented film of $\mathbf{P t}_{3}$ on rotating quartz substrate. (b) Electronic absorption spectra of the oriented film of $\mathbf{P t}_{\mathbf{3}}$ on a quartz substrate recorded upon exposure to unpolarized light with various incident angles $(\theta)$ at $90^{\circ}, 75^{\circ}, 60^{\circ}, 45^{\circ}, 30^{\circ}$ and $15^{\circ}$, respectively. The spectra were corrected for both the irradiated area and the contribution of the absorption of the substrate. (c) Schematic representation of the absorption feature of $\mathbf{P t}_{3}$ in highly oriented film resulting from anisotropic orientation. The larger MMLCT absorption was shown at smaller incident angles, indicating that the dimeric $\mathrm{Pt}^{\mathrm{II}}(\mathrm{tpy})$ building blocks adopt out-of-plane configurations almost perpendicular to the surface of the oriented film. 
a

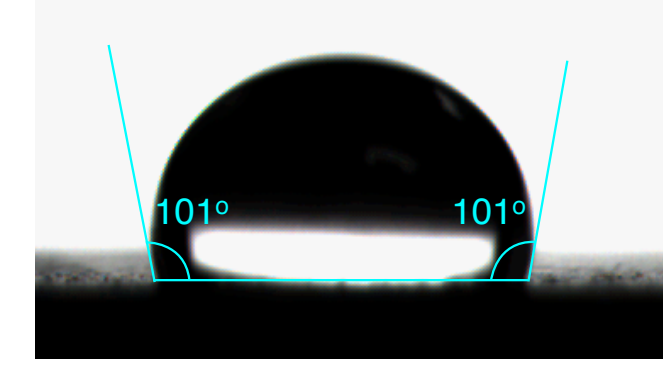

b

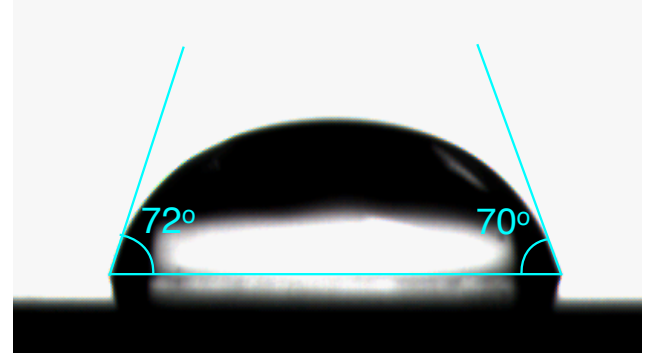

Figure S30. Evaluation on surface wettability of thin films of $\mathrm{SP}_{\mathrm{P} t 3}$ and PC. Photographs of one water droplet on the surface of thin films prepared by spin coating the chloroform solutions of $\mathbf{P t}_{3}$ (a) and $\mathrm{PC}$ (b) on silicon wafer substrates, respectively. The average contact angles for $\mathbf{S P}_{\mathbf{P} t 3}$ and $\mathbf{P C}$ films were determined to be $101^{\circ}$ and $71^{\circ}$, respectively. 

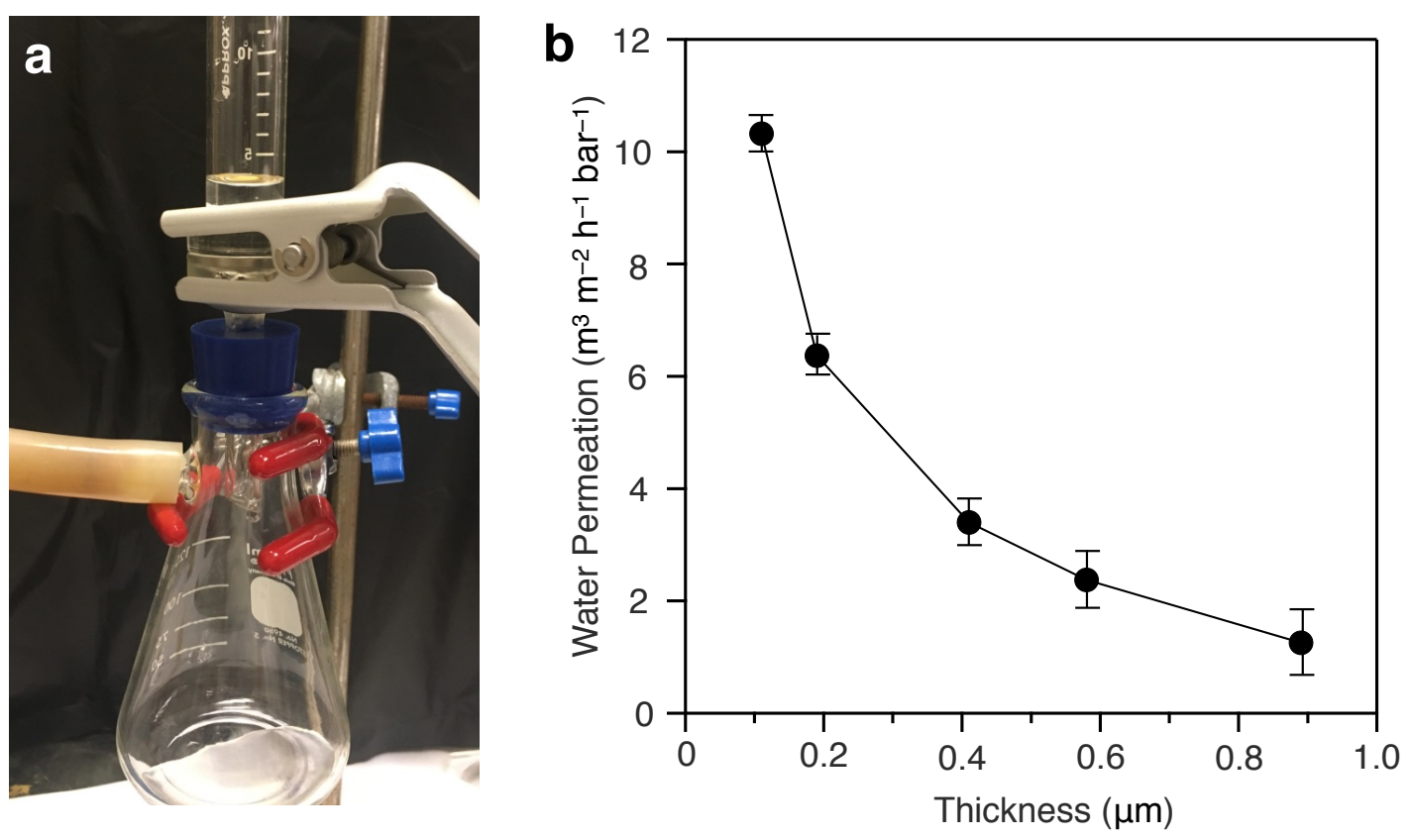

Figure S31. Evaluation on thickness-dependent permeation of pure water. (a) A photograph of permeation setup using reduced pressure filtration device with an $\mathbf{S P}_{\mathbf{P t 3}}$-based membrane. The fluxing volume and time was recorded. (b) Plot of the permeation of pure water against the thickness of membranes. 

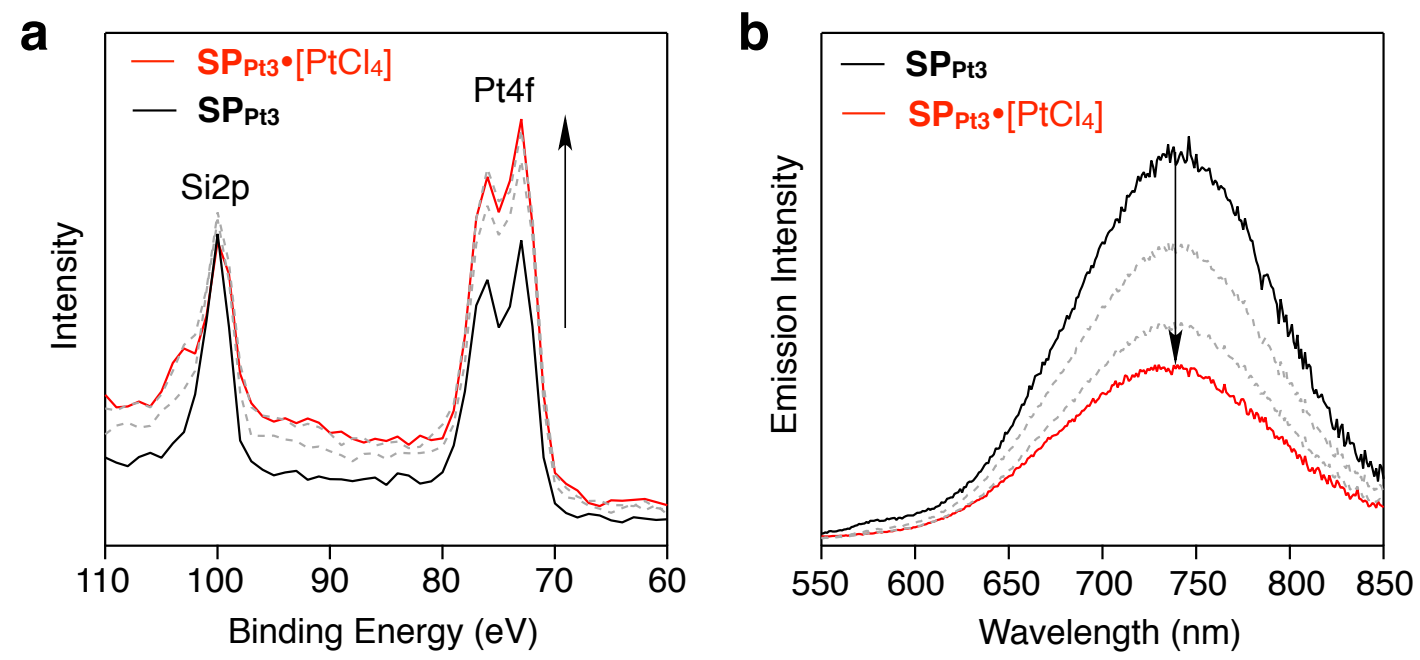

Figure S32. Evaluation on adsorption of $\left[\mathrm{PtCl}_{4}\right]^{2-}$ using $\mathrm{SP}_{\mathrm{Pt3}}$-based membranes. XPS profiles (a) and emission spectra (b) of the $\mathbf{S P}_{\mathbf{P t 3}}$-based membrane before (black line) and after adsorption of $\left[\mathrm{PtCl}_{4}\right]^{2-}$ by filtration for several times (dash lines) until saturation (red line). 


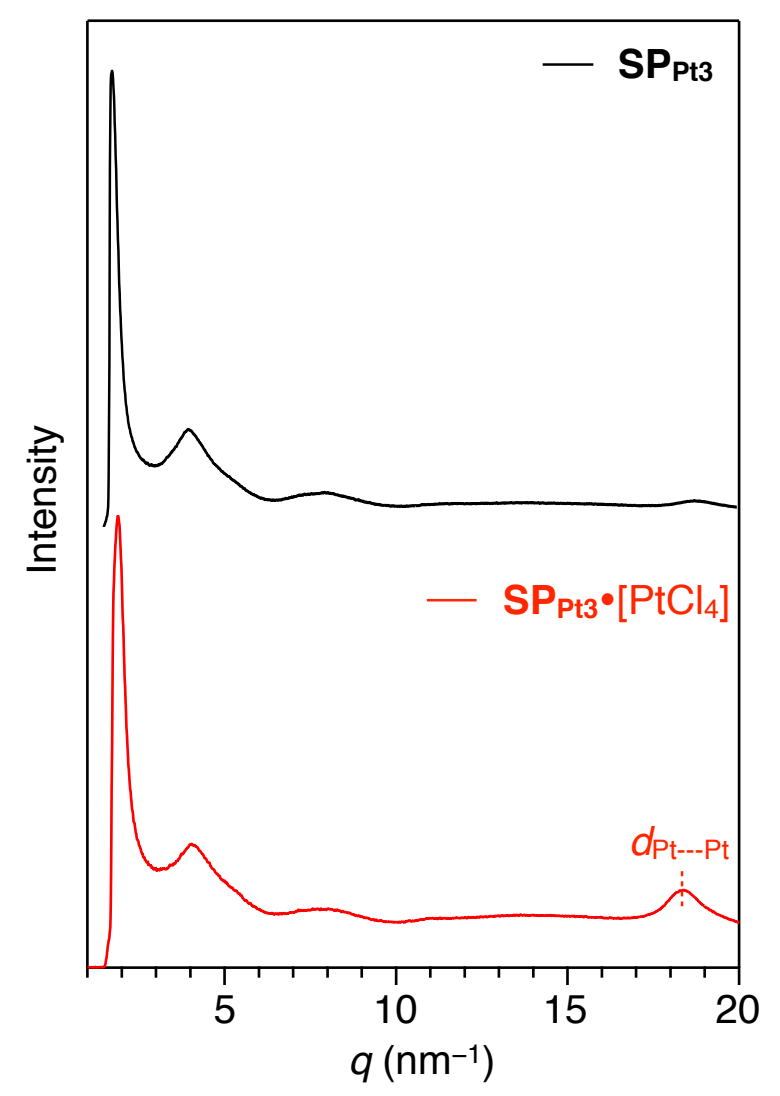

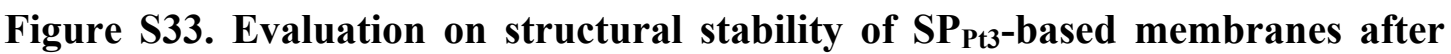
adsorption of $\left[\mathbf{P t C l}_{4}\right]^{2-}$. 1D GI-XRD patterns of the $\mathbf{S P}_{\mathbf{P t 3}}$-based membrane before (black line) and after (red line) adsorption of $\left[\mathrm{PtCl}_{4}\right]^{2-}$. The diffraction peak in 1D pattern corresponding to $\mathrm{Pt} \cdots \mathrm{Pt}$ distance $\left(d_{\mathrm{P} t} \cdots \mathrm{Pt}\right)$ became intensive after adsorption of $\left[\mathrm{PtCl}_{4}\right]^{2-}$ possibly resulting from the host-guest $\mathrm{Pt} \cdots \mathrm{Pt}$ interactions between the dimeric $\mathrm{Pt}^{\mathrm{II}}\left(\right.$ tpy) linkers and $\left[\mathrm{PtCl}_{4}\right]^{2-}$. 

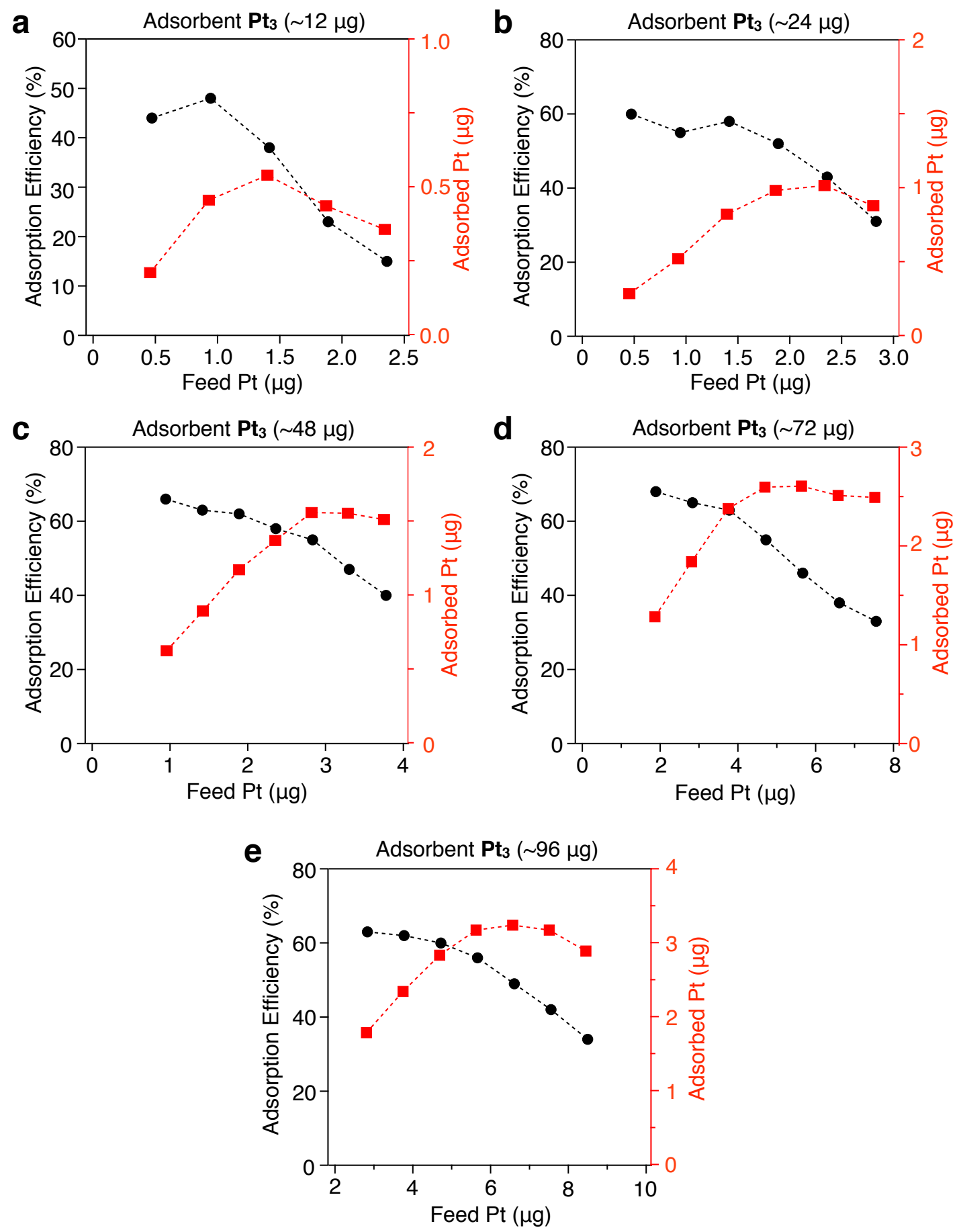

Figure S34. Evaluation on adsorption efficiency of $\left[\mathrm{PtCl}_{4}\right]^{2-}$ using $\mathrm{SP}_{\mathrm{Pt3}}$-based membranes. Plots of the adsorption efficiency (right) and net weight (left) of Pt against the feeding weight of Pt using membranes prepared by $12.5-\mu \mathrm{L}$ (a), $25-\mu \mathrm{L}$ (b), 50- $\mu \mathrm{L}$ (c), $75-\mu \mathrm{L}$ (d), and 100- $\mu \mathrm{L}$ (e) solution of $\mathbf{P t}_{3}$, respectively. 


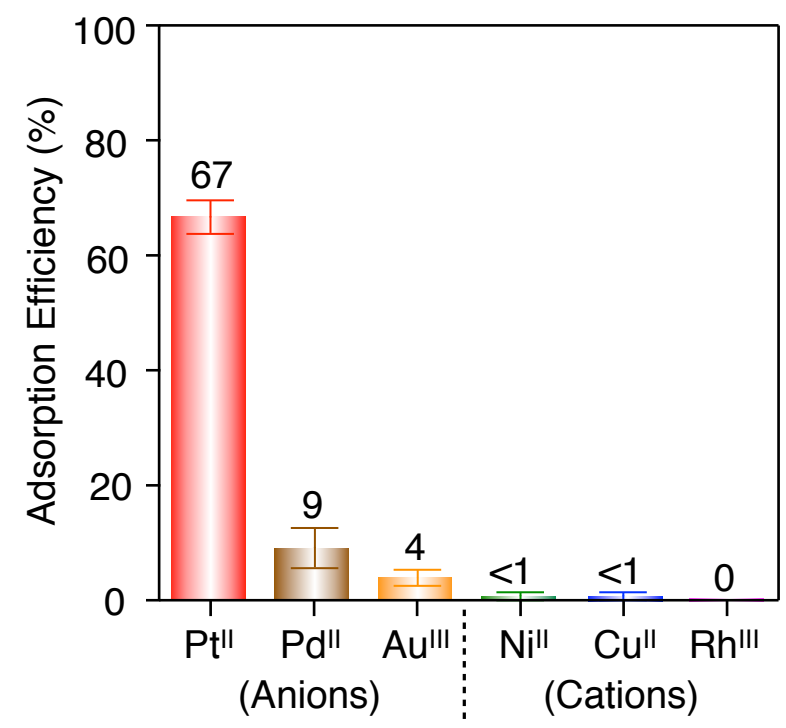

Figure S35. Evaluation on correlated adsorption efficiencies of a matrix

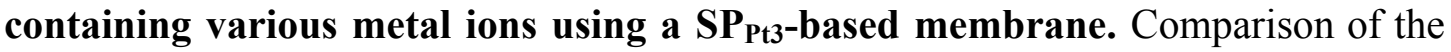
adsorption efficiencies of $\left[\mathrm{PtCl}_{4}\right]^{2-}\left(\mathrm{Pt}^{\mathrm{II}}\right),\left[\mathrm{PdCl}_{4}\right]^{2-}\left(\mathrm{Pd}^{\mathrm{II}}\right),\left[\mathrm{AuCl}_{4}\right]^{-}\left(\mathrm{Au}^{\mathrm{III}}\right), \mathrm{Ni}^{2+}\left(\mathrm{Ni}^{\mathrm{II}}\right)$, $\mathrm{Cu}^{2+}\left(\mathrm{Cu}^{\mathrm{II}}\right),\left[\mathrm{RhCl}_{\mathrm{x}}\right]^{\mathrm{n}+}\left(\mathrm{Rh}^{\mathrm{III}}\right)$ in an aqueous solution. The concentrations of ions in water are identical $\left(3 \mu \mathrm{g} \mathrm{mL}^{-1}\right)$. The resultant membrane was prepared by $50-\mu \mathrm{L}$ solution of $\mathbf{P t}_{3}$. Error bars represent mean \pm s.d. 


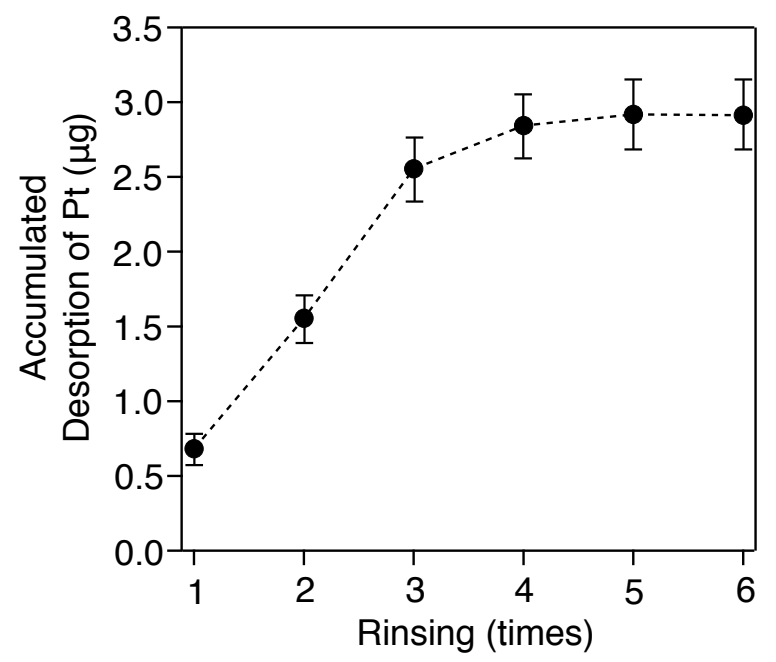

Figure S36. Evaluation on desorption of $\mathrm{Pt}^{\mathrm{II}}$ embodied in $\mathrm{SP}_{\mathrm{Pt3}_{3} \text {-based }}$ membranes by rinsing with aqueous $\mathrm{NH}_{4} \mathrm{Cl}$ solution for several times. Plot of the accumulated desorption amounts of $\mathrm{Pt}$ against the rinsing times $\left(1 \mathrm{~mL}\right.$ times $\left.^{-1}\right)$ of aqueous $\mathrm{NH}_{4} \mathrm{Cl}$ solution ( $\sim 10$ wt.\%). The resultant membrane contained $\sim 96 \mu \mathrm{g}$ of $\mathbf{P t}_{3}$ adsorbent, which can adsorb $\sim 3.2 \mu \mathrm{g}$ of Pt (element). Therefore, the maximum desorption efficiency is determined to be $\sim 91 \%$. 


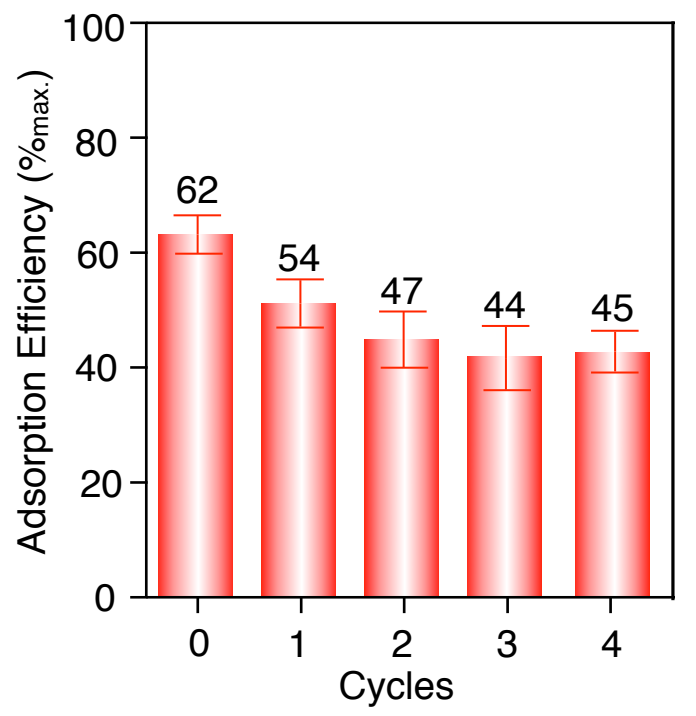

Figure S37. Evaluation on regeneration activity of $\mathrm{SP}_{\mathrm{Ptz}_{3}}$-based membranes. Comparison of the maximum adsorption efficiency of $\left[\mathrm{PtCl}_{4}\right]^{2-}$ in four adsorption/desorption cycles. Error bars represent mean \pm s.d. 

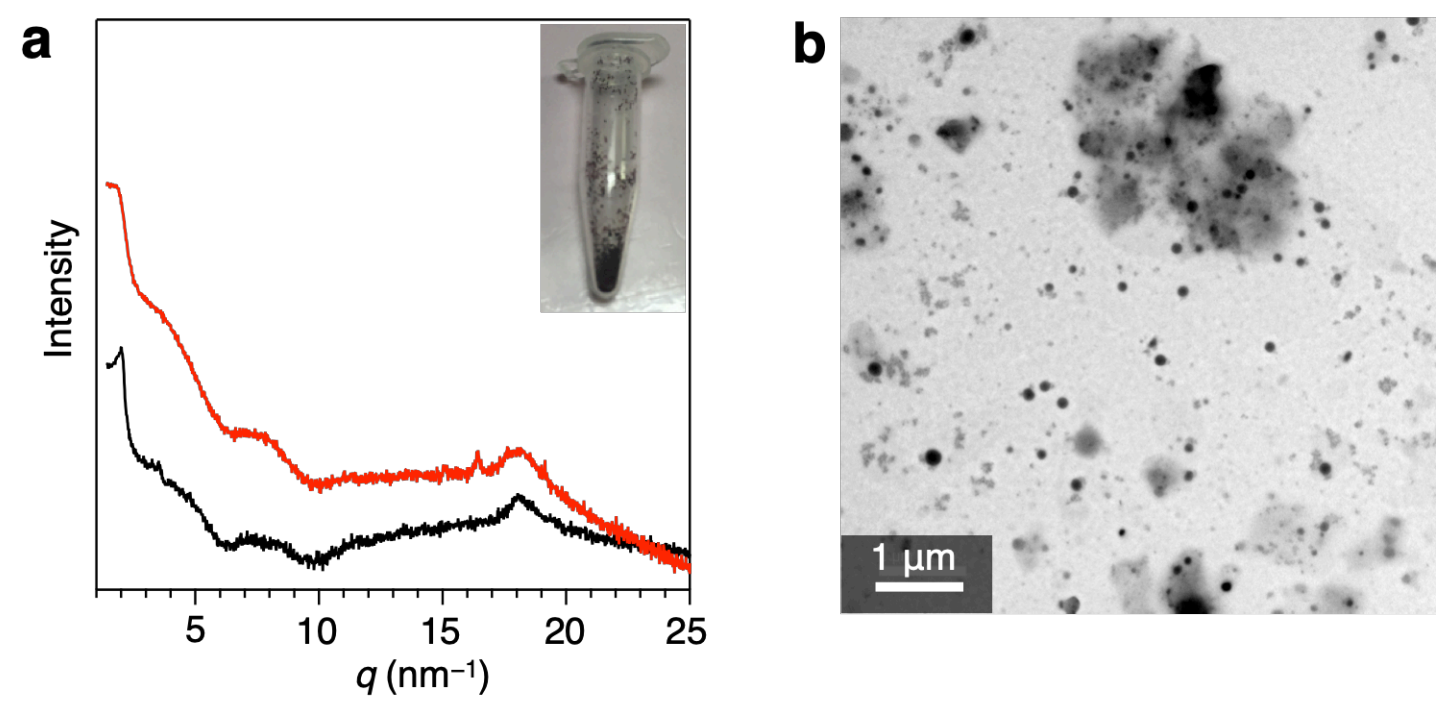

Figure S38. Evaluation on amorphous nature of ${ }^{\text {core }} \mathrm{Pt}_{3}$ complex without side chains. (a) PXRD patterns of the solid samples ( $\sim 10 \mathrm{mg}$, inset) of ${ }^{\text {core }} \mathbf{P t}_{\mathbf{3}}$ obtained from the slow diffusion of diethyl ether vapor into its chloroform (black line) and acetonitrile (red line) solution, respectively. (b) A typical TEM image of the acetonitrile solution of ${ }^{\text {core }} \mathbf{P t}_{\mathbf{3}}$ drop-casted on a carbon-nickel grid. 
Table S1. Powder XRD Data of $\mathrm{Pt}_{3}$

\begin{tabular}{|c|c|c|c|c|}
\hline Lattice & $\begin{array}{c}q \\
\left(\mathrm{~nm}^{-1}\right)\end{array}$ & $\begin{array}{l}d_{\text {obs. }} \\
(\mathrm{nm})\end{array}$ & $\begin{array}{c}d_{\text {cal. }} \\
(\mathrm{nm})\end{array}$ & $h k l$ \\
\hline 2D $P 6 m^{a}$ & 2.00 & 3.14 & 3.10 & 100 \\
\hline \multirow[t]{4}{*}{$(298 \mathrm{~K})$} & 3.51 & 1.79 & 1.79 & 110 \\
\hline & 4.02 & 1.56 & 1.55 & 200 \\
\hline & 5.30 & 1.19 & 1.18 & 210 \\
\hline & 18.45 & 0.34 & 0.34 & $-{ }^{b}$ \\
\hline
\end{tabular}

Table S2. Thermodynamic Parameters of Self-assembly of $\mathrm{Pt}_{3}$ in Solution.

$\frac{C(\mu \mathrm{M})}{3.0} \frac{T_{\mathrm{m}}(\mathrm{K})}{328} \frac{\Delta H\left(\mathrm{~kJ} \mathrm{~mol}^{-1}\right)}{-86.0} \frac{K_{e}\left(\mathrm{M}^{-1}\right)^{a}}{2.10 \times 10^{6}} \frac{\Delta S\left(\mathrm{~J} \mathrm{~mol}^{-1} \mathrm{~K}^{-1}\right)}{-180} \frac{\Delta G\left(\mathrm{~J} \mathrm{~mol}^{-1} \mathrm{~K}^{-1}\right)^{a}}{-32.4}$

${ }^{a}$ Determined at $298 \mathrm{~K}$.

Table S3. Binding Constants $\left(K_{\mathrm{a}}\right)$ and Hill Coefficients $(n)$ Determined by Hill plots. $^{a}$

\begin{tabular}{ccc|cc}
\hline \multirow{2}{*}{ Guest } & \multicolumn{2}{c|}{$\mathrm{UV}^{- \text {vis }^{b}}$} & \multicolumn{2}{c}{ Emission $^{c}$} \\
\cline { 2 - 5 } & $\log K_{\mathrm{a}}$ & $n$ & $\log K_{\mathrm{a}}$ & $n$ \\
\hline $\mathbf{G}_{\mathbf{P t}}$ & $13.8 \pm 0.60$ & 2.98 & $13.4 \pm 0.70$ & 2.75 \\
$\mathbf{G}_{\mathbf{A u}}$ & $7.17 \pm 0.34$ & 1.45 & $7.02 \pm 0.27$ & 1.65 \\
$\mathbf{G}_{\mathbf{P d}}$ & $9.68 \pm 0.14$ & 2.00 & $9.71 \pm 0.39$ & 1.89 \\
{$\left[\mathrm{PtCl}_{4}\right]^{--}$} & - & - & $8.89 \pm 0.22$ & 2.77 \\
{$\left[\mathrm{Pt}(\mathrm{CN})_{4}\right]^{2-}$} & - & - & $9.16 \pm 0.26$ & 3.06 \\
{$\left[\mathrm{PdCl}_{4}\right]^{2-}$} & - & - & $6.68 \pm 0.13$ & 2.19 \\
{$\left[\mathrm{AuCl}_{4}\right]^{-}$} & - & - & $5.14 \pm 0.08$ & 1.04 \\
\hline
\end{tabular}

${ }^{a}$ Determined at $298 \mathrm{~K} ;{ }^{b}$ Analysis by UV-vis absorption spectroscopy; ${ }^{c}$ Analysis by emission spectroscopy. 
Table S4. Electrochemical and Photophysical Data of $\mathbf{P t}_{3}$ and Pt-containing anions.

\begin{tabular}{ccccccc}
\hline Sample $^{a}$ & $\begin{array}{c}E_{1 / 2} \\
(\mathrm{~V})^{b}\end{array}$ & $\begin{array}{c}E_{\mathrm{pa}} \\
(\mathrm{V})^{c}\end{array}$ & $\begin{array}{c}\Delta G_{\mathrm{ox}} \\
(\mathrm{eV})^{d}\end{array}$ & $\begin{array}{c}\Delta G_{\text {red }} \\
(\mathrm{eV})^{e}\end{array}$ & $\begin{array}{c}E_{\text {triplet }} \\
(\mathrm{eV})^{f}\end{array}$ & $\begin{array}{c}\Delta E_{\text {triplet }} \\
(\mathrm{eV})^{h}\end{array}$ \\
\hline $\mathbf{P t}_{3} \cdot 3(\mathrm{OTf})$ & $-0.90,-1.50$ & +1.34 & - & - & 2.32 & - \\
$(\mathrm{PPN})_{2}\left[\mathrm{PtCl}_{4}\right]$ & -0.92 & +0.88 & -0.06 & -0.54 & - & - \\
$(\mathrm{PPN})_{2}\left[\mathrm{Pt}(\mathrm{CN})_{4}\right]$ & -0.96 & $+1.18,+1.48$ & -0.02 & -0.24 & $3.37^{g}$ & -1.05 \\
$(\mathrm{PPN})_{2}\left[\mathrm{PtCl}_{6}\right]$ & $-0.68,-1.12$ & - & -0.30 & - & - & - \\
\hline
\end{tabular}

${ }^{a}$ In $\mathrm{CH}_{2} \mathrm{Cl}_{2}$ at $298 \mathrm{~K} ;{ }^{b}$ Reversible reduction couple vs. SCE; ${ }^{c}$ Irreversible oxidation waves vs. SCE; ${ }^{d}$ Gibbs free energy change for oxidative quenching of the excited state of $\mathbf{P t}_{\mathbf{3}}$ by guest ions; ${ }^{e} \mathrm{Gibbs}$ free energy change for reductive quenching of the excited state of $\mathbf{P t}_{\mathbf{3}}$ by guest ions; ${ }^{f}$ Triplet state energy obtained from 0-0 transition; ${ }^{g}$ Obtained from ref. $13 ;{ }^{h}$ Difference from the triplet state energy of $\mathbf{P t}_{\mathbf{3}}$.

Table S5. Adsorption Performances of ${ }^{\text {core }} \mathrm{Pt}_{3}$-based Membranes.

\begin{tabular}{cccc}
\hline Entry & $\begin{array}{c}\text { Drop-casted Volume } \\
(\mu \mathrm{L})^{a}\end{array}$ & $\begin{array}{c}\text { Permeation Rate } \\
\left(\mathrm{m}^{3} \mathrm{~m}^{2} \mathrm{~h}^{-1} \mathrm{bar}^{-1}\right)^{b}\end{array}$ & $\begin{array}{c}\text { Adsorption Efficiency } \\
(\%)\end{array}$ \\
\hline 1 & 25 & 15.1 & 4.7 \\
2 & 50 & 12.4 & 2.8 \\
3 & 100 & 11.3 & 1.9 \\
\hline
\end{tabular}

${ }^{a}$ Concentration is $2.0 \mathrm{mg} \mathrm{mL}{ }^{-1} ;{ }^{b}$ Feed is aqueous solution of $\mathrm{K}_{2}\left[\mathrm{PtCl}_{4}\right]\left(1 \mu \mathrm{g} \mathrm{mL} \mathrm{m}^{-1}\right)$ and reduced pressure is about -0.05 bar. 


\section{Supporting Videos Captions}

Video S1. An extraction procedure of $\mathrm{CH}_{2} \mathrm{Cl}_{2}$ organic phase containing complex $\mathbf{P t}_{3}$ (30 nmol) and aqueous phase containing $\mathrm{K}_{2}\left[\mathrm{PtCl}_{4}\right](60 \mathrm{nmol})$. The video reproduces at real-time speed under the daylight and UV light irradiation. The red emission of organic phase was immediately quenched after the addition of aqueous $\mathrm{K}_{2}\left[\mathrm{PtCl}_{4}\right]$ solution $\left(1 \mathrm{mg} \mathrm{mL}^{-1}\right)$ followed by vigorous shaking.

Video S2. An extraction procedure of $\mathrm{CH}_{2} \mathrm{Cl}_{2}$ organic phase containing complex $\mathbf{P t}_{3}$ (30 nmol) and aqueous phase containing $\mathrm{K}_{2}\left[\operatorname{Pt}(\mathrm{CN})_{4}\right](60 \mathrm{nmol})$. The video reproduces at real-time speed under the daylight and UV light irradiation. The red emission of organic phase was dramatically enhanced after the addition of aqueous $\mathrm{K}_{2}\left[\mathrm{Pt}(\mathrm{CN})_{4}\right]$ solution $\left(1 \mathrm{mg} \mathrm{mL}^{-1}\right)$ followed by vigorous shaking. 


\section{Supporting References}

1. Lin, C.-P.; Florio, P.; Campi, E. M.; Zhang, C.; Fredericks, D. P.; Saito, K.; Jackson, W. R.; Hearn, M. T. W. Synthesis of substituted terpyridine ligands for use in protein purification. Tetrahedron 70, 8520-8531 (2014).

2. Ohshiro, N.; Takei, F.; Onitsuka, K.; Takahashi, S. Synthesis of organometallic dendrimers with a backbone composed of platinum-acetylide units. J. Organomet. Chem. 1998, 569, 195-202.

3. Po, C.; Tam, A. Y.-Y.; Wong, K. M.-C; Yam, V. W.-W. Supramolecular self-assembly of amphiphilic anionic platinum(II) complexes: a correlation between spectroscopic and morphological properties. J. Am. Chem. Soc. 2011, $133,12136-12143$.

4. Lu, W.; Chan, M. C.-W.; Cheung, K.-K.; Che, C.-M. $\pi-\pi$ interactions in organometallic systems. Crystal structures and spectroscopic properties of luminescent mono-, bi-, and trinuclear trans-cyclometalated platinum(II) complexes derived from 2,6-diphenylpyridine. Organometallics 2001, 20, 2477-2486.

5. Abu-salah, O. M.; Al-Ohaly, A. R.; Al-Qahtani, H. A. Preparation and reactivity of bis (phenylethynyl)argentate(I) and chlorophenyl-ethynylargentate(I) complex anions. Inorg Chim Acta 1986, 117, L29-L30.

6. Hendricks, S. B.; Dickinson, R. G. The crystal structures of ammonium, potassium and rubidium cupric chloride dihydrates. J. Am. Chem. Soc. 1927, 49, 2149-2162.

7. FIT2D, http://www.esrf.eu/computing/scientific/FIT2D/

8. Materials Studio v.6.0 (Accelrys Software, San Diego, 2013)

9. Smulders, M. M. J.; Nieuwenhuizen, M. M. L.; de Greef, T. F. A.; van der Schoot, P.; Schenning, A. P. H. J.; Meijer, E. W. How to distinguish isodesmic from cooperative supramolecular polymerization. Chem. Eur. J. 2010, 16, 362-367.

10. Bailey, J. A.; Hill, M. G.; Mash, R. E.; Miskowski, V. M.; Schaefer, W. P.; Gray, H. B. Electronic spectroscopy of chloro(terpyridine)platinum(II). Inorg. Chem. 1995, 34, 4591-4599.

11. Tanaka, Y.; Wong, K. M.-C.; Yam, V. W.-W. Platinum-based phosphorescent double-decker tweezers: a strategy for extended heterologous metal-metal interactions. Angew. Chem. Int. Ed. 2013, 52, 14117-14120. 
12. Tanaka, Y.; Wong, K. M.-C.; Yam, V. W.-W. Host-guest interactions of phosphorescent molecular tweezers based on an alkynylplatinum(II) terpyridine system with polyaromatic hydrocarbons. Chem. Eur. J. 2013, 19, 390-399.

13. Schindler, J. W.; Fukuda, R. C.; Adamson, A. W. Photophysics of aqueous $\operatorname{Pt}(\mathrm{CN})_{4}{ }^{2-}$. J. Am. Chem. Soc. 1982, 104, 3596-3600.

14. Alsbaiee, A.; Simth, B. J.; Xiao, L.; Ling, Y.; Helbling, D. E.; Dichtel, W. R. Rapid removal of organic micropollutants from water by a porous $\beta$-cyclodextrin polymer. Nature 2016, 529, 190-194. 